
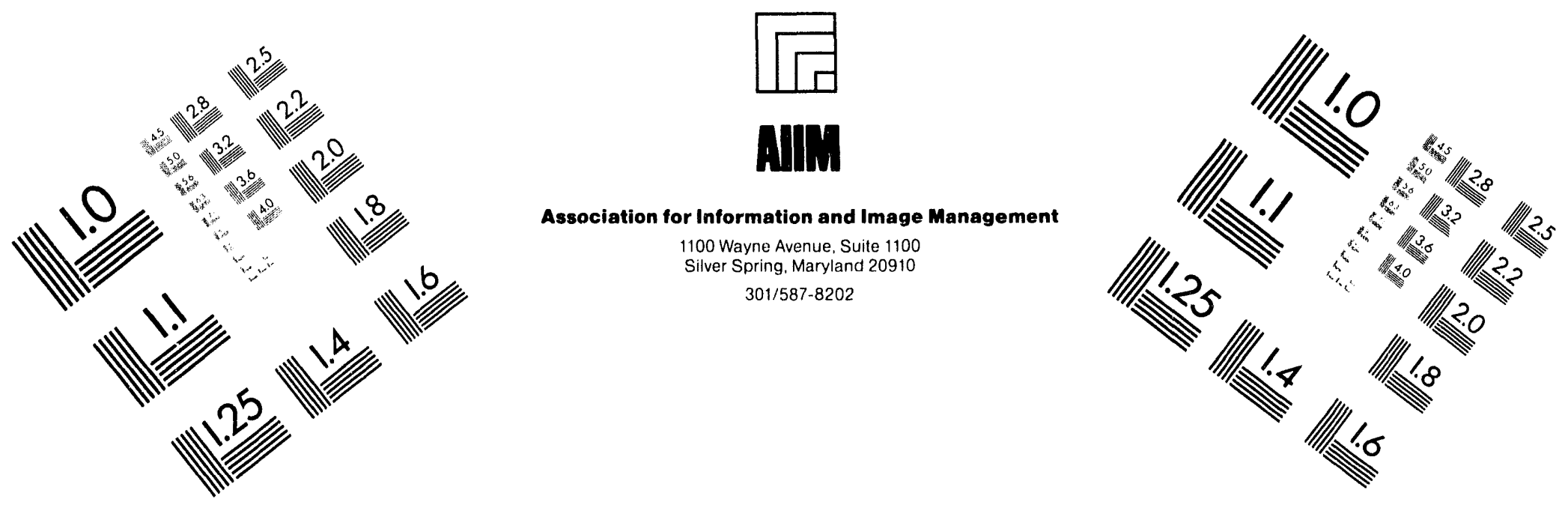

\title{
Centimeter
}

$\left.\right|_{1} ^{1}$ Inches
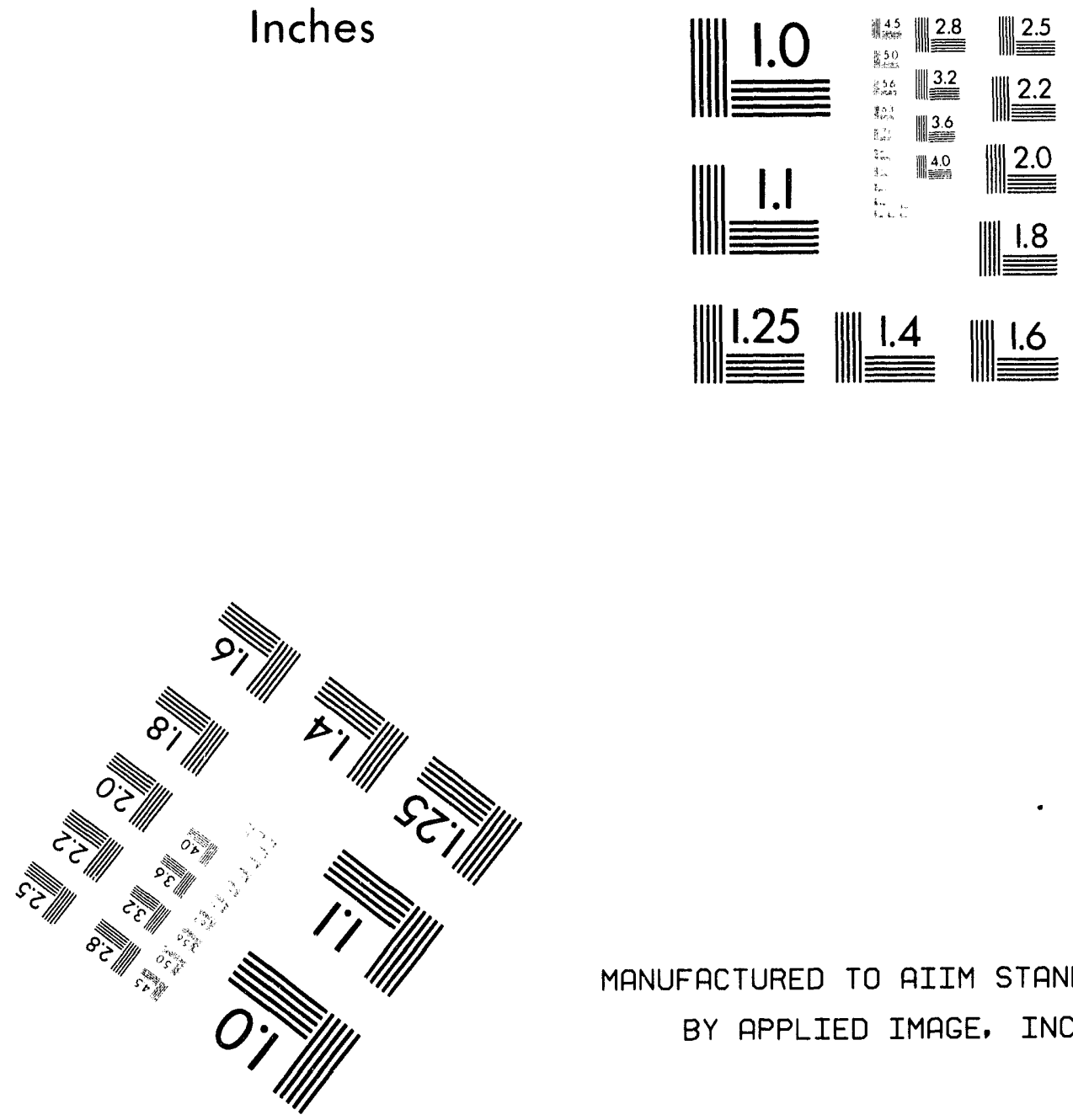

MANUFACTURED TO AIIM STANDARDS

BY APPLIED IMAGE, INC.

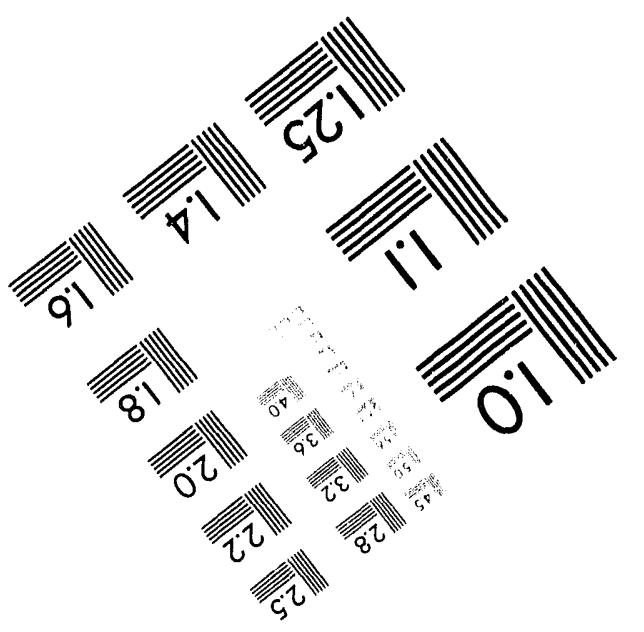



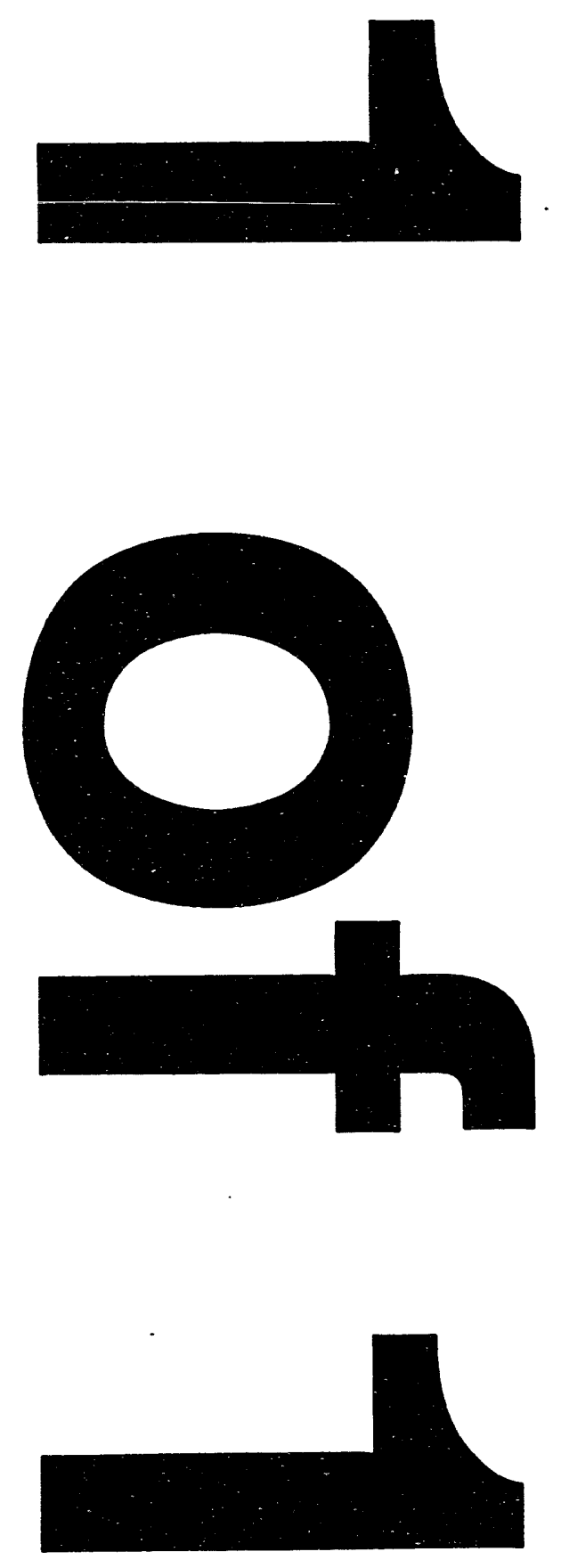
$10 / 1949 S D$
SANDIA REPORT

SAND93-1251 $\cdot$ UC -236

Unlimited Release

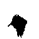

Printed May 1994

\section{On-Sun Test Results from Second-Generation and Advanced-Concepts Alkali-Metal Pool-Boiler Receivers}

J. B. Moreno, C. E. Andraka, T. A. Moss, P. G. Cordeiro, V. E. Dudley, K. S. Rawlinson

\section{Prepared by}

Sandia National Laboratoriee

Albuquerque, Now Mexico 87185 and Livermore, Callfornla 94550

for the United States Department of Energy

under Contract DE-ACO4-04AL85000

Approved for public release; distribution is unlimited. 
Issued by Sandia National Laboratories, operated for the United States Department of Energy by Sandia Corporation.

NOTICE: This report was prepared as an account of work sponsored by an agency of the United States Government. Neither the United States Government nor any agency thereof, nor any of their employees, nor any of their contractors, subcontractors, or their ernployees, makes any warranty, express or implied, or assumes any legal liability or responsibility for the accuracy, completeness, or usefulness of any information, apparatus, product, or process disclosed, or represents that its use would not infringe privately owned rights. Reference herein to any specific commercial product, process, or service by trade name, trademark, manufacturer, or otherwise, does not necessarily constitute or imply its endorsement, recommendation, or favoring by the United States Government, any agency thereof or any of their contractors or subcontractors. The views and opinions expressed herein do not necessarily state or reflect those of the United States Government, any agency thereof or any of their contractors.

Printed in the United States of America. This report has been reproduced directly from the best available copy.

Available to DOE and DOE contractors from

Office of Scientific and Technical Information

PO Box 62

Oak Ridge, TN 37831

Prices available from (615) 576-8401, FTS 626-8401

Available to the public from

National Technical Information Service

US Department of Commerce

5285 Port Royal Rd

Springfield, VA 22161

NTIS price codes

Printed copy: A04

Microfiche copy: A01 
SAND93-1251

Unlimited Release

Printed May 1994

Distribution

Category UC-236

\title{
On-Sun Test Results \\ from Second-Generation and Advanced-Concepts Alkali-Metal Pool-Boiler Receivers
}

\author{
J. B. Moreno, C. E. Andraka and T. A. Moss \\ Solar Thermal Technology Department \\ P. G. Cordeiro, V. E. Dudley, and K. S. Rawlinson \\ Solar Thermal Test Department \\ Sandia National Laboratories \\ Albuquerque, New Mexico 87185
}

\begin{abstract}
Two 75-kWt alkali-metal pool-boiler solar receivers have been successfully tested at Sandia National Laboratories' National Solar Thermal Test Facility. The first one, Sandia's "secondgeneration pool-boiler receiver", was designed to address commercialization issues identified during post-test assessment of Sandia's first-generation pool-boiler receiver. It was constructed from Haynes alloy 230 and contained the alkali-metal alloy NaK-78. The absorber's wetted side had a brazed-on powder-metal coating to stabilize boiling. This receiver was evaluated for boiling stability, hot- and warm-restart behavior, and thermal efficiency. Boiling was stable under all conditions. All of the hot restarts were successful. Mild transient hot spots observed during some hot restarts were eliminated by the addition of $1 / 3$ torr of xenon to the vapor space. All of the warm restarts were also successful. The heat-transfer crisis that damaged the first receiver did not recur. Thermal efficiency was $92.3 \%$ at $750^{\circ} \mathrm{C}$ with $69.6 \mathrm{~kW}_{\mathrm{t}}$ solar input.
\end{abstract}

The second receiver tested, Sandia's "advanced-concepts receiver," was a replica of the firstgeneration receiver except that the cavities, which were electric-discharge-machined in the absorber for boiling stability, were eliminated. This step was motivated by bench-scale test results that showed that boiling stability improved with increased heated-surface area, tilt of the heated surface from vertical, and added xenon. The bench-scale results suggested that stable boiling might be possible without heated-surface modification in a $75-\mathrm{kW}_{\mathrm{t}}$ receiver. Boiling in the advancedconcepts receiver with $1 / 3$ torr of xenon added has been stable under all conditions, confirming the bench-scale tests.

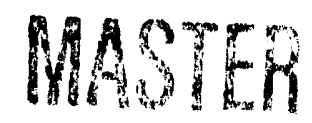

-3- DISTRIBUTION OF THIS DOCUMENT IS UNLIMITES 


\section{Acknowledgments}

The authors are indebted to Rich Diver for valuable discussions and for solar flux and heat-loss calculations, to Ed Hoffman and Mike Stone for stress analyses, to Rod Mahoney for emissivity and solar absorptivity measurements, and to Daniel Ray and Walt Einhorn for test support activities at the National Solar Thermal Test Facility. 


\section{Contents}

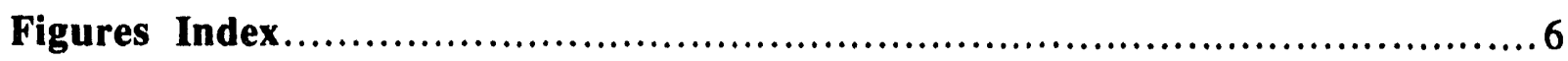

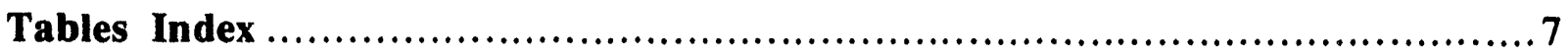

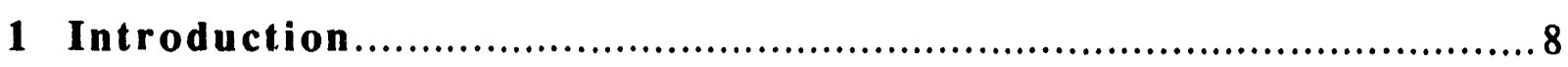

2 Second-Generation Pool-Boiler Receiver .................................... 11

2.1 Background................................................................ 11

2.2 Receiver Envelope Design Details................................................... 12

2.2.1 Absorber Flux Distribution ........................................... 12

2.2.2 Safety Factor for Film Boiling.............................................. 14

2.2.3 Safety Factor for Flooding............................................ 18

2.2.4 Absorber Stress Distribution................................................. 19

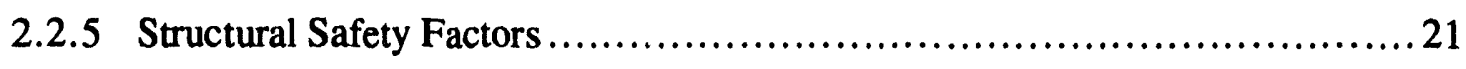

2.3 Other Design Details .......................................................... 24

2.3.1 Powdered-Metal Boiling Surface.............................................. 24

2.3.2 Optical Cavity and Insulation Package..................................... 24

2.3.3 Thermal Efficiency..................................................... 28

2.3.4 Dump Tank and Miscellaneous.......................................... 28

3 Advanced-Concepts Pool-Boiler Receiver .................................... 31

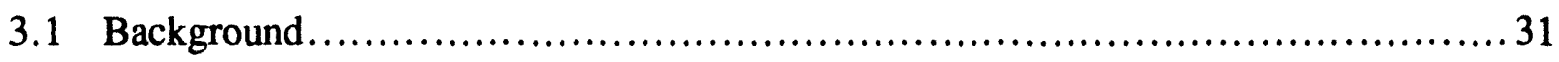

3.2 Design Details .......................................................... 32

4 Test Objectives, Preparations and Equipment ................................ 33

4.1 Receiver Fabrication, Evacuation and Filling.................................. 33

4.2 Receiver Instrumentation ................................................ 34

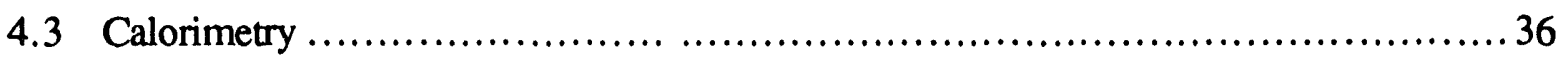

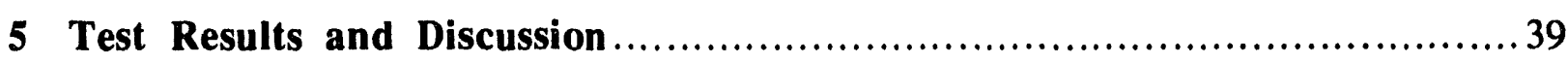

5.1 Second-Generation Receiver Results ........................................... 39

5.2 Advanced-Concepts Receiver Results ......................................51

6 Summary and Conclusions ............................................... 56

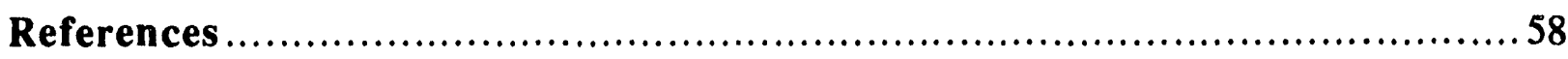

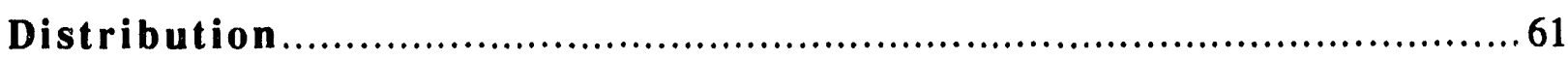




\section{List of Figures}

1. Schematic of the liquid-metal pool-boiler reflux receiver ..............................9

2. Photograph of the first-generation pool-boiler receiver in its mounting ring ...............9

3. Comparison of the first- and second-generation receiver sizes...............................13

4. Photographs of the second-generation pool-boiler receiver in its mounting ring ........... 13

5. Schematic of the second-generation pool-boiler receiver in its mounting ring ............. 15

6. Comparison of the first- and second-generation receiver flux distributions ............... 16

7. Film-boiling critical heat fluxes for sodium and NaK-78 ........................... 17

8 Flooding safety factors for the first- and second-generation receivers .................. 17

9. Stress distribution predicted for the second-generation receiver ....................... 22

10. Haynes 230 properties and ASME Code Case 2063 allowed stress; predicted stresses .... 22

11a. Cross section of $-60 /+80$ powdered-metal coating selected for 2 nd-generation receiver..... 25

11b. Powdered-metal coating on a replica of the 2 nd-generation receiver's absorber............ 25

12. Optical cavity with open aperture for boiling-behavior tests (both receivers) ..............26

13. Optical cavity with cylindrical sidewall and 8.66-inch aperture for efficiency tests .........26

14. Optical cavity with conical sidewall and 8.66-inch aperture for the final efficiency test ....27

15. Second-generation receiver in its weather housing with Kaowool insulation ................29

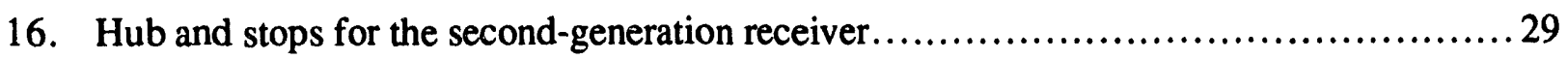

17. System used to remove xenon from the advanced-concepts receiver.............................35

18. System used to add xenon to the advanced-concepts receiver......................................35

19. Arrangement of thermocouples on the second-generation receiver ....................... 37

20. Arrangement of thermocouples on the advanced-concepts receiver ...................... 37

21. Second-generation receiver results, first test day ................................. 41

22a. Second-generation receiver, hot-restart superheating before xenon addition.............. 42

22b. Second-generation receiver, well-behaved hot-restart series after xenon addition..........42 42

23a. Second-generation receiver, hot-restart overheating before xenon added, with IR images. . 43

23b. Second-generation receiver, well-behaved hot restart after xenon added, with IR images . 43

24. Second-generation-receiver stable boiling, second test day .......................... 45

25. Second-generation receiver stable boiling and well-behaved restarts, third test day.......... 45

26. Second-generation receiver stable boiling results, fourth test day ......................47 47

27. Second-generation receiver well-behaved warm restarts, fifth test day .................. 47

28. Second-generation receiver well-behaved warm and hot restarts, sixth test day.............49

29. Second-generation receiver: a sequence of three well-behaved warm restarts..................49

30. Second-generation receiver: a single well-behaved warm restart with IR-camera images ...50

31. Second-generation receiver efficiency results, seventh test day.................................50 


\section{$4: 1: 1: 1$}

Eigure

\section{List of Figures (continued)}

32. Advanced-concepts receiver with xenon: startup and stable-boiling results , 1st test day. . 52

33. Advanced-concepts-receiver stable boiling and well-behaved hot restarts, 2nd test day .....52

34. Advanced-concepts-receiver startup behavior after xenon was removed, 3rd test day.......54

35a. Details of well-behaved 1st start-up w/o xenon, advanced-concepts receiver, 3rd test day . 54

35b. Details of advanced-concepts-receiver aborted 2nd start-up without xenon, 3rd test day.... 55

36. Advanced-concepts-receiver stable boiling, good hot restarts after xe refill, 4 th test day.... 55

Table

\section{List of Tables}

1. Second-generation receiver operating modes and conditions................................ 21

2. Second-generation receiver structural analysis summary ............................ 23

3. Input data for AEETES for the last test of the second-generation receiver..................... 30

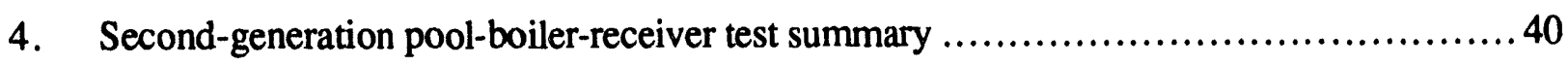

5. Advanced-concepts pool-boiler-receiver test summary ............................ 51 


\section{Introduction}

Solar dish/Stirling electric systems are under development by private industry and government laboratories both here and abroad [1-5]. In early designs the Stirling-engine heater-head tubes were directly illuminated with concentrated solar flux [6]. Most of the current designs propose using a two-phase refluxing liquid-metal-receiver interface between the concentrator and the heater-head tubes; the reflux receiver's near-isothermal nature offers improvements in heater-head lifetime and engine efficiency [7]. The reflux receiver also allows decoupling of the design of the various heattransfer surfaces (absorber, heater tubes, and for hybrid systems, the fossil-fuel-fired surface). This means that the design of each surface can be optimized for its specific function.

At Sandia National Laboratories, the development of refluxing liquid-metal solar receivers is funded by the United States Department of Energy's Solar Thermal Technology Program. Two types of receivers are being developed: pool boilers and heat pipes. The pool-boiler concept [8] is shown in Figure 1. Solar flux that is concentrated on the absorber heats a liquid-metal pool. The liquid boils, cooling the absorber, and the resulting metal vapor condenses on the Stirling-engine heater tubes, providing heat to run the engine. The condensate flows back to the pool, completing the heat-transport cycle. The heat-pipe version of this device uses a wick instead of a pool to distribute the liquid over the absorber. For both pool-boiler and heat-pipe receivers, the planned range of operating temperatures is $675^{\circ} \mathrm{C}$ to $800^{\circ} \mathrm{C}$. At these temperatures, the alkali metals sodium (Na) and potassium (K), and their alloy NaK-78 (78\% potassium by weight) are of primary interest because they have vapor pressures near one atmosphere [9] -- high enough for efficient heat transfer yet acceptable from a structural standpoint.

Both receiver concepts have advantages and drawbacks. The pool-boiler receiver has few parts and is simple to construct, but it requires more liquid-metal inventory than a similar heat pipe - 12.7 pounds of sodium in the first $75-\mathrm{kW}_{\mathrm{t}}$ demonstration $[10,11]$ and 19.5 pounds of $\mathrm{NaK}-78$ in the second-generation receiver described herein. Because the receiver must always be oriented so that the pool covers the absorber, its application on polar-drive concentrators is problematical. Most importantly, some aspects of the boiling behavior of liquid metals are not well understood (see Sections 2.2.2, 2.2.3, and 2.3.1). In contrast, the heat pipe has more parts with more complexity, but it has a smaller liquid-metal inventory: 6.4 pounds of sodium in the first Cummins Power Generation (CPG) /Thermacore Inc. 75-kW prototype [1]. Its principles of operation are betterunderstood, but a $75-\mathrm{kW}_{\mathrm{l}}$ heat-pipe receiver requires a wick/artery structure for which the design tools are not yet proven [1]. 


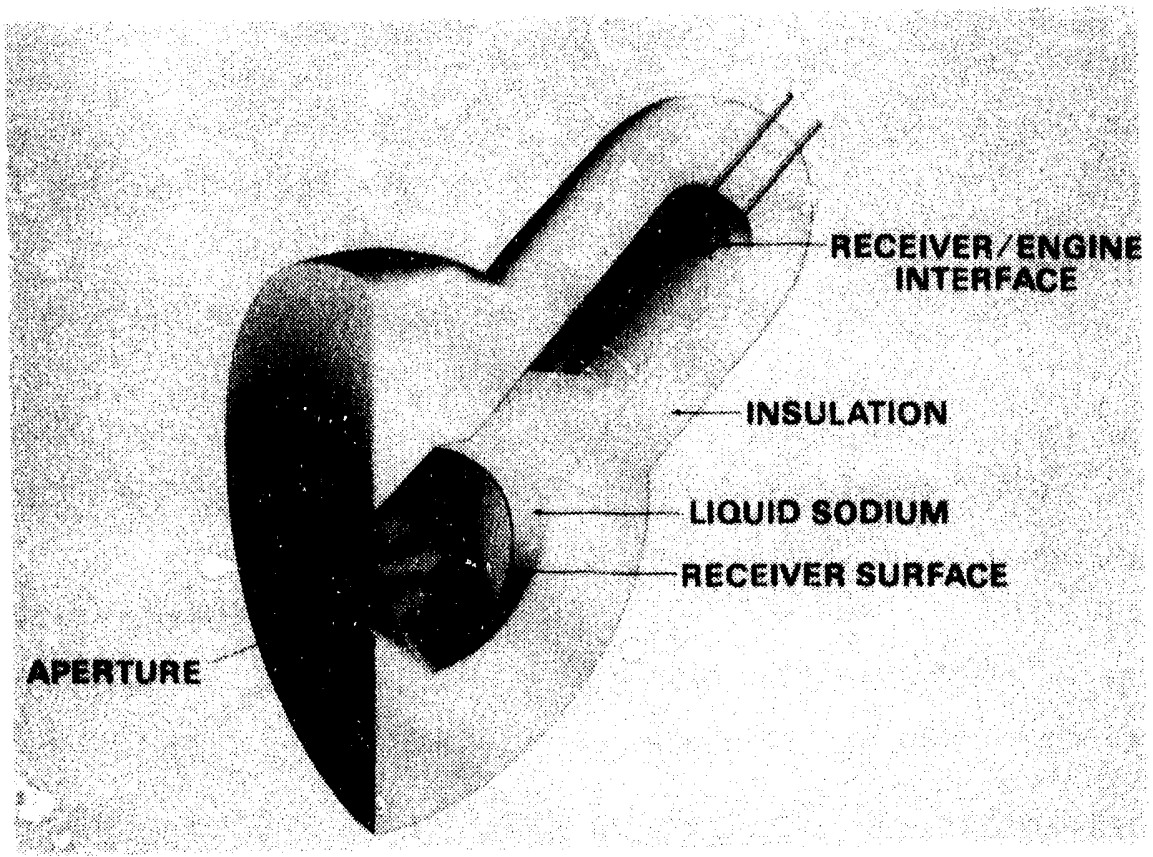

Figure 1. Schematic of the liquid-metal pool-boiler reflux receiver.

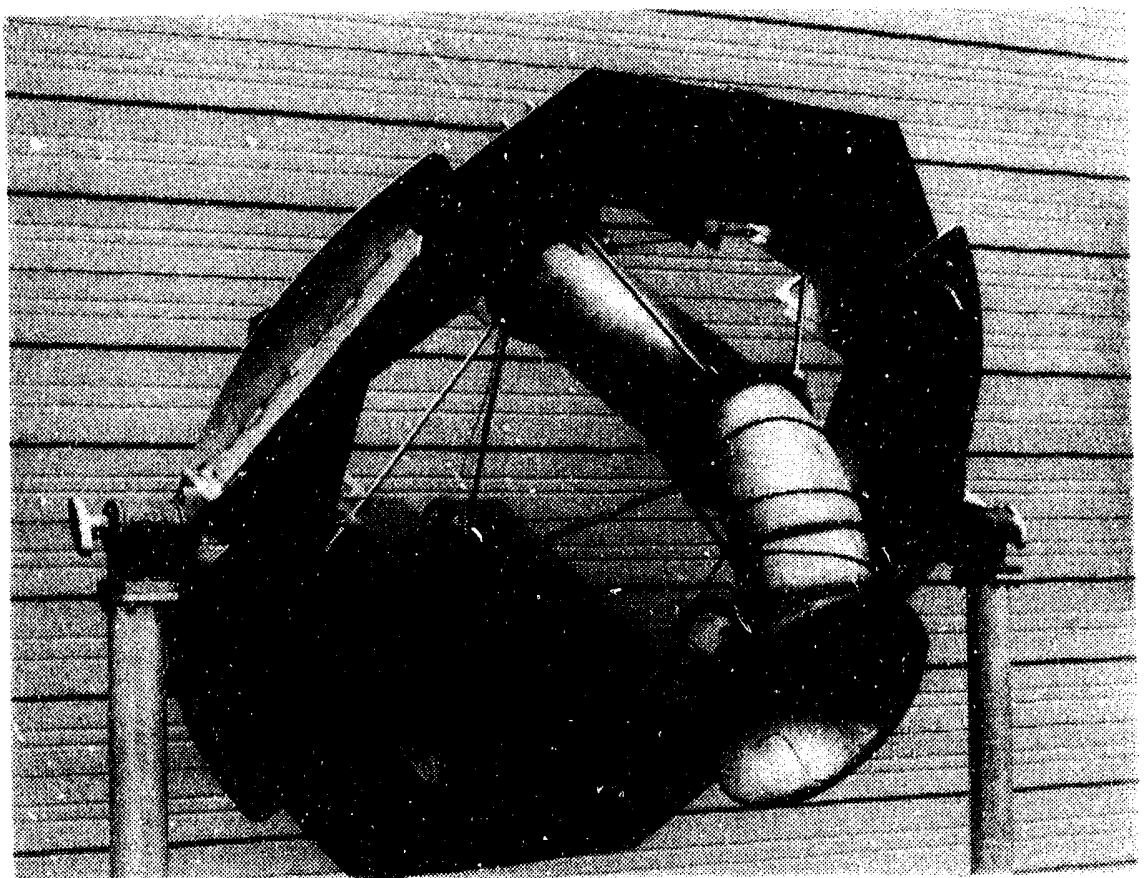

Figure 2. Photograph of the first-generation pool-boiler receiver in its mounting ring. 
The first pool-boiler reflux receiver, shown in Figure 2, was operated at Sandia National Laboratories in the Fall of 1989 and Spring of $199 \mathrm{C}$ at up to $62 \mathrm{~kW}_{\mathrm{t}}$ throughput power and $800^{\circ} \mathrm{C}$ sodium-vapor temperature $[10,11]$. From extensive evidence in the literature and from our own bench-scale tests, we expected that boiling would not be stable without special control techniques [12-14]. We also expected that hot restarts would require excessive heated-surface superheats $[13,14]$. Here we define hot (warm) restarts as having a pool temperature above (at or below) $450^{\circ} \mathrm{C}$ upon application of power. To assure stable boiling, our first boiler was built with 35 equally-spaced "artificial cavities". These were 0.006 -inch-diameter x 0.02 inch-deep blind holes electric-discharge-machined (EDM) in the wetted side of the absorber. According to the (approximate) boiling-stability theory of Shai and Rohsenow [15], these cavities were deep enough to avoid deactivation [13]. Passive control of the hot-restart problem was achieved by adding a trace ( 0.07 torr) of xenon to the boiler headspace, an approach suggested by Saaski [16].

During the testing of the first pool-boiler receiver, two important boiling-behavior concerns were at least partially settled: excellent boiling stability was demonstrated under all conditions and good hot-restart behavior was demonstrated at sun elevations up to about 55 degrees. After approximately 50 hours of testing, the receiver developed a leak during a warm restart in late May 1990. Post-test analysis indicated the leak was probably a result of heat-transfer crisis (film boiling or flooding) due to the unusually low-temperature restart $[11,17]$.

The post-test analysis of the first pool-boiler receiver produced a list of actions deemed necessary to move the concept closer to commercialization. The list included (1) determining what changes will improve commercial potential, (2) identifying candidate materials and methods to achieve those changes, (3) screening the candidate materials and methods in short-term bench-scale tests, (4) designing, building and demonstrating a 2nd-generation pool-boiler receiver based on the outcome of the short-term tests, and (5) demonstrating lifetime potential in long-term bench-scale tests. The outcome of items $1-3$ have been reported previously [18,19]. Item 5 is nearly $2 / 3$ completed and an interim report has been published [20]. The outcome of item 4, the design, construction and testing a 2nd-generation pool-boiler receiver, is reported here. In addition, unexpected results from the short-term bench-scale tests have motivated the construction and testing of an "advanced-concepts receiver", which is also documented in this report. 


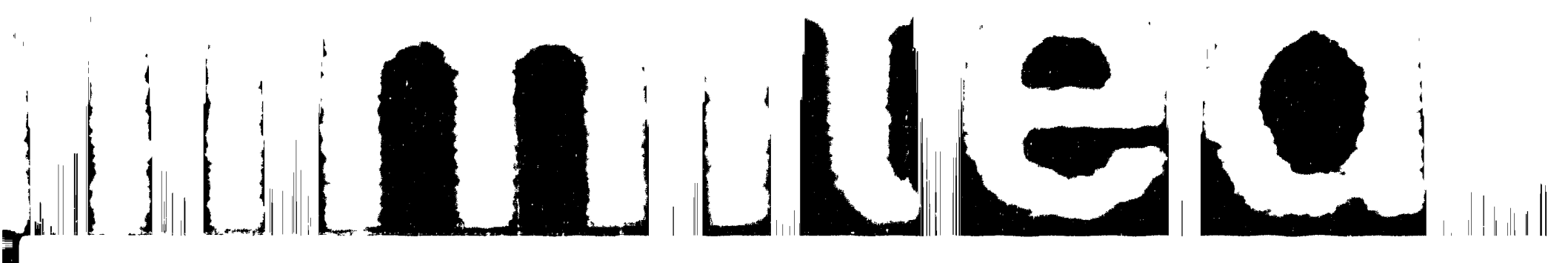

\section{Second-Generation Pool-Boiler Receiver}

\subsection{Background}

Sandia's second-generation pool-boiler receiver was conceived to move the pool-boiler concept closer to commercialization. The plan to achieve this goal was formulated during our post-test analysis of the first-generation receiver. The starting point was a list of improvements suggested by our analysis. The list included reducing cost, improving robustness and lifetime, and increasing industry confidence in pool-boiler receivers [19].

We identified two major cost reductions: (1) elimination of the $\$ 3500$ worth of electric-dischargemachined cavities used to stabilize boiling, in favor of methods costing $\$ 125$ or less, such as laserdrilled cavities, powder-metal coatings and inert-gas additions; and (2) elimination of the $\$ 350$ worth of electrical heaters uscd to melt sodium, by replacing the sodium with NaK-78, which remains liquid down to $-12.6^{\circ} \mathrm{C}$. Groundwork in these areas had already been carried out by Thermacore Inc. [21].

To improve the receiver's robustness and lifetime, the following steps were proposed: (1) optimize the choice of added gases and pressures, to eliminate the hot-restart superheats that occurred at sun elevations greater than 55 degrees; (2) increase the surface area of the absorber and the gap between it and the rear dome, to improve the safety factors for warm-restart film boiling and flooding (believed to have caused burnout of the first pool boiler); and (3) fabricate the receiver envelope from Haynes ${ }^{\circledR}$ alloy 230 (Haynes International, Kokomo, IN), instead of $316 \mathrm{~L}$ and $304 \mathrm{~L}$ stainless steels, to increase the receiver's oxidation resistance and strength.

Measures to increase industry confidence in pool boilers included: (1) designing the receiver to Section VIII Division I ASME Boiler and Pressure Vessel Code; (2) bench-scale screening the proposed materials and methods changes and demonstrating the new receiver on sun; and (3) demonstrating the lifetime potential of the materials and methods employed in the secondgeneration receiver in a 10,000 hour round-the-clock bench-scale test [20].

The bench-scale screening tests have been reported in previous publications $[18,19]$. The tests showed that stable boiling could be expected in a Haynes alloy 230 boiler containing NaK-78 with a heated-surface coating of type $304 \mathrm{~L}$ stainless steel $-60 /+80$ powder applied using a brazing process developed by Friction Coating Corp. of Sterling Heights, Michigan. Other surface modifications tested either did not adequately stabilize boiling or were judged more difficult to 
apply. The addition of noncondensible gas to bench-scale boilers without surface modification did not adequately stabilize boiling, although a positive effect was seen. Hot restart behavior was best (but still unacceptable) with $1 / 3$ torr of xenon added; higher pressures of xenon did not lead to further improvement, and helium was not beneficial. The bench-scale tests did provide evidence that xenon affects hot-restart behavior as a result of entrainment in the liquid metal, that entrainment depends on the shape of the receiver envelope, and that as a result, hot-restart behavior could be expected to be better in our full-scale receiver than in the bench-scale receiver. Details of the benchscale screening tests can be found in References 18 and 19; details of the second-generation poolboiler receiver design are presented in the next section.

\subsection{Design Details}

The firsi-generation pool-boiler receiver design is shown superposed on the second in Figure 3. The new receiver has a larger absorber and a larger gap between its domes. The larger absorber was moved farther from the concentrator focal plane, resulting in lower incident peak fluxes and thus increasing the safety factor for film boiling. The larger gap between the domes reduces the vapor velocities, thereby increasing the safety factor for flooding. These safety factors are discussed in Sections 2.2.2 and 2.2.3. Figure 4 shows several views of the receiver in its mounting ring. The receiver is an all-welded construction made from Haynes alloy 230. Most of it was roll-formed or hydroformed from 0.063 -inch-thick sheet. The absorber was hydroformed from 0.032 -inch sheet. (The first-generation receiver was made from $316 \mathrm{~L}$ and $304 \mathrm{~L}$ stainless steel, with a 0.032 -inch-thick absorber and a 1/8-inch-thick rear dome, and used eight-inch schedule 10 pipe sections for the condenser section). In the new design, the closer thickness match between the front and rear domes reduces thermal stresses. The general use of thinner sections results in a much lighter receiver.

\subsubsection{Absorber Flux Distribution}

Figure 5 is a schematic of the receiver in its mounting ring. The schematic contains a number of details relevant to the flux distribution on the absorber. First consider the optical cavity. Figure 5 shows the configuration used in the final performance test; other configurations are described in Section 2.3.2. The optical cavity consists of three elements: a 9.6-inch-radius $70^{\circ}$-half-angle spherical absorber, an 8.66-inch-diameter aperture, and a conical sidewall with a $45^{\circ}$ half-angle located between the aperture and the absorber. Direct illumination of the sidewall is avoided because the concentrator rim angle is also $45^{\circ}$. Direct illumination of the absorber rim weld is avoided by locating it radially just outboard of the sidewall. These details are all illustrated in 


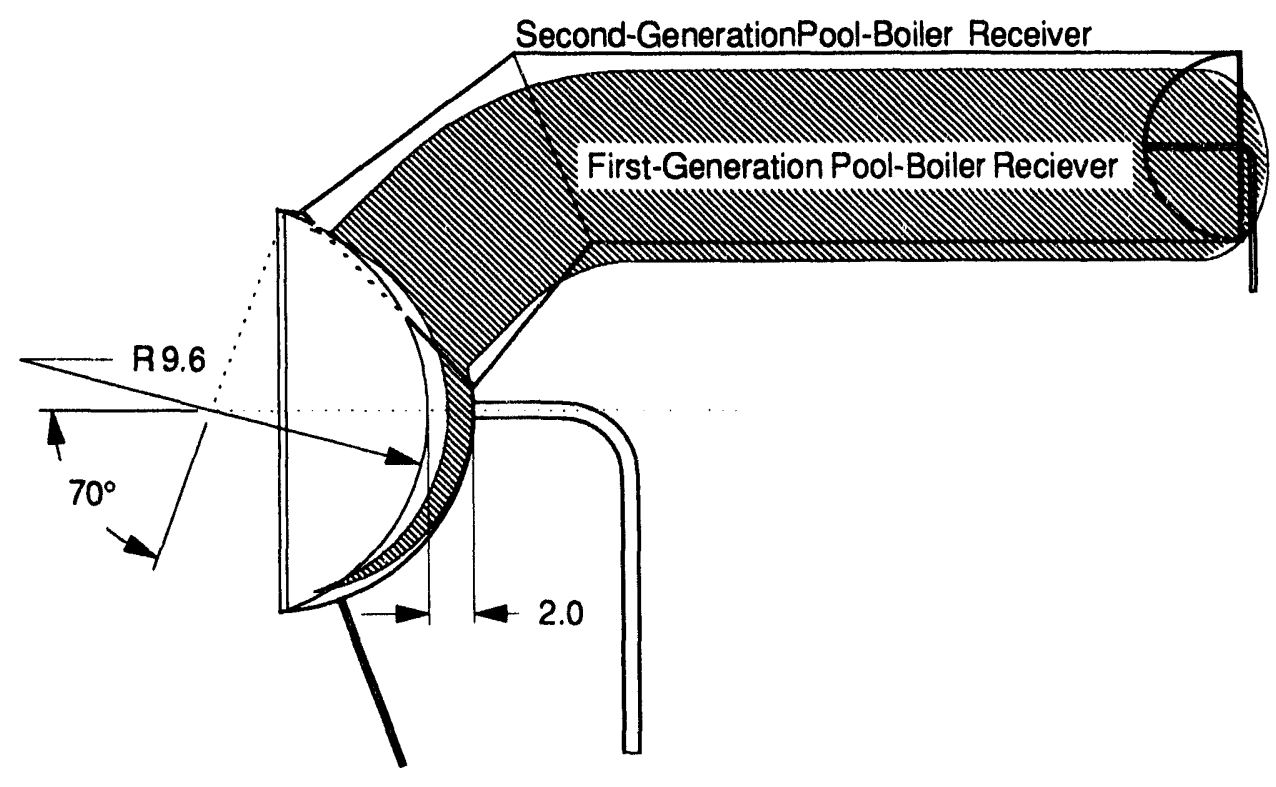

Figure 3. Comparison of the first- and second-generation receiver sizes.
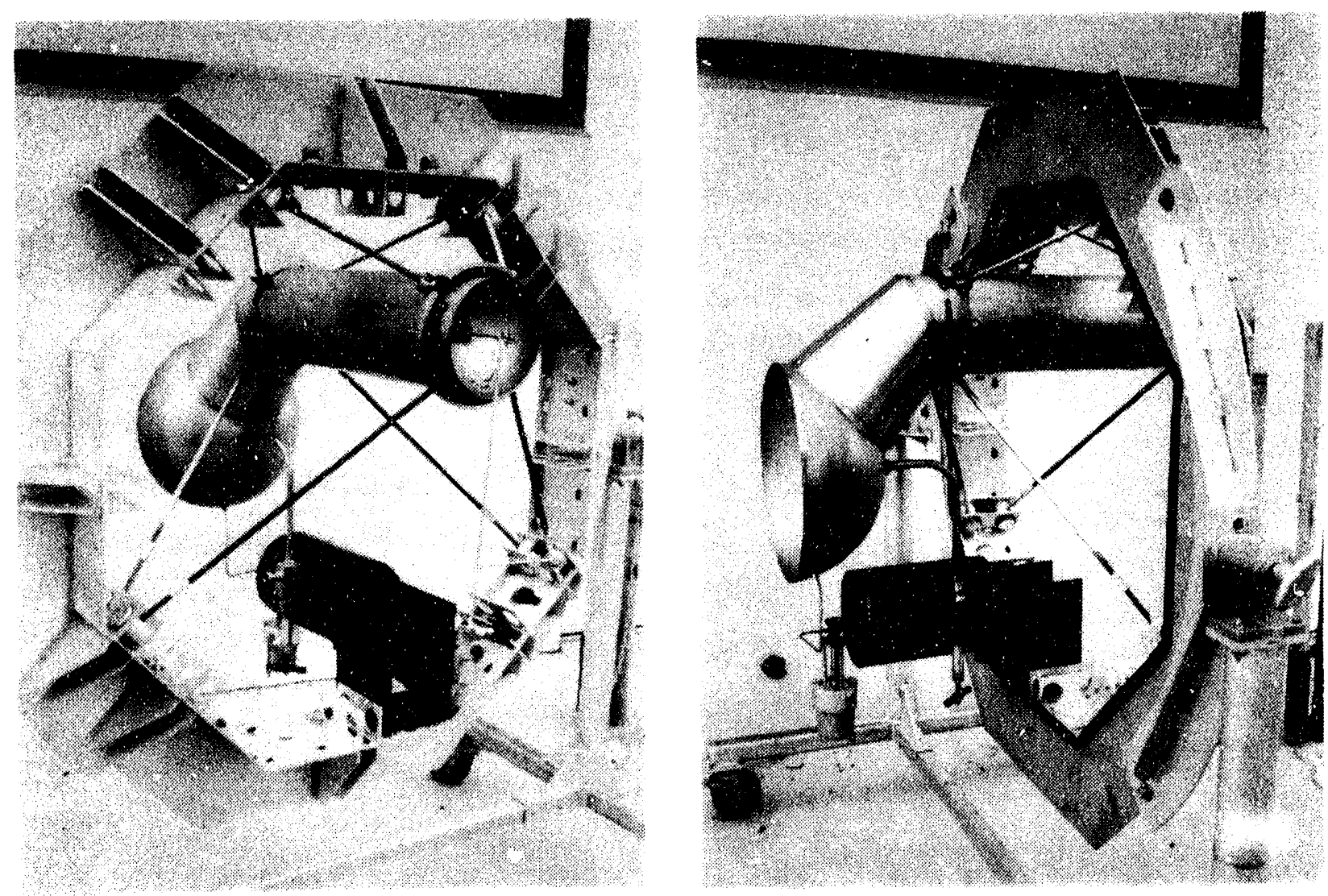

Figure 4. Photographs of the second-generation pool-boiler receiver in its mounting ring. 
Figure 5. Also shown are the mean locations [22] for the aim points of the 64 "A" mirrors and 156 "B\&C" mirrors of Test Bed Concentrator Two (TBC-2, the solar concentrator on which the receiver was tested). The distance from the origin of the facet coordinate system to the mounting plane is 288.33 inches [22]. Facet position data for TBC-2 are the same as for TBC-1 [23], whose facet position data are documented in Reference [11]. Mirror corrosion data for TBC-2 remain in memo form [23]. Using the conical optics code CIRCE2 [24] and these details, we have computed the incident flux distribution for the new receiver at the design condition of $75 \mathrm{~kW}_{\mathrm{t}}$ incident power. In Figure 6, the computed distributions for the first and second-generation receivers are compared. The computed peak flux is seen to be reduced from 75 to $58 \mathrm{~W}_{\mathrm{t}} \mathrm{cm}^{2}$. The estimated effect of this reduction in peak flux level on heat-transfer crises is discussed in Sections 2.2.2 and 2.2.3.

The computed incident flux distribution is the starting point for the receiver thermal model AEETES [25]. This model takes into account the incident flux, re-radiated energy, multiple reflections, conduction, and cavity convection. In addition to the incident flux distribution, AEETES requires the receiver's geometry and thermal properties, including those of the insulation package. The model can then predict the distribution of net flux into the receiver, temperature distributions, heat loss, and efficiency. Results from AEETES are discussed in Sections 2.2.4 and 2.3.3.

\subsubsection{Saffety Factor for Film Boiling}

Film boiling occurs at a spot on a heated surface when the local rate of vapor generation is so great that liquid is prevented from contacting the surface. Only a handful of reports address the topic of critical heat fluxes (CHF's) for film boiling of alkali metals [26]. In Figure 6.14 of Reference 12, the CHF's for sodium and $\mathrm{NaK}$ are compared. Four sets of sodium data are represented as a function of the form $\mathrm{CHF}=$ constant $\times \mathrm{P}^{0.2}$, where $\mathrm{P}$ is the pressure in the liquid at the boiling surface. A single set of NaK-78 data is presented, which we fit with a curve of the form $\mathrm{CHF}=$ constant $\times \mathrm{P}^{0.28}$. Letting $\mathrm{P}$ equal the saturated vapor pressure, we expressed the CHF's as functions of temperature. All of the data correspond to temperatures above $600^{\circ} \mathrm{C}$. Our extrapolations down to $300^{\circ} \mathrm{C}$ are shown in Figure 7. An alternative function for both metals of the form $\mathrm{CHF}=$ constant $\times \mathrm{P}^{0.125}$ has been used in the past $[11,16,17]$; the present fit is more conservative at the lower temperatures where film boiling is most likely to occur. In any event, the results must be used with caution, since they were obtained in boilers with configurations and orientations very different from ours. Their safest application is in making relative comparisons. 


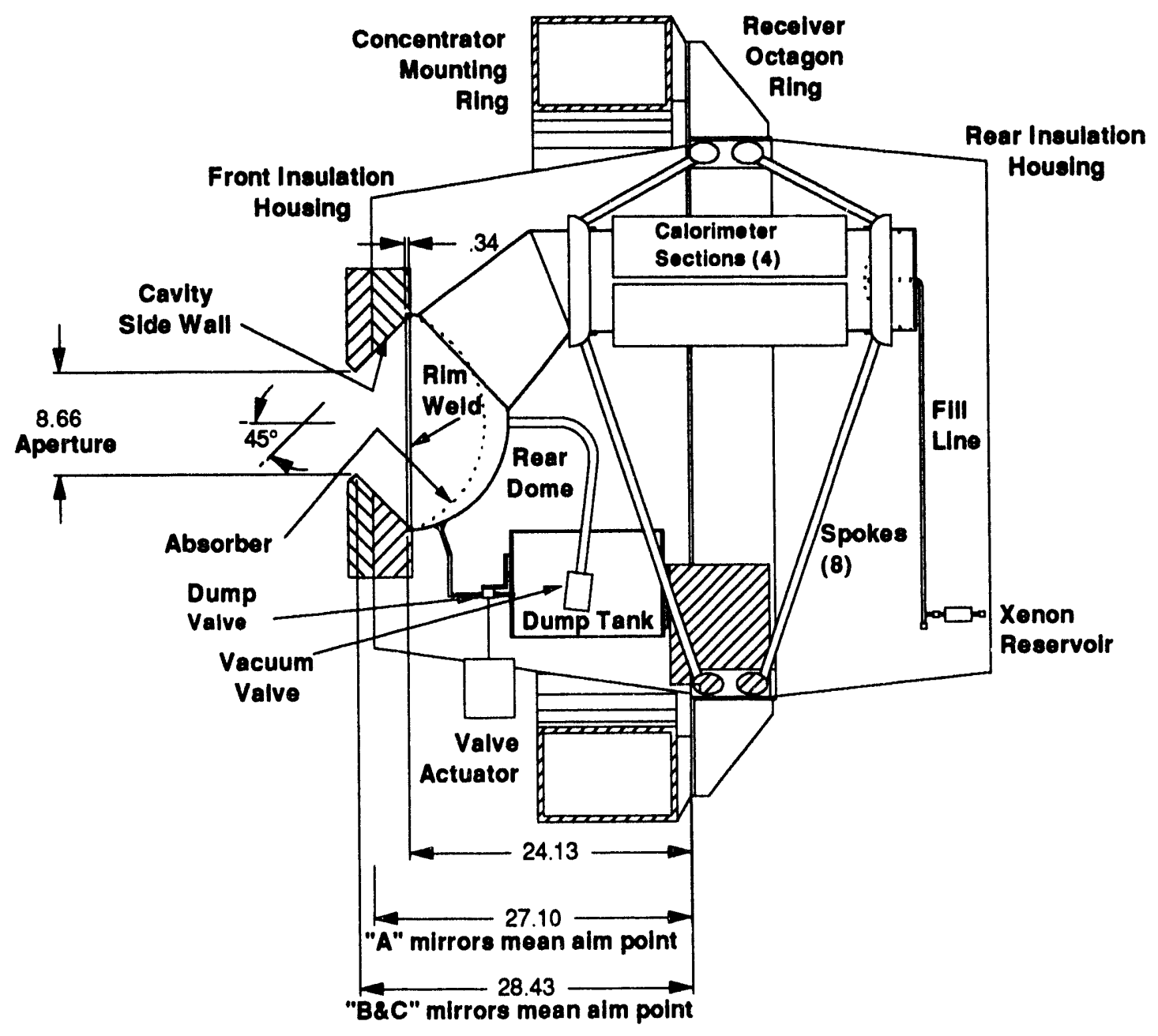

Figure 5. Schematic of the second-generation pool-boiler receiver in its mounting ring. 


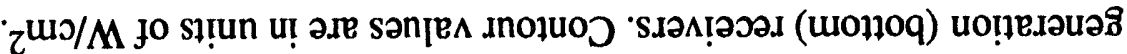

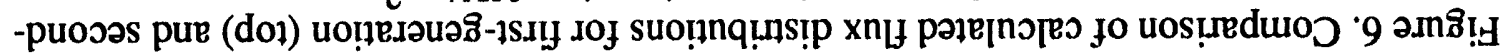

(seyou!) uo!!!sod peloo!lodd

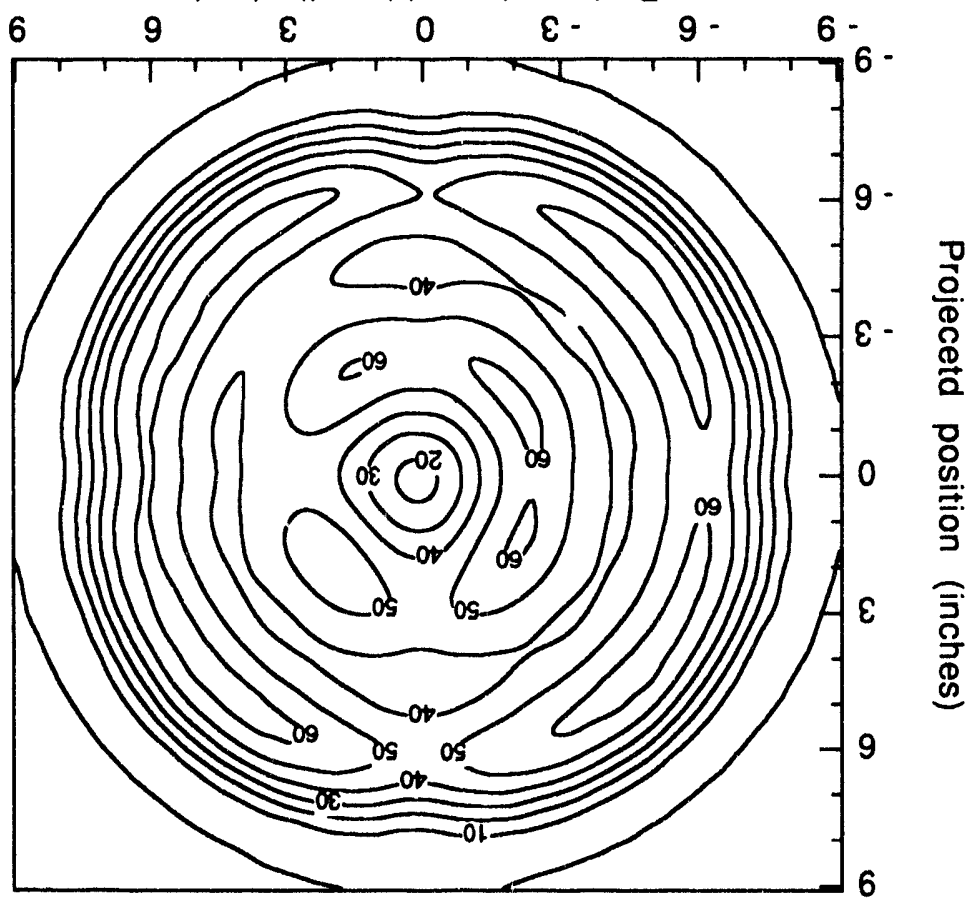

(soyou!) uo!!!sod peloө!odd

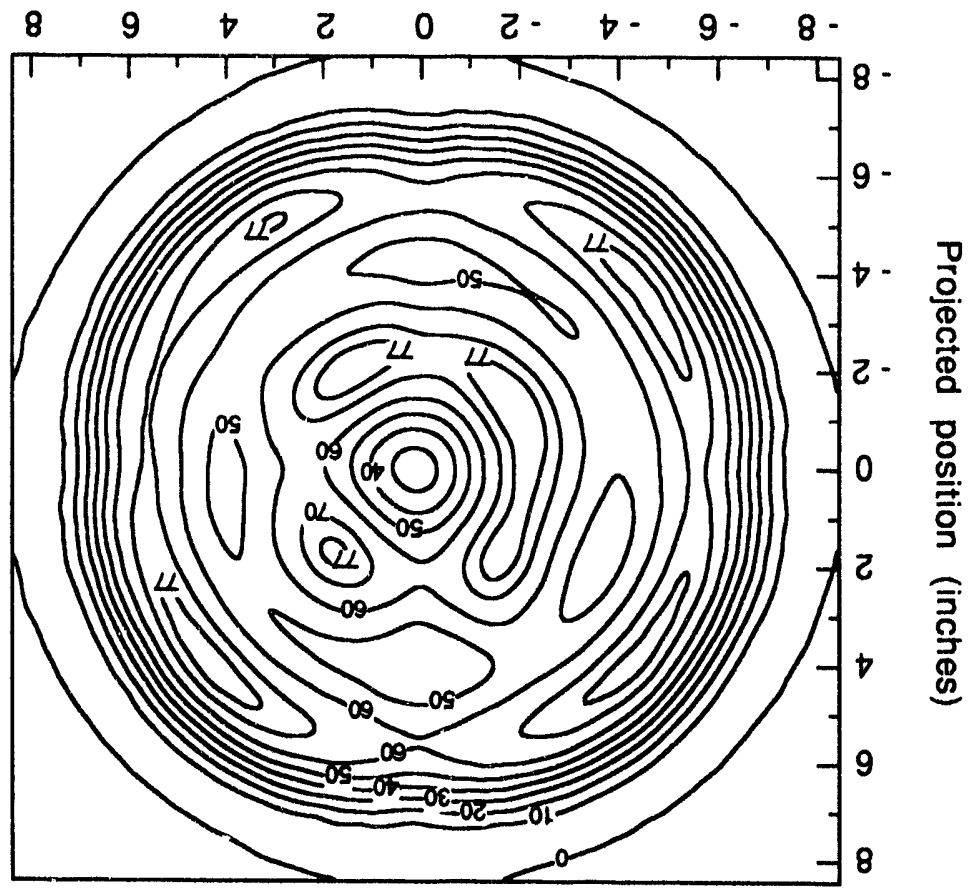




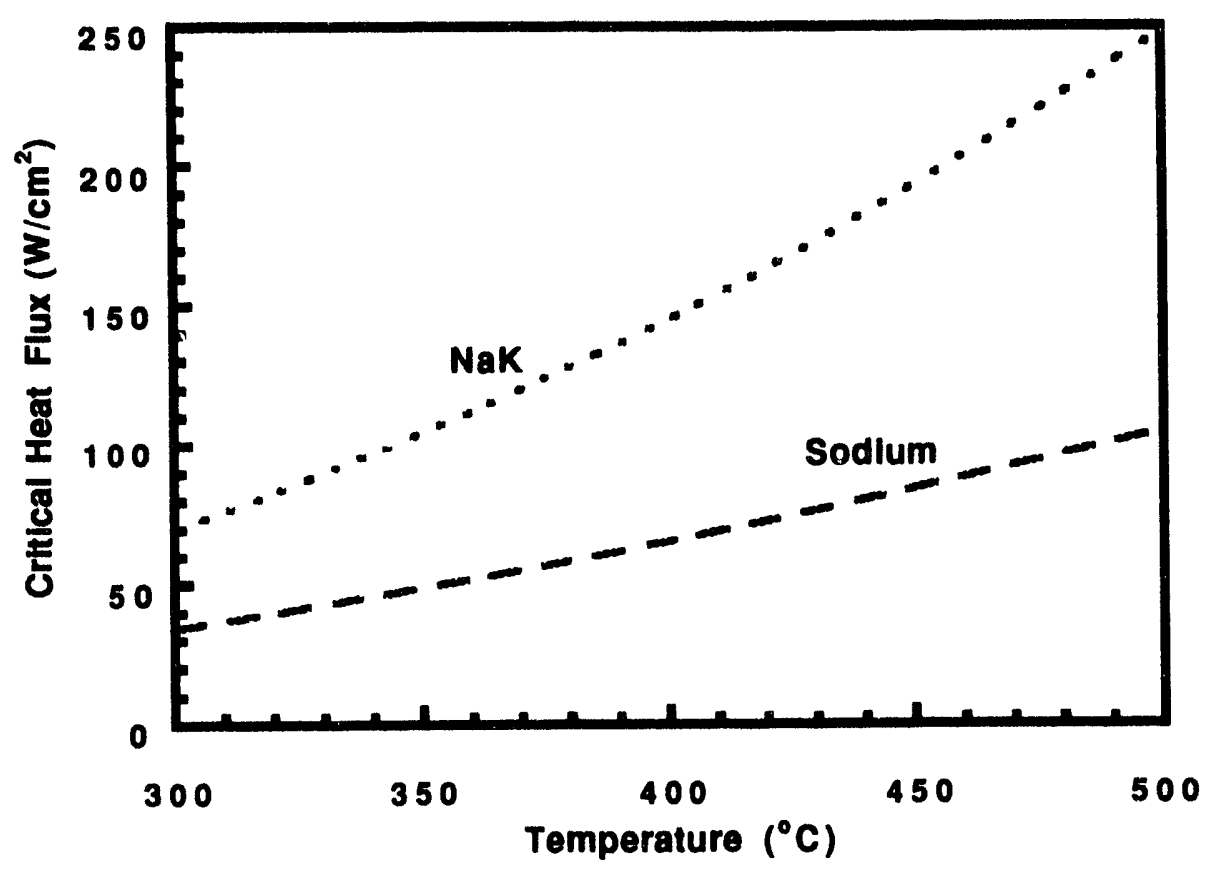

Figure 7. Film-boiling critical heat fluxes for sodium and NaK-78 [from Ref. 26].

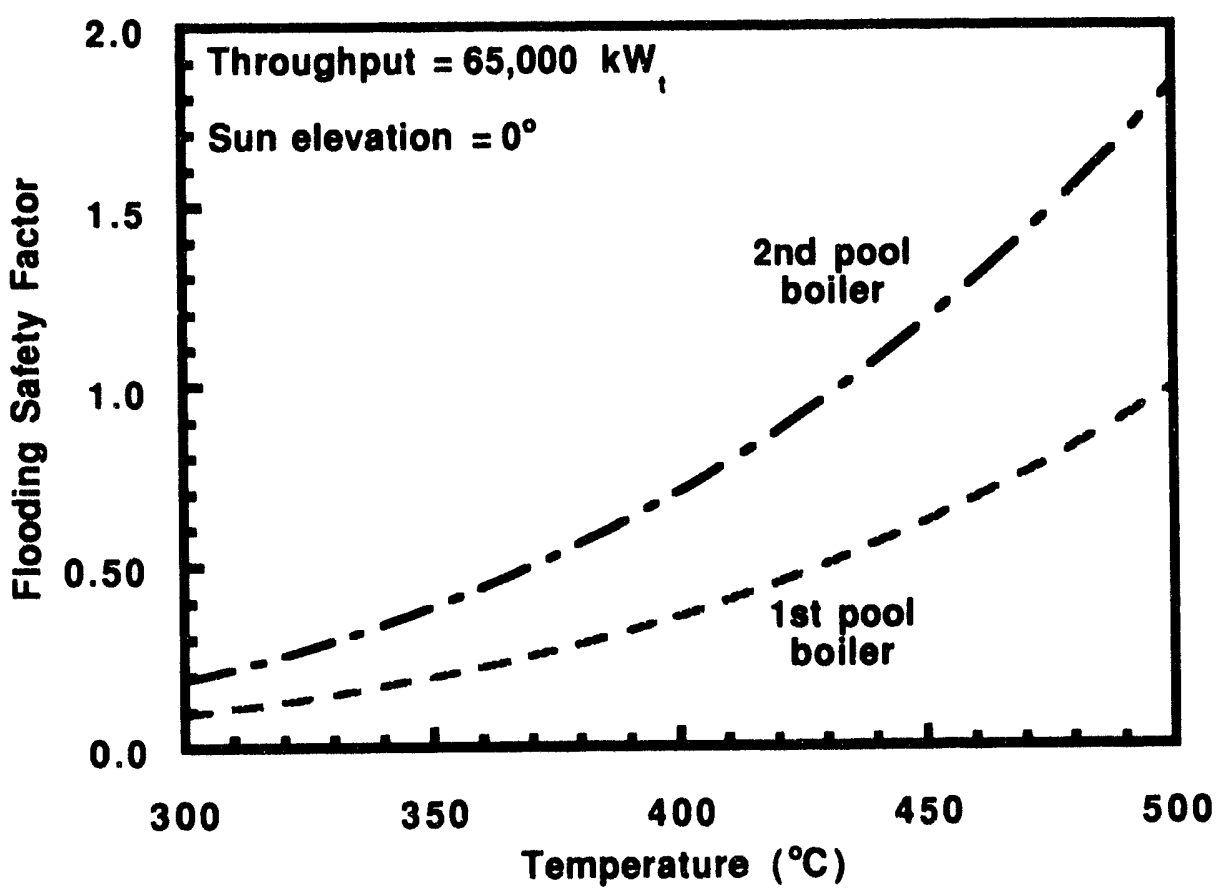

Figure 8. Flooding safety factors for the first- and second-generation receivers. 
For example, Figure 7 shows that the film-boiling safety factor for $\left.\mathrm{NaK}_{(\mathrm{SF}} \mathrm{NaK}(\mathrm{T})\right)$ will be about twice the value for sodium, at any given temperature $T$ :

$$
\frac{S F_{N a K}(T)}{S F_{N a}(T)} \equiv \frac{C H F_{N a K}(T)}{F l u x_{N a K}} \frac{F l u x_{N a}}{C H F_{N a}(T)}=\frac{C H F_{N a K}(T)}{C H F_{N a}(T)} \approx 2
$$

To compare the safety factors of the first and second-generation receivers, one should use their respective peak fluxes, and evaluate the CHF's at boiling incipience, where they are smallest:

$$
\frac{(S F)_{2}}{(S F)_{1}} \equiv \frac{C H F_{N a}\left(T_{\text {incipient }}\right)_{1}}{F l u x_{1}} \frac{F l u x_{2}}{C H F_{\text {NaK }}\left(T_{\text {incipient }}\right)_{2}}=\frac{C H F_{N a}\left(T_{\text {incipient }}\right)_{1}}{75 W / \mathrm{cm}^{2}} \frac{58 \mathrm{~W} / \mathrm{cm}^{2}}{C H F_{\text {NaK }}\left(T_{\text {incipient }}\right)_{2}}
$$

Sodium typically started boiling in the first-generation receiver at $480^{\circ} \mathrm{C}$, which from Figure 7 means $C H F_{\mathrm{Na}}\left(T_{\text {incipient }}\right)_{1}=95 \mathrm{~W} / \mathrm{cm}^{2}$. Then for the safety factors to be equal, the above equation requires that $C H F_{\text {NaK }}\left(T_{\text {incipient }}\right)_{2}=73.5 \mathrm{~W} / \mathrm{cm}^{2}$. Figure 7 shows that this occurs at about $308^{\circ} \mathrm{C}$. It follows that the smallest film-boiling safety factor for the second-generation receiver will be larger/smaller than for the first-generation receiver depending on whether boiling starts above/below $308^{\circ} \mathrm{C}$. The actual outcome will be discussed in the presentation of results.

\subsubsection{Safety Factor for Flooding}

Flooding occurs when the vapor velocities in the boiler are so high that condensate is prevented from returning to the pool. The critical heat flux at which this happens is expressed in terms of the rate of heat transport by vapor between the pool and the condenser per unit of vapor-duct crosssectional area. The only reported observations of critical heat flux for flooding in boiling alkali metals are in a paper recently presented by Thermacore Inc. [21]. The Thermacore boiler contained NaK-78 in a vertical tube with a central conical insert, and was axisymmetrically heated. The results were compared with the correlation of Kutateladze, which is based on data from ordinary liquids in vertical tubes with axisymmetric heating. The critical heat fluxes observed by Thermacore were somewhat less than those predicted by the correlation. For the configurations and orientations of current full-scale receiver designs, the Kutateladze correlation is not strictly applicable. However, for lack of an alternative, it has been modified [27] to account for non- 
vertical internal flow, and has been used to estimate the critical heat flux of a number of pool-boiler receiver designs $[17,27]$. The modified expression is:

$$
\Phi=K u \frac{h_{v}\left[\rho_{v}^{2} g \gamma\left(\rho_{l}-\rho_{v}\right) \sin (\alpha)\right]^{0.25}}{\left[1+\left(\rho_{v} / \rho_{l}\right)^{0.25}\right]^{2}}
$$

Here $\Phi$ is the critical heat flux, $h_{v}$ is the heat of vaporization, $\rho$ is density (with $l$ referring to liquid and $v$ referring to vapor), $\gamma$ is surface tension, $\alpha$ is the angle between the vapor flow direction and horizontal, and $g$ is the gravitational constant. The term $\mathrm{Ku}$ is the critical value of the Kutateladze number. For air bubbling through water $\mathrm{Ku}$ is equal to 3.2; this value is assumed to be appropriate here as well. The safety factor for flooding is the ratio of the critical heat flux to the actual heat flux. We have evaluated the actual heat flux at the plane dividing the absorber into an upper and lower half. As with film-boiling, the best use of these safety factors is in making islative comparisons. Values for our first- and second-generation receivers are presented in Figure 8. It can be seen that the safety factor for the second-generation receiver is about twice that of the first. This is almost entirely due to the larger cross-sectional area and is essentially unaffected by the choice of liquid metal. As with film boiling, the smallest factors of safety for flooding occur at boiling incipience. The same rationale that was applied in the case of film boiling can be used here, to show that the smallest flooding safety factor for the second-generation receiver will be larger/smaller than for the first-generation receiver depending on whether boiling starts above/below $412^{\circ} \mathrm{C}$. As with film boiling, the actual outcome will be discussed in the presentation of results.

\subsubsection{Absorber Stress Distribution}

The most critical stresses in the second-generation receiver occur in the absorber. The methodology for calculating the stresses has been reported in connection with the first receiver elsewhere $[28,29]$. A brief review of previously unpublished results for the second-generation receiver $[30,31,32]$ is presented in the following discussion.

Stresses in the absorber arise as a result of two influences: the temperature distributions in the absorber and the rear dome, and the difference between the vapor pressure within the receiver and local atmospheric pressure. The temperature distribution in the absorber arises as a result of the net heat flux conducted through it into the pool. The net heat flux is calculated as described in Section 2.2.1. The pressure difference that must be supported by the receiver envelope is the difference 
between the vapor pressure of NaK-78 at operating temperature [9] and local atmospheric pressure. For Albuquerque this difference is:

$$
\Delta P(\text { psig })=14.7 \times 10^{4.114-\frac{4367}{r\left({ }^{\circ} K\right)}}-12.2
$$

Two modes of receiver operation were considered. The first is operation of the receiver alone, at vapor temperatures up to $750^{\circ} \mathrm{C}$, to establish technical feasibility. This satisfies our current objectives. The second mode of operation goes beyond our original design goals to meet a onetime requirement: operation in an integrated receiver/engine package, at vapor temperatures up to $820^{\circ} \mathrm{C}$. In each case, the design should anticipate excursions to a higher, maximum allowable working temperature, at which point the shutter in front of the aperture automatically closes. The two modes of operation with their corresponding design maximum conditions and ambienttemperature vacuum conditions are illustrated in Table 1 , and will be discussed further in the next section.

There is an additional consideration for mode- 2 operation: overpressurization in the event of a helium leak from the engine into the receiver. This may require a pressure-relief device and perhaps some design allowance for deformation of the receiver. Until the engine/receiver interface is specified, the pressures following a leak cannot be predicted and consideration of these details must be deferred.

The stresses in the absorber and rear dome were calculated using a general-purpose finite-element code [28]. For thermal boundary conditions at steady-state operation, the temperature on the inside surface of the receiver and through the rear dome was taken to be equal to the vapor temperature. On the outside of the absorber, the azimuthally-averaged net flux from AEETES was applied. The predicted stress distribution for operation at $750^{\circ} \mathrm{C}$ is shown in Figure 9. The maximum stress is seen to be about $40 \mathrm{MPa}(5.8 \mathrm{kpsi})$, which occurs on the absorber at the net-flux peak. The error introduced by using the azimuthally-averaged flux is not large (approximately 5\%) in the present case. This was confirmed by performing a full non-axisymmetric stress analysis for a single case with the non-axisymmetric incident flux substituted for the azimuthally-averaged net flux [32].

Other analyses (not illustrated) were carried out for steady operation of the receiver at temperatures up to $830^{\circ} \mathrm{C}$ and for startup conditions. For steady conditions, the maximum stress is dominated by the temperature change through the absorber thickness, and is only weakly dependent upon temperature (for example, at $830^{\circ} \mathrm{C}$ the maximum stress was calculated to be about 
Table 1. Second-generation receiver operating modes and conditions using NaK-78, assuming 12.2 psia atmospheric pressure.

\begin{tabular}{|c|c|c|c|c|c|}
\hline MODE & PURPOSE & $\begin{array}{c}\text { OPERATING } \\
\text { VAPOR } \\
\left.\text { TEMP. }{ }^{\circ} \mathrm{C}\right)\end{array}$ & $\begin{array}{c}\text { DESIGN } \\
\text { OPERATING } \\
\text { PRESS. } \\
\text { (PSIG) }\end{array}$ & $\begin{array}{c}\text { DESIGN } \\
\text { VAPOR } \\
\text { TEMP. } \\
\left({ }^{\circ} \mathrm{C}\right)\end{array}$ & $\begin{array}{c}\text { MAXIMUM } \\
\text { WORKING } \\
\text { PRESS. } \\
(\text { PSIG) }\end{array}$ \\
\hline 1. & $\begin{array}{c}\text { Receiver technical } \\
\text { reasibility tests }\end{array}$ & 750 & -1.9 & 785 & $+2.0 / \cdot 12.2$ \\
\hline 2. & $\begin{array}{c}\text { Receiver/engine } \\
\text { max efficiency tests }\end{array}$ & 820 & 7.1 & 830 & $+8.8 / .12 .2$ \\
\hline
\end{tabular}

$35 \mathrm{MPa}(5.1 \mathrm{kpsi})$, again occurring on the absorber at the net-flux peak). For startup conditions, the net flux was (conservatively) set equal to the incident flux, and an estimated worst-case temperature distribution similar to that measured on the first receiver was applied to the external surface. The maximum calculated stress in this case was located at the absorber rim and amounted to about $90 \mathrm{MPa}(13 \mathrm{kpsi})$ at $260^{\circ} \mathrm{C}$. These stresses will be discussed in the context of safety factors in the next section.

\subsubsection{Structural Safety Factors}

The second-generation pool boiler receiver has been designed to Section VIII Division I ASME Boiler and Pressure Vessel Code intent. The word "intent" is used because the design conforms to the code in terms of allowable configurations, formulas for minimum thicknesses (structural safety factors), head opening reinforcement, and weld-joint design and inspection. But at the same time the thickness of t.e absorber ( 0.032 inch) is less than the general requirement of $1 / 16$ th inch specified for shells and heads in paragraph UG-17(b) of Section VIII Division I [33]. In addition, we have opted to deviate from the code by (a) using a temperature-control safety system rather than a pressure relief device to prevent overpressure in the event of overtemperature, (b) not hydrostatically testing the receiver, and (c) not proof testing the 70- and 87-degree domes against buckling.

Allowable stresses and procedures for the use of Haynes alloy 230 are covered by ASME Boiler and Pressure Vessel Code Case 2063. Figure 10 compares the code-case allowable stress with the material's ultimate, yield and creep-rupture stresses at various temperatures [34]. This illustrates 


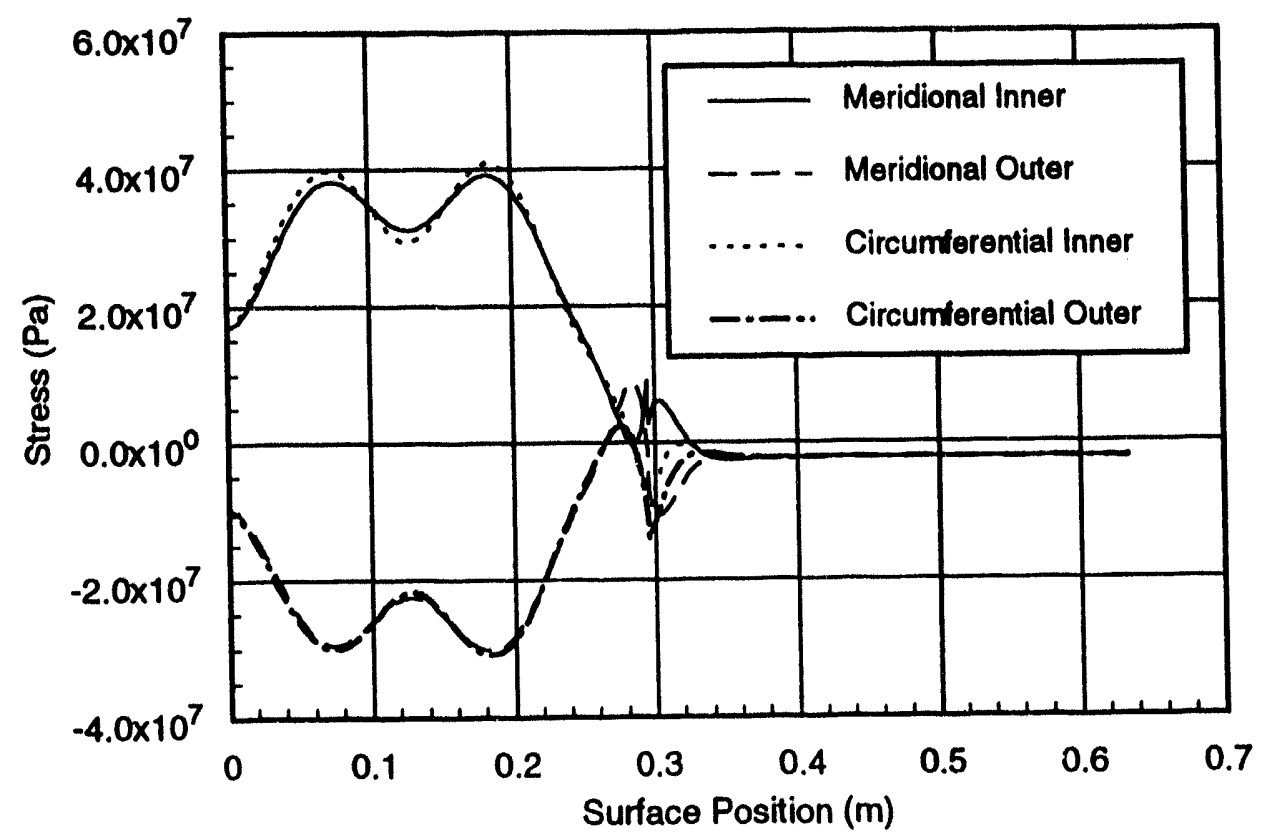

Figure 9. Stress distribution predicted for the second-generation receiver [from Ref 30].

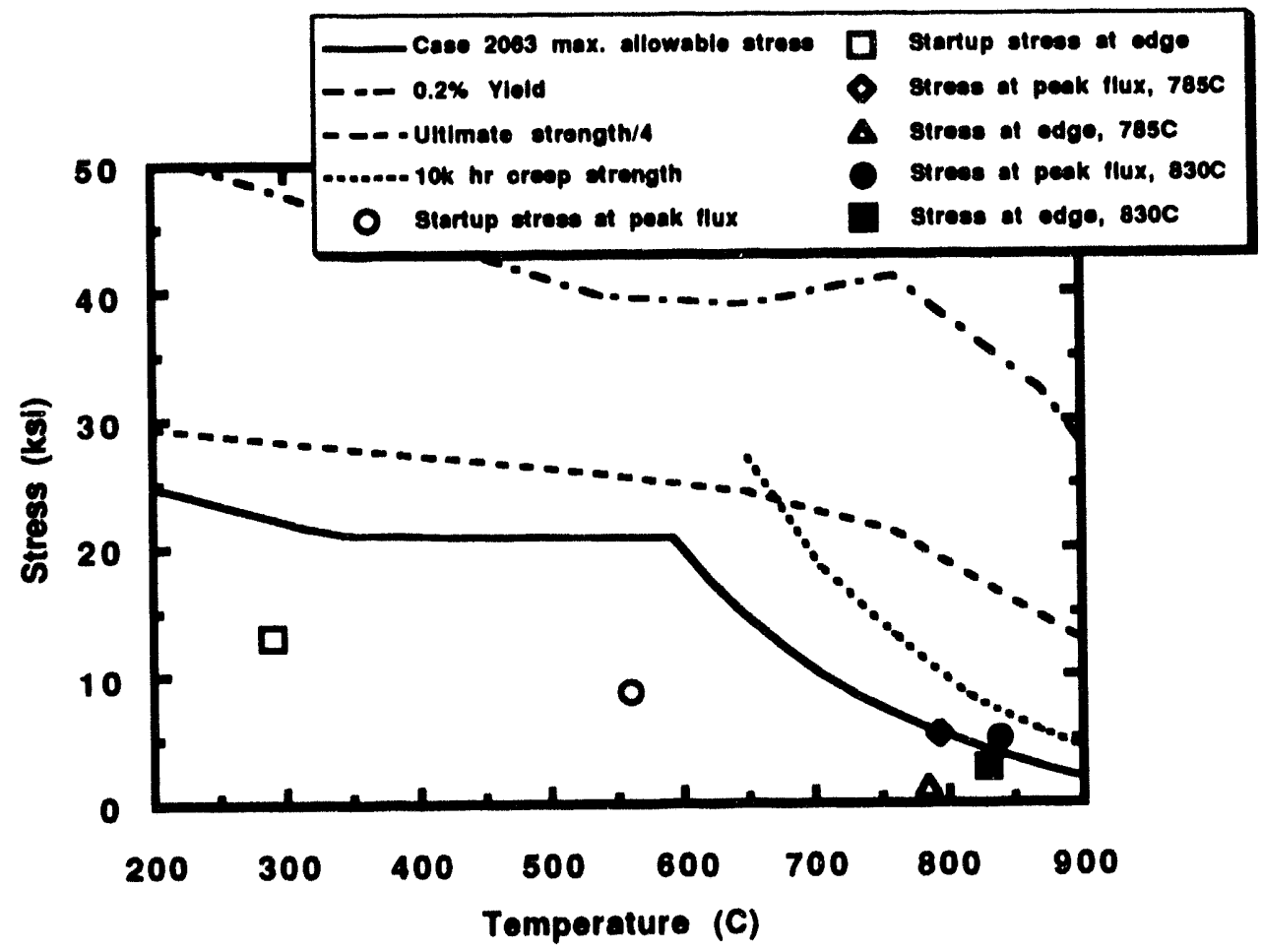

Figure 10. Haynes alloy 230 properties, ASME Code Case 2063 allowable stress [from Ref 34], and largest predicted stresses for the second-generation receiver's absorber. 
the conservatism of the code case. Also in Figure 10 are the largest calculated stresses in the absorber for both mode 1 and mode 2 operation (Section 2.2.4), shown at the local temperature averaged across the material thickness. The only stress that is larger than allowed is at the design maximum condition of mode- 2 operation -- recall that this is a one-time application of the second. generation receiver that goes beyond our original design requirements. At that condition, the $10^{4}$. hour creep-rupture strength has been heavily factored into the maximum allowable stress. For the tens of hours of mode- 2 operation that might eventually be required, the design should be adequate.

In addition to performing finite-element analysis on the absorber and the rear dome that supports it, we have tested our design against the applicable formulas of the boiler code (plus an empirical formula for buckling of spherical segments). Table 2 lists the maximum allowable working pressure (MAWP) for the various structural elements, with the material properties evaluated at the

Table 2. Second-generation receiver structural analysis summary

\begin{tabular}{|c|l|c|c|c|c|}
\hline ITEM & $\begin{array}{l}\text { STRUCTURAL } \\
\text { ELEENT }\end{array}$ & $\begin{array}{c}\text { FAILURE } \\
\text { MODE }\end{array}$ & $\begin{array}{c}\text { APPLIED } \\
\text { PRESSURE }\end{array}$ & $\begin{array}{c}\text { MAWP } \\
\text { (PSIG) }\end{array}$ & NOTES \\
\hline 1. & Absorber & tensile & external & 30.3 & \\
\hline 2. & Absorber & buckling & internal & 7.8 & a \\
\hline 3. & Absorber rim weld & tensile/shear & ext./int. & 13.7 & b \\
\hline 4. & Rear dome & tensile & internal & 57.1 & \\
\hline 5. & Rear dome & buckling & external & 27.6 & a \\
\hline 6. & Dome to cone weld & tensile & internal & 79.6 & c \\
\hline 7. & Cone & tensile & internal & 46.9 & c \\
\hline 8. & Cone & buckling & external & 37.5 & \\
\hline 9. & Condenser tube & tensile & internal & 61.1 & c \\
\hline 10. & Condenser tube & buckling & external & 19.3 & \\
\hline 11. & Condenser end cap & tensile & external & 122.9 & \\
\hline 12. & Condenser end cap & buckling & internal & 70.4 & \\
\hline 13. & Condens.cap weld & tensile/shear & ext./int. & 55.3 & b \\
\hline
\end{tabular}

Notes: a. Empirical formula [35], not code, safety factor $=6$

b. Fillet-weld-joint code efficiency $=\mathbf{0 . 4 5}$

c. Butt-weld-joint code efficiency $=1.0$ 
highest applicable temperature. Comparing Tables 1 and 2 shows that the design is adequate for mode 1 operation. For mode 2 operation, the design maximum working pressure is slightly higher ( 8.8 vs $7.8 \mathrm{psig}$ ) than permitted by our empirical buckling formula with a safety factor of six. For the limited purposes of our engine test, with suitable restrictions on personnel exposure, this modest reduction in safety factor would be allowable. As mentioned in Section 2.2.4, the issue of helium leakage from the engine into the receiver has not been addressed, and cannot until the engine/receiver interface is defined.

\subsection{Other Design Details}

Beyond the receiver envelope, there are a number of other aspects of the second-generation poolboiler receiver that are different than in the first pool-boiler tests. These details are covered in the following subsections.

\subsubsection{Powdered-Metal Boiling Surface}

The Friction Coating, Inc. 304L stainless-steel $-60 /+80$ powdered-metal coating was qualified in bench-scale tests [19]. Included were boiling-behavior and mechanical strength tests. The boiling behavior tests showed that this coating produced slightly better stability than coatings of the same type made from $-80 /+100$ and $-100 /+150$ powders. A cross section of a sample of the $-60 /+80$ powdered-metal coating is shown in Figure 11a, and a replica of the coated dome used in the present tests is shown in Figure 11b. The coating was applied as triangular patches, as is evident in the figure.

\subsubsection{Optical Cavity and Insulation Package}

The optical cavity consisted of a sidewall and aperture made from Fiberfrax ${ }^{\circledR} 3000$ insulation board (Carborundum Resistant Materials Company, Niagara Falls, NY). For most of the tests, the sidewall was cylindrical and the aperture was the same diameter as the absorber rim, as illustrated in Figure 12. This configuration allowed an unobstructed view of the absorber with the infrared video camera (Section 4.2), crucial for safe operation during the initial restart tests. For the performance tests, an 8.66-inch aperture was added. Heat-warping of the aperture holder was a problem: to keep air from leaking past the warped parts, a Kaowool ${ }^{\circledR}$ (Babcock and Wilcox, Augusta, GA) gasket was installed as shown in Figure 13. In the final performance test, inserts were placed in the optical cavity to make the sidewalls conical, as depicted in Figure 14. 


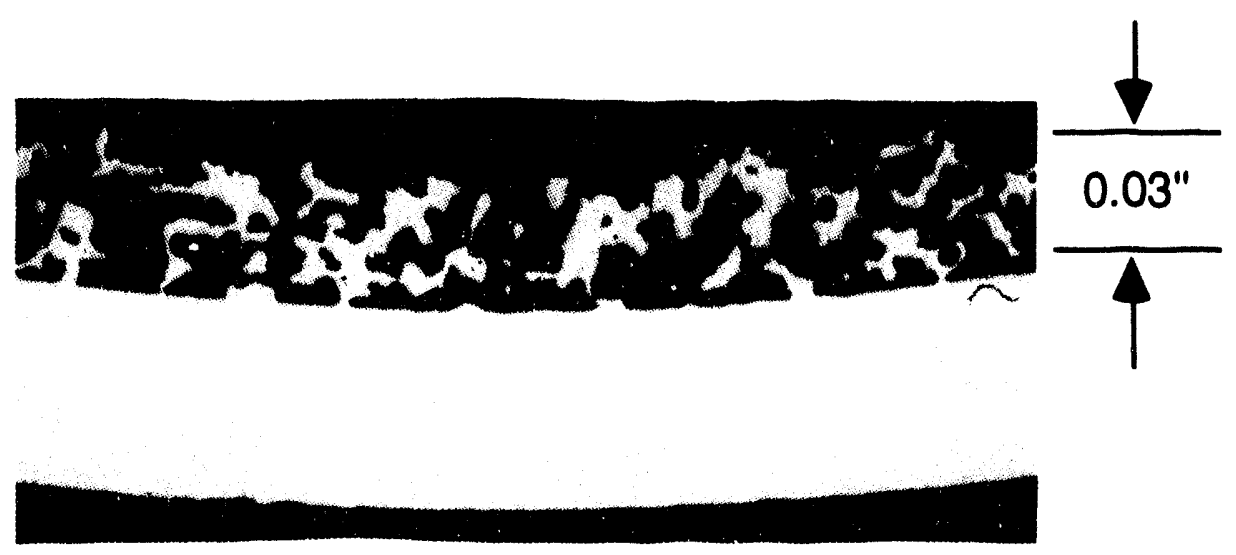

Figure 11a. Cross section of $-60 /+80$ powdered-metal coating selected for 2 nd-generation receiver.

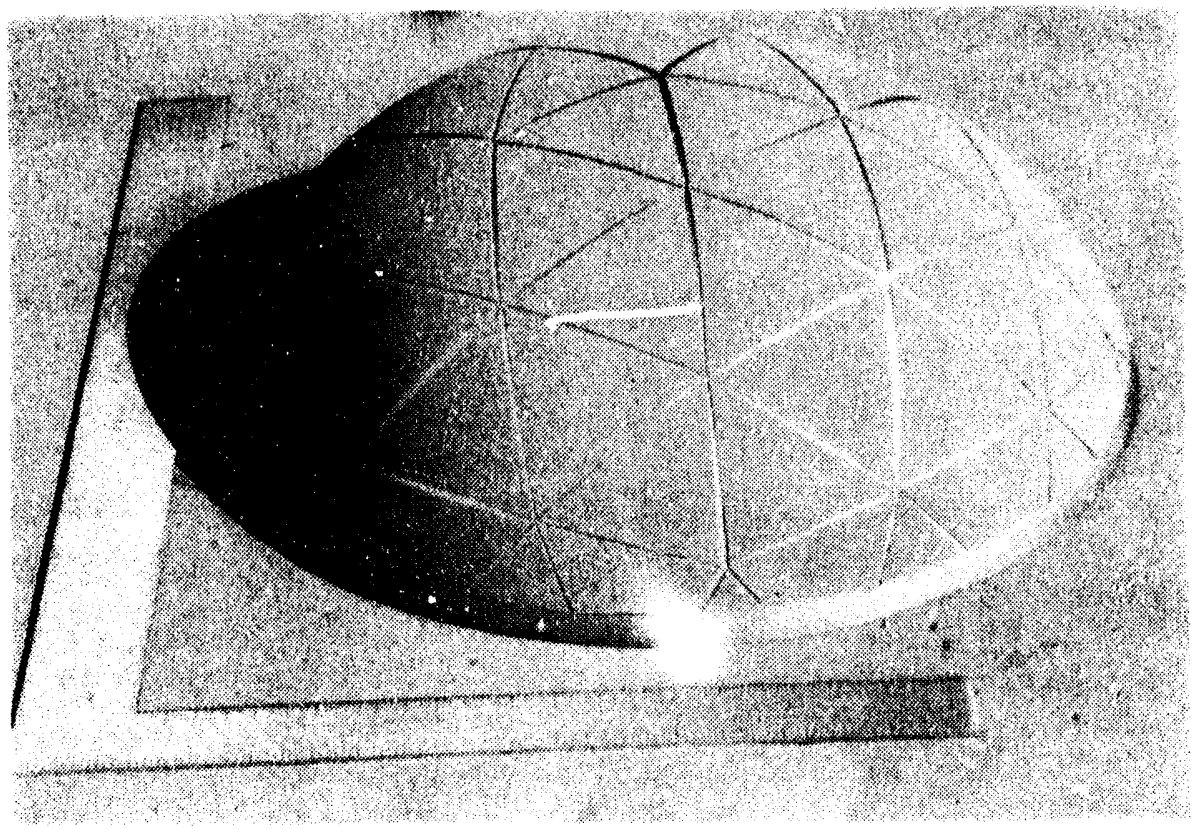

Figure $1 \mathrm{lb}$. Powdered-metal coating on a replica of the 2 nd-generation receiver's absorber. 


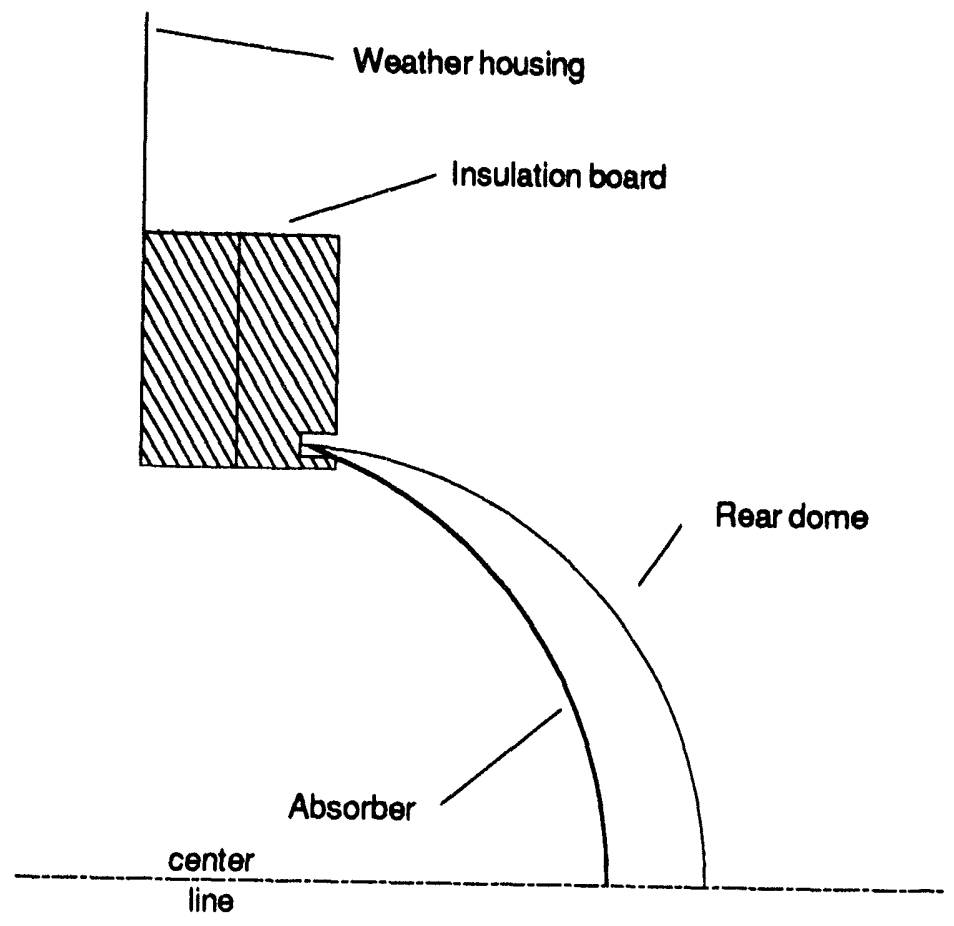

Figure 12. Optical cavity with open aperture for boiling-behavior tests (both receivers).

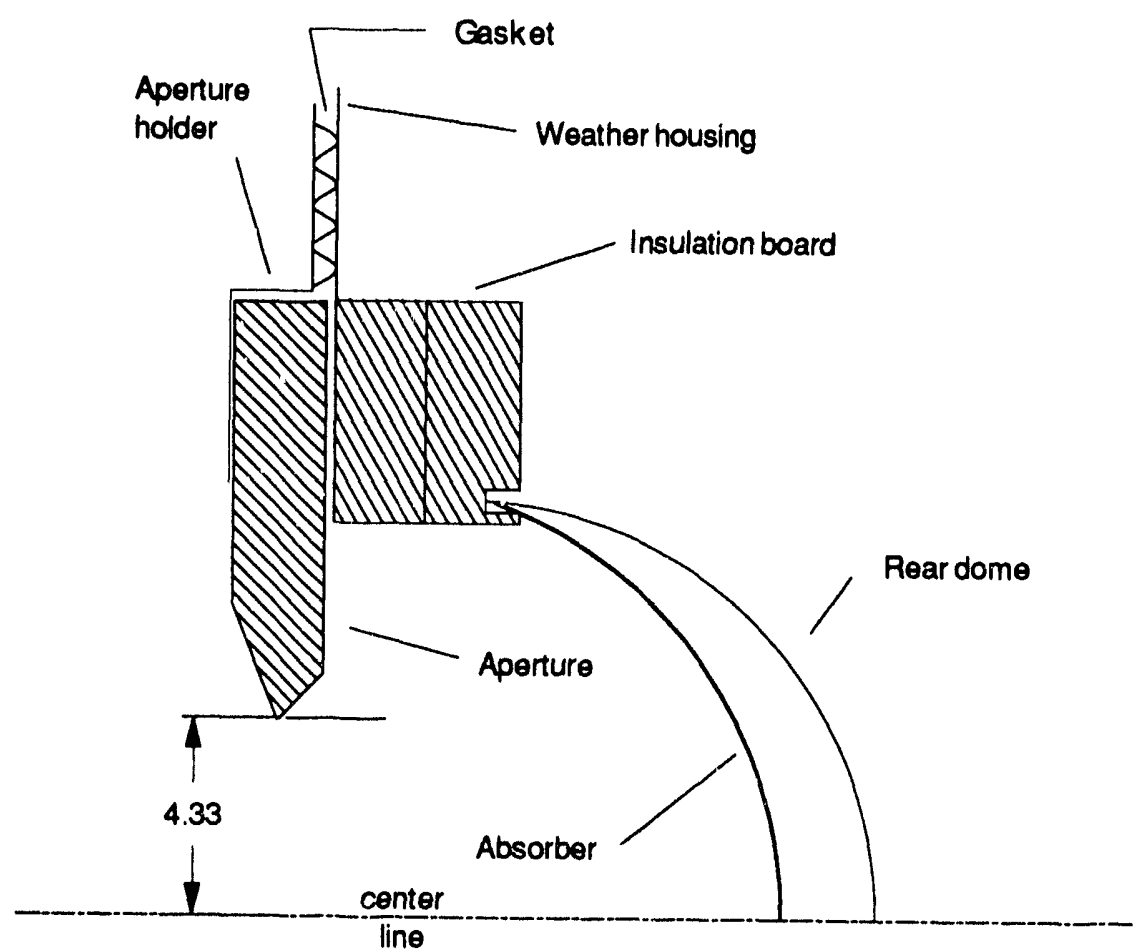

Figure 13. Optical cavity with cylindrical sidewall and 8.66-inch aperture for efficiency tests. 


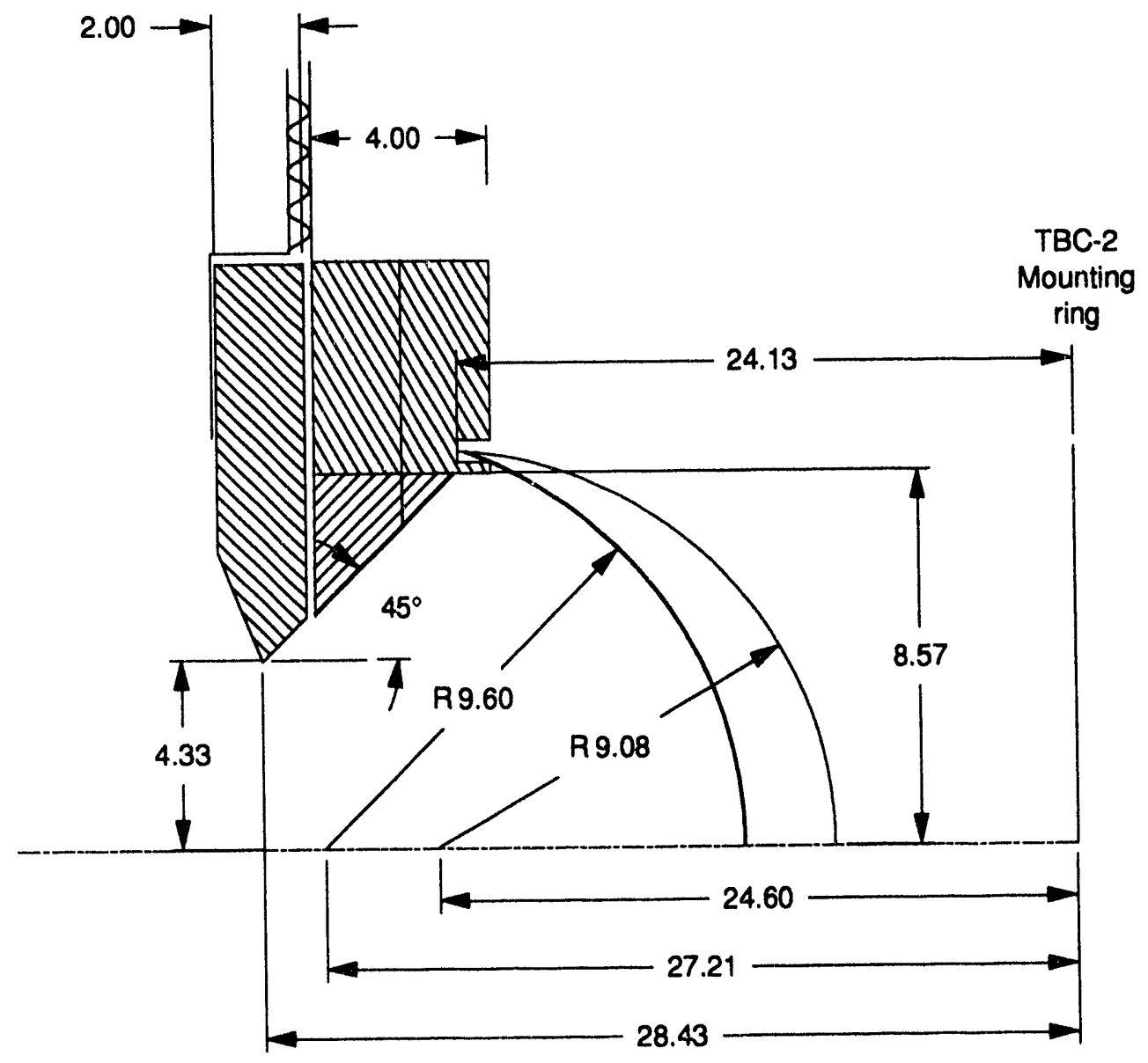

Figure 14. Optical cavity with conical sidewall and 8.66-inch aperture for the final efficiency test. 
The absorber's solar absorptivity was measured after the first 9 hours of operation above $700^{\circ} \mathrm{C}$. The mean of measurements at 16 points was 0.83 with a standard deviation of 0.02 [36]. Previous measurements on samples baked in air at $850^{\circ} \mathrm{C}$ have yielded solar absorptivities of 0.87 after 2 hours and 0.91 after 280 hours, and an estimated emissivity at elevated temperature of about 0.8 [37]. For our final performance test, the absorptivity was enhanced by painting the absorber with Pyromark $^{\circledR} 1200$, manufactured by Tempil (South Plainfield, NJ). This product was used because it does not require temperature-controlled curing and because it was available on site. Painting improved the solar absorptivity to 0.87 [36]. We estimate that the elevated-temperature emissivity for Pyromark 1200 is about 0.5 .

Most of the Kaowool insulation used during receiver vacuum-bakeout was left in place for the onsun tests. The exception was the insulation applied to the condenser section, which was removed in order to install the cold-water gas-gap calorimeter (Section 4.2). Figure 15 shows the receiver in its insulation housing with the Kaowool insulation in place. The receiver's weather housing was filled with vermiculite to complete the insulation package.

\subsubsection{Thermal Efficiency}

The measured and predicted thermal efficiency of the first-generation pool boiler configuration has been discussed elsewhere [11]. Reference 11 describes in detail how the prediction is obtained using the cone-optics code CIRCE2 and the receiver thermal model AEETES. A brief recap of this information appears in Section 2.2.1. The input data for AEETES are shown in Table 3. The operating conditions in Table 3 correspond to the steady-state portion of the seventh (last) test reported in Section 5.1. Under these conditions, AEETES predicts that the heat loss will be 4.1 $\mathrm{kW}_{\mathrm{t}}$ and the receiver efficiency will be $94.1 \%$. These values will be compared with the experimental determinations in Section 5.1.

\subsubsection{Dump Tank and Miscellaneous}

The second-generation pool-boiler receiver was equipped with an evacuated "dump tank", illustrated in Figures 4 and 5, the purpose of which was to accept all of the NaK-78 in the event of a breach. This would shorten the duration of any fire resulting from a breach, and simplify the handling of the receiver afterward. The tank was made of Haynes alloy 230 and designed to Section VIII Division I ASME Boiler and Pressure Vessel Code to assure that, at the maximum temperature of the feasibility tests, it would not collapse when evacuated or burst in an unintended dump. It was connected to the bottom of the rear dome with a short length of $1 / 4$-inch tubing and 


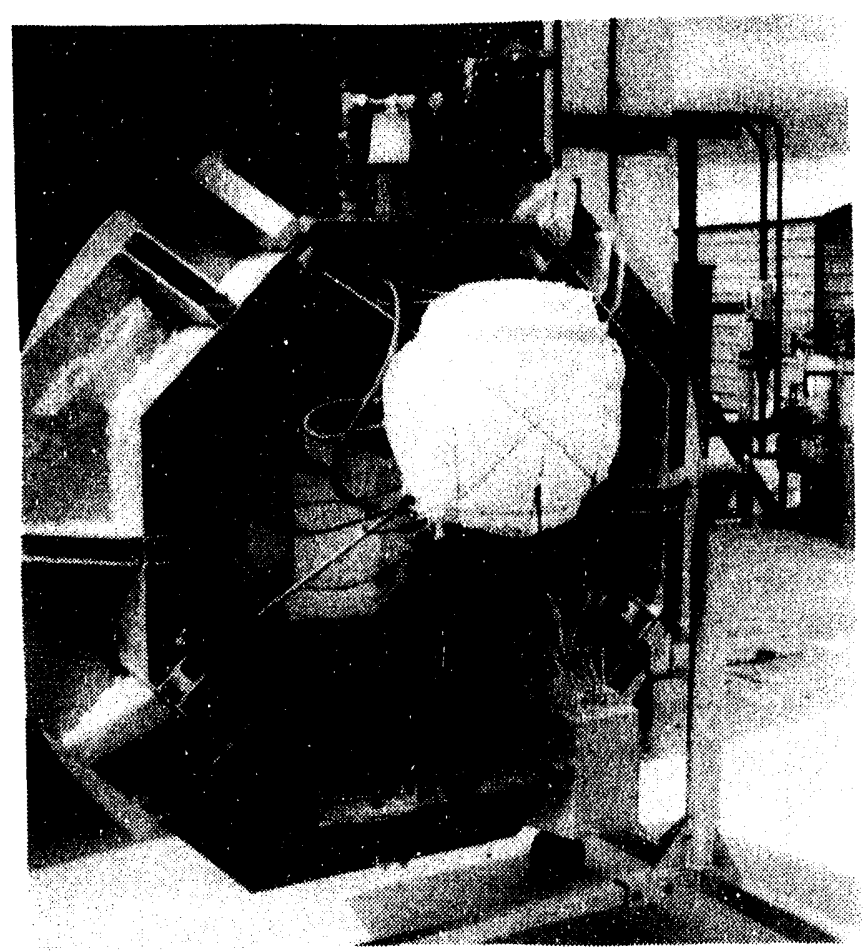

Figure 15. Second-generation receiver in weather housing with Kaowool insulation.

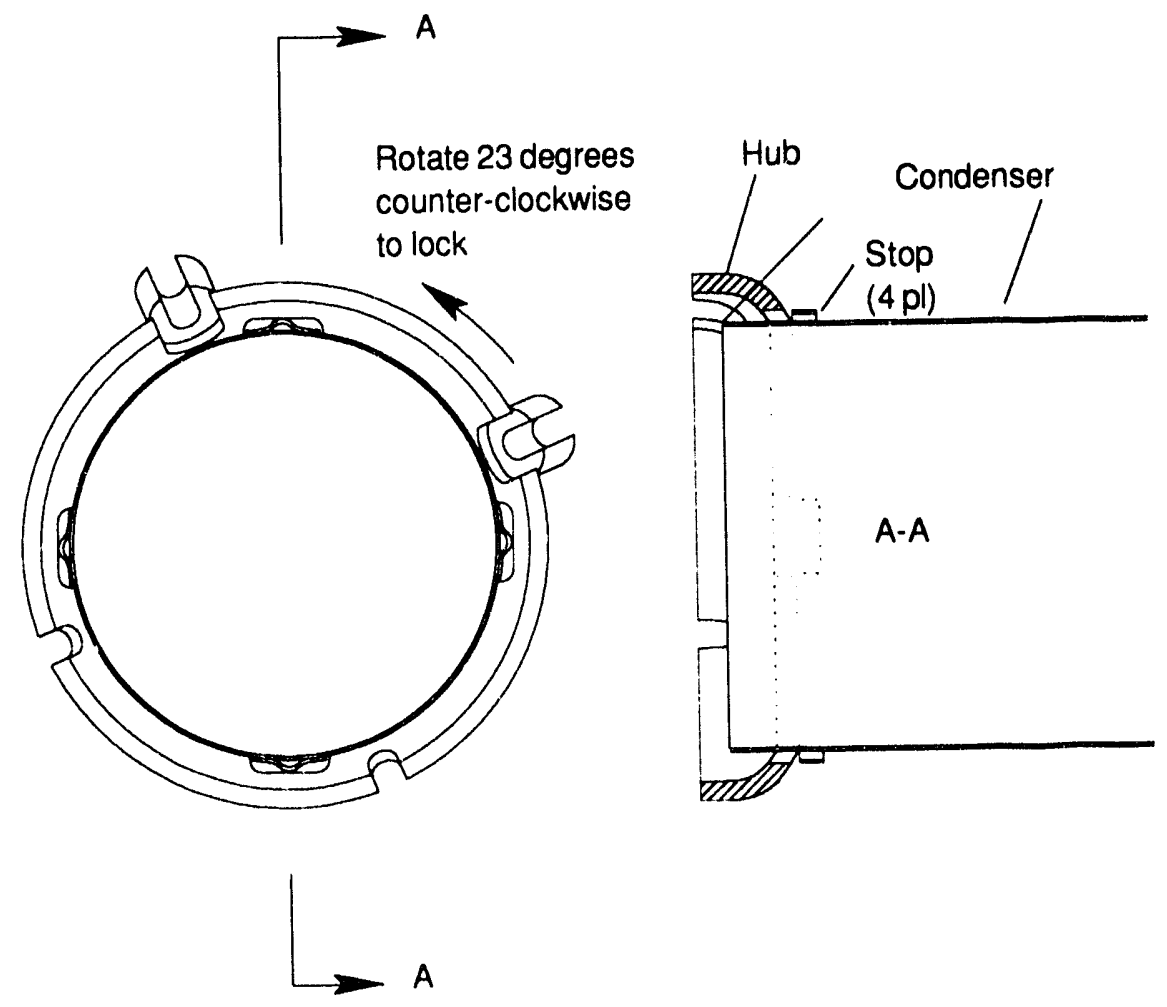

Figure 16. Hub and stops for the second-generation receiver. 
Table 3. Input data for AEETES corresponding to the final minutes of the seventh (last) test of the second-generation receiver .

\begin{tabular}{|c|c|c|c|c|c|}
\hline $\begin{array}{c}\text { Sun } \\
\text { Elevation } \\
\end{array}$ & $\begin{array}{c}\text { Ambient } \\
\text { Temperature }\end{array}$ & $\begin{array}{l}\text { Wind } \\
\text { Speed }\end{array}$ & $\begin{array}{c}\text { NaK-78 } \\
\text { Vapor } \\
\text { Temperature } \\
\end{array}$ & $\begin{array}{l}\text { Input } \\
\text { Power } \\
\end{array}$ & $\begin{array}{c}\text { Absorber } \\
\text { Flux } \\
\text { Distribution }\end{array}$ \\
\hline $74^{\circ}$ & $28^{\circ} \mathrm{C}$ & unaccounted & $752^{\circ} \mathrm{C}$ & $69.6 \mathrm{~kW}_{\mathrm{t}}$ & TBC-2 \\
\hline $\begin{array}{l}\text { Absorber } \\
\text { Radius of } \\
\text { Curvature }\end{array}$ & $\begin{array}{c}\text { Absorber } \\
\text { Sphere Angle }\end{array}$ & $\begin{array}{c}\text { Absorber } \\
\text { Thickness }\end{array}$ & $\begin{array}{c}\text { Cavity } \\
\text { Sidewall } \\
\text { Shape }\end{array}$ & $\begin{array}{l}\text { Aperture } \\
\text { Diameter }\end{array}$ & $\begin{array}{l}\text { Insulation } \\
\text { Thickness } \\
\end{array}$ \\
\hline 9.6 inches & 700 & 0.032 inches & $45^{\circ}$ Cone & 8.66 inches & 6 inches \\
\hline $\begin{array}{c}\text { Insulation } \\
\text { Conductivity }\end{array}$ & $\begin{array}{c}\text { Absorber } \\
\text { Conductivity } \\
\end{array}$ & $\begin{array}{c}\text { Cavity } \\
\text { Sidewall } \\
\text { Solar Absorp }\end{array}$ & $\begin{array}{c}\text { Cavity } \\
\text { Sidewall } \\
\text { Emissivity } \\
\end{array}$ & $\begin{array}{c}\text { Absorber } \\
\text { Solar } \\
\text { Absorptivity } \\
\end{array}$ & $\begin{array}{c}\text { Absorber } \\
\text { Emissivity }\end{array}$ \\
\hline $0.4 \mathrm{~W} / \mathrm{m}-\mathrm{K}$ & $24.4 \mathrm{~W} / \mathrm{m}-\mathrm{K}$ & 0.15 & 0.8 & 0.87 & 0.5 \\
\hline
\end{tabular}

an air operated valve (AOV). The valve and connections were of all-welded construction. A small electric solenoid valve could be switched on from the control room to admit compressed gas to the AOV actuator. A cover on the switch was secured with wire to prevent an inadvertent dump. Compressed gas for the AOV was stored in a small tank attached to the rear surface of the receiver's weather housing. Four-wire resistance probes were spot-welded to the dump tank near its lowest and highest points, both to detect an inadvertent dump and to sense when a dump was completed. Before and after each test a checklist was followed to connect/disconnect the system's compressed-gas and electrical sources to assure both safety and reliability. The list included items such as checking the operation of the electrical switch and the solenoid valve and verifying that the switch cover was wired in place with the switch in the off position before the air line was connected to the AOV.

The small reservoir shown attached to the receiver fill line in Figure 5 was charged with about 12 psia of high-purity xenon before the first test. Before being charged, the reservoir and a connecting xenon manifold were vacuum baked and leak checked. The pressure in the reservoir was measured with a capacitance type gauge. We calculated that the xenon would expand into the receiver to a final room-temperature pressure of about $1 / 3$ torr when the valve leading to the fill line was opened. 
The NaK-78 bench-scale tests used a getter made from 0.004-inch-thick zirconium sheet measuring 1 inch $\times 12$ inch. The getter in the second-generation receiver was also made from 0.004-inch-thick zirconium sheet, but with a total surface area of approximately $100 \mathrm{in}^{2}$. For 19.5 pounds of $\mathrm{NaK}-78$, the conversion of the entire getter to $\mathrm{ZrO}_{2}$ would provide an ultimate capacity of $828 \mathrm{ppm}$ (by weight) of oxygen [38]. This capacity is over an order of magnitude greater than the amount of oxygen initially present plus 30 years of leakage at the design maximum rate.

On the first-generation receiver, the suspension hubs were welded to the schedule-10 eight-inch pipe that formed the condenser section. For the second-generation receiver, this method of attachment was not chosen, because: (1) in the first receiver, thermal expansion differences between the hubs and condenser cracked the welds, (2) the new condenser wall is only $1 / 16$ th-inch thick, and (3) the chosen alternative permits the hubs to be removed without cutting and grinding. Instead, sheet-metal stops were spot-welded on the new condenser during construction (Figure 16). The original front hub was modified by the addition of keyways machined on its inside diameter (Figure 16), so that it could pass over the sheet-metal stops. Once over the stops, it is rotated so the front stops prevent rearward displacement. The combination of spoke tension and stops is all that is needed to maintain the position of the hubs.

\section{Advanced-Concepts Pool-Boiler Receiver}

The advanced-concepts receiver was built to test a hypothesis that evolved out of our bench-scale test results. The hypothesis was that stable boiling could be achieved in a full-scale $(75 \mathrm{~kW})$ poolboiler receiver without special conditioning of the heated surface such as artificial cavities, powdered-metal coatings, etc.. Confirmation of this hypothesis would add important new information to what little is known about boiling stability. It would also represent a significant reduction in receiver cost.

\subsection{Background}

The bench-scale screening tests for the second-generation receiver had a number of unexpected results $[18,19]$. These included: (1) stable boiling was not achieved in NaK-78 or sodium with electric discharge machined (EDM) cavities in the heated surface, even though the incident flux was as large and the cavities were the same size as in the first (stable boiling) receiver; (2) for a fixed heated-surface area, boiling stability was best with powder-metal coatings that covered all of the heated area; (3) boiling stability improved with increased vertical extent of a powder-metal-coated heated surface; (4) tilt of the heated surface in either direction out of the vertical improved the poor 
stability achieved with small-area modifications and unmodified surfaces; and (5) the addition of $1 / 3$ torr of xenon generally improved stability without noticeably affecting condensation heat transfer.

An important question raised by these resuits is why boiling was stable in the first full-scale receiver but not in the bench-scale receiver that had two EDM cavities. First of all, it should be understood that there are no rigorous design tools to analyze these two cases. The stability theory of Shai and Rohsenow suggests that the EDM cavities will stabilize boiling. However, the theory is only approximate and cannot guarantee that boiling will be stable [15]. To explain the difference between the full-scale and bench-scale tests, we propose the following line of reasoning. The bench-scale results indicate that our EDM cavities were not immune to deactivation (filling with liquid). In the case of just two EDM cavities, after some period of stable boiling, random fluctuations at the two cavities cause their simultaneous deactivation, and boiling stops. The surface temperature then increases until a bubble inflates at a much smaller natural cavity. Once a bubble forms, the deactivated cavities become reactivated [39] and another period of stable boiling follows. This stop-start behavior is the classical description of unstable boiling. Now suppose that the number of EDM cavities is greatly increased: we expect that the probability of simultaneous deactivation of all the cavities will decrease essentially to zero. With this picture in mind, we hypothesize that in our bench-scale tests two EDM cavities were not sufficient for stability while the thirty-five in our full-scale test were. An even more interesting supposition is that stability will improve not only with increasing extent of heated-surface modifications, but with increasing extent of the heated surface alone, as the natural cavities become sufficient in number and character for boiling stability. This idea was the fundamental motivation for the advanced-concepts receiver.

Even if natural cavities alone cannot stabilize a very-large version of our bench-scale boiler, the trends seen in the bench-scale tests suggest that the additional enhancements obtained from heatedsurface tilt or added xenon might make stable boiling possible in our full-scale receiver.

\subsection{Design Details}

The advanced-concepts pool-boiler receiver was made from spare parts left over from the firstgeneration pool-boiler receiver. It was a near-duplicate of the first receiver, which has been described in detail elsewhere [11]. Its most important difference from the first receiver was the absence of EDM cavities in the wetted side of the absorber. The wetted side finish was as delivered after hydroforming 0.035 -inch-thick $316 \mathrm{~L}$ stainless-steel stock sheet metal to the dome shape. Additionally, there were no internal or external thermocouples brazed on the absorber (see Section 
4.2). Instead the receiver had intrinsic thermocouples on external surfaces to characterize both external and internal temperatures. The last difference was that xenon was added before rather than during the test series.

\section{Test Objectives, Preparations and Equipment}

This section applies to both the second-generation and advanced-concepts receivers, with differences noted as applicable. For both receivers, the primary aim was to determine technical feasibility. Long-term testing was not planned.

For the second-generation receiver, the test objectives were to assess boiling stability and hot restart $\left(>450^{\circ} \mathrm{C}\right)$ behavior, and to show that the new design successfully dealt with the warmrestart problem. In addition, we wanted to establish the thermal efficiency of the second-generation receiver, since it had a larger absorber than the first one.

For the advanced-concepts receiver, the objectives were simply to assess boiling stability and hot restart behavior. These were the aspects of boiling that we hypothesized would be unaffected by the removal of EDM cavities. Warm restarts were omitted because the advanced concepts receiver was not designed to correct the warm-restart problem that occurred in the first receiver. Efficiency determinations were not planned because they had already been done for this same size and shape with the first receiver.

\subsection{Receiver Fabrication, Evacuation and Filling}

The second-generation receiver was fabricated by Ultimate Hydroforming, Inc., of Sterling Heights, MI. Welding and welding inspections were subcontracted to Saffran Engineering (an ASME Code shop) of St. Clair Shores, MI, and XRI Testing of Troy, MI, respectively. Vacuum leak testing was subcontracted to Vac Met, Inc., of Warren, MI. The primary welds are referenced in the notes in Table 2. Welding operators were qualified as required by Section IX of the ASME Boiler and Pressure Vessel Code. All welds were inspected using dye penetrant. In addition, the butt welds were inspected radiographically. The absorber rim weld was tested both radiographically and ultrasonically, in order to inspect both legs of the fillet weld. This was the only weld that presented unusual difficulties. The ultrasonic inspection was inconclusive because of problems with the configuration and lack of resolution. Radiographic indications required grinding and re-welding at a few locations on the rim; the reworked weld was no longer a simple fillet, and further inspection was inconclusive. A rim weld configuration more amenable to 
inspection would require that the two domes be formed so that they are tangent at the weldment. Leak testing revealed no leaks using a helium mass spectrometer with a sensitivity better than $1.0 \mathrm{x}$ $10^{-8}$ standard $\mathrm{cc} / \mathrm{second}$. The remaining procedures and standards for fabrication and preparation were the same as for the first-generation receiver [11], including back-purged welds, internal cleaning, additional leak checks, and vacuum bakeout. Unlike the first receiver, the secondgeneration receiver was filled with 19.5 pounds of NaK-78 instead of 12.7 pounds of sodium. To determine when enough NaK-78 had been added, the liquid level was sensed using two 4-wire resistance probes. Xenon was not initially added to the receiver. Instead, xenon was added after the first on-sun test, using the reservoir and method described in Section 2.3.4.

The advanced-concepts pool-boiler receiver was prepared using exactly the same procedures and standards as the first-generation receiver. It was filled with 12.7 pounds of sodium, following the defined-volume fill manifold used with the first-generation receiver. After the sodium transfer, 1/3 torr of xenon was added through the receiver's evacuation tube, using a capacitance gauge to monitor pressure (xenon was added out of concern that the boiling behavior might be so poor as to result in damage to the receiver on its first test). After the first two successful tests, the xenon was removed through the fill tube with the arrangement illustrated in Figure 17. First the sodium was melted and drained from the fill tube into the trap below the fill valve. Then a clear path through the fill tube and fill valve was established after about 24 hours of vacuum baking at $450^{\circ} \mathrm{C}$. The clear path was confirmed by repeatedly observing expansions of 0.01 torr of xenon from the vacuumsystem manifold into the receiver. The pool was melted and held at $120^{\circ} \mathrm{C}$ while pumping was continued for another 22 hours. With the pump valved off, the pressure remained below 0.001 torr, which was the minimum observable with our capacitance gauge. The reservoir, shown in Figure 18, was filled with 600 torr of xenon, which could later be expanded into the receiver to again obtain a pressure of about $1 / 3$ torr.

For both receivers, the final liquid-metal level was confirmed radiographically.

\subsection{Receiver Instrumentation}

Because of the uncertainty regarding boiling behavior and the consequent risk of absorber burnout, an important instrument in both the second-generation receiver and advanced-concepts tests was the solar-blind infrared video camera. A description of the camera system can be found elsewhere $[1,40]$. In our safety system, the maximum pixel value from the camera is continually compared with an adjustable threshold value. If the threshold value is exceeded (signifying that a hot spot has developed on the absorber), the safety-shutdown system is activated, closing the shutter in front of 


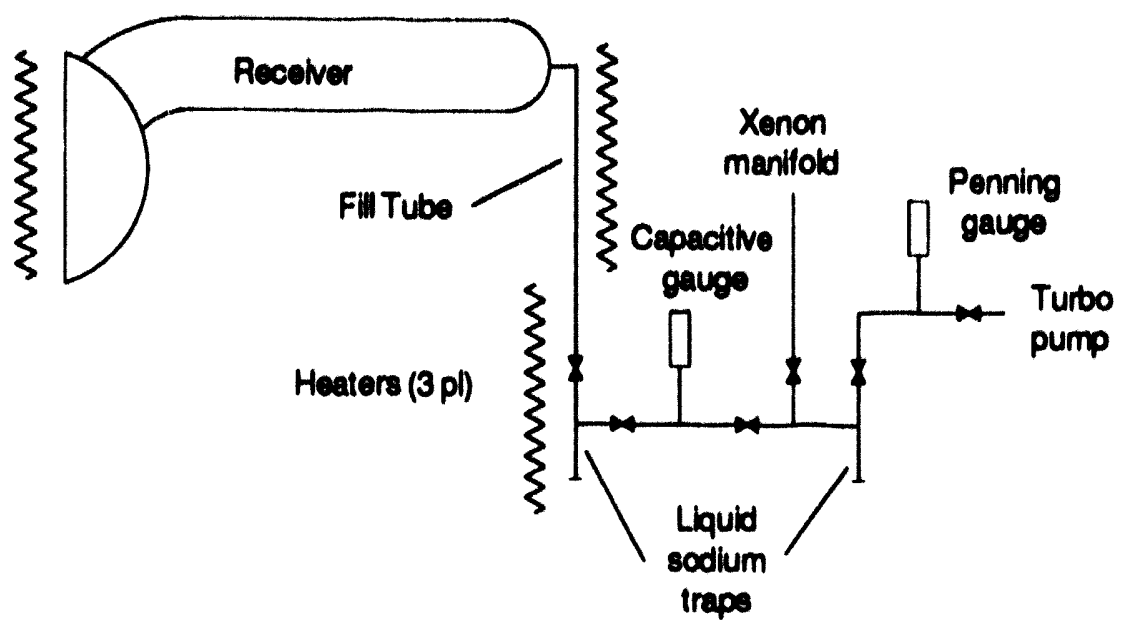

Figure 17. System used to remove xenon from the advanced-concepts receiver.

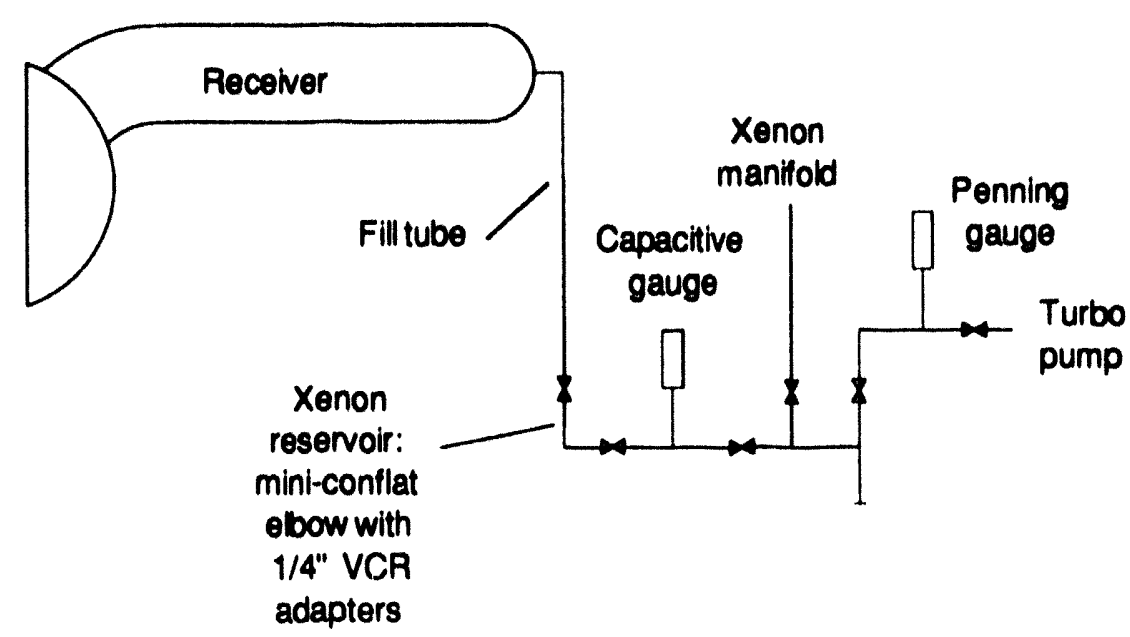

Figure 18. System used to add xenon to the advanced-concepts receiver. 
the receiver. During evaluations of boiling stability and restarts, the receivers were tested using an aperture approximately the same size as the absorber, so that the camera field of view included nearly the entire absorber surface. A visible-spectrum video camera was also focused on the absorber. The camera outputs were displayed in real time and were also recorded.

The arrangements of thermocouples on the second-generation and advanced-concepts receivers are illustrated in Figures 19 and 20 . The details of installation were influenced by our experience with previous receivers. The first receiver used metal-sheathed thermocouples, which in most cases were furnace brazed to the receiver. Internal thermocouples were particularly expensive to install, and were trouble-prone. We found that we could adequately characterize both transient and steadystate boiling behavior with signals from external thermocouples alone. On the present receivers, all of the thermocouples were installed on external surfaces. Moreover, we used spot-welded intrinsic type-K thermocouples, avoiding the cost of sheathed thermocouples and furnace brazing. Intrinsic thermocouples can easily be added to the receiver as needed, as well as repaired or relocated. Since test time was expected to be on the order of ten hours, the shorter lifetime of intrinsic thermocouples was acceptable.

Finally, as with the first-generation pool-boiler receiver, a microphone was clamped to one of the spokes supporting the receivers, to enable us to hear boiling noises. These noises, recorded with the video signals, helped us to determine when boiling started and to characterize boiling behavior.

\subsection{Calorimetry}

The receiver efficiency $\eta$ depends on the power extracted from the receiver $Q_{R}$ and the power delivered to the cavity aperture $Q_{c}$ :

$$
\eta(\%)=100 Q_{R} / Q_{C} .
$$

Both $Q_{R}$ and $Q_{C}$ were determined using liquid-cooled calorimeters. For $Q_{R}$, the calorimeter was the same one that was used on the first-generation pool-boiler receiver [11]. It is a water jacket surrounding the receiver condenser section and separated from it by a gap on the order of 0.04 inches. A mixture of helium and argon is flowed slowly through the gap. By varying the argon to helium ratio in the gap using two mass-flow control valves and a proportional/integral/derivative controller, we used the calorimeter not only to extract heat from the receiver but also to regulate its temperature. For $Q_{c}$, the receiver was replaced with a cavity-type calorimeter [41] with an aperture the same size as the receiver's. For both $Q_{R}$ and $Q_{C}$, the power 


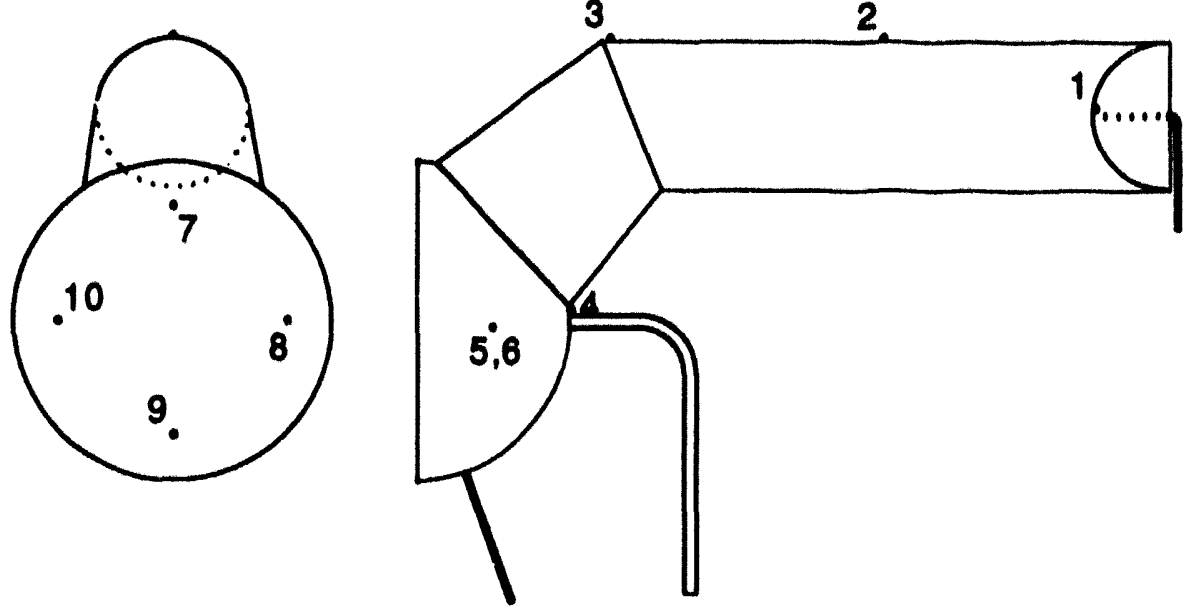

Figure 19. Arrangement of thermocouples on the second-generation receiver.
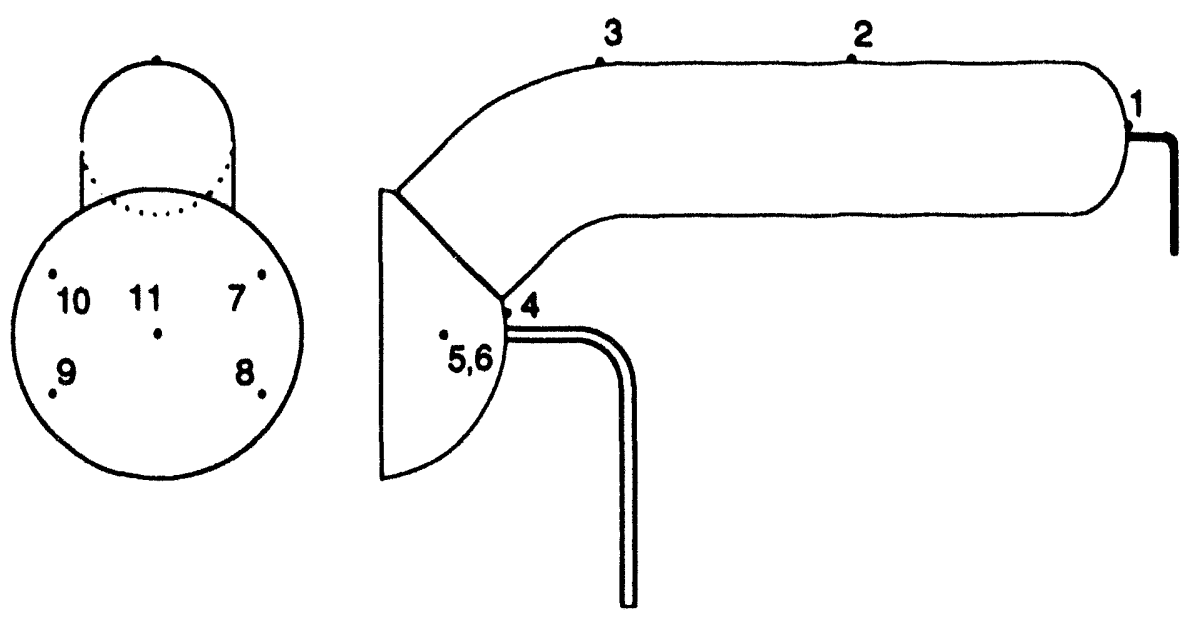

Figure 20. Arrangement of thermocouples on the advanced-concepts receiver. 
was determined from measurements of the coolant volumetric flow rate $\dot{V}$, its temperature $\mathrm{T}$ at the calorimeter inlet, its temperature change $\Delta T$ between inlet and outlet, and from the known temperature dependence of the coolant density $\rho$ and specific enthalpy $h$ [41]:

$$
\dot{Q}=\rho(T) \dot{V}[h(T+\Delta T)-h(T)]
$$

In the expression for receiver efficiency, any difference in insolation (I) between the receiver and concentrator calorimetry was accounted for by writing:

$$
Q_{C}=\rho\left(T_{C}\right) \dot{V}_{C}\left[h\left(T_{C}+\Delta T_{C}\right)-h\left(T_{C}\right)\right] I_{R} / I_{C}
$$

The complete expression for efficiency becomes:

$$
\eta(\%)=100 \frac{\rho\left(T_{R}\right) \dot{V}_{R}\left[h\left(T_{R}+\Delta T_{R}\right)-h\left(T_{R}\right)\right] I_{C}}{\rho\left(T_{C}\right) \dot{V}_{C}\left[h\left(T_{C}+\Delta T_{C}\right)-h\left(T_{C}\right)\right] I_{R}}
$$

The expression for heat loss is:

$$
Q_{\text {loss }}=\rho\left(T_{C}\right) \dot{V}_{C}\left[h\left(T_{C}+\Delta T_{C}\right)-h\left(T_{C}\right)\right] \frac{I_{R}}{I_{C}}-\rho\left(T_{R}\right) \dot{V}_{R}\left[h\left(T_{R}+\Delta T_{R}\right)-h\left(T_{R}\right)\right]
$$

The measurement instruments were: a type- $K$ thermocouple for $T$, a one-piece Type- $T$ thermopile made by Delta-T Company (Santa Clara, California) for $\Delta T$, a Flow Technology (Phoenix, Arizona) turbine flow meter for $\dot{V}$, and an Eppley (Newport, Rhode Island) pyrheliometer for I. During most of the current receiver tests, a closed-loop cooling system containing a mixture of ethylene glycol and water was used. While this system is adequate for boiling.behavior tests, it has a lower cooling capacity than a once-through water system, and $h(T)$ for the coolant mixture is not accurately known. Therefore, in the final determination of receiver efficiency, we used oncethrough water cooling for both the concentrator and receiver calorimetry.

The instruments were calibrated as follows. The thermopile was field-calibrated during subsequent calorimetry unrelated to the present tests, by comparison with a pair of thermocouples that in turn had been laboratory calibrated against a platinum resistance-temperature-device secondary standard. The pyrheliometer was compared with a self-calibrating Technical Measurements, Inc. (La Canada, California) Kendall MK VI radiometer. The turbine meter was calibrated by weighing the water throughput accumulated in a 55-gallon drum over a 3-minute period. 
An error analysis for $Q_{C}$ (and by implication $Q_{R}$ ) can be found in Reference 41 . There, the uncertainty in $Q_{c}$ for representative test conditions is estimated to be on the order of $1.4 \%$. For the present work, the analysis must be revisited for several reasons. One reason is that new issues have arisen regarding the accuracy of the instruments. For example, the accuracy of the thermopile appears to be less than previously thought (it was field-calibrated in the present case). The turbine meter had to be field-calibrated, bringing into question the accuracy of the bucket, scale and stopwatch method. The effect of circumsolar radiation on the pyrheliometer and on the actual power delivered to the aperture has also been questioned. Besides these new issues and others regarding instrument accuracy, revisitation is necessary to determine the uncertainties of our results for $\eta$ and $Q_{\text {loss. }}$ In general these will be less than the uncertainties in $Q_{C}$ and $Q_{R}$ because of error correlation. For all these reasons, a new error analysis is underway and will be the subject of a future report.

\section{Test Results and Discussion}

Because the advanced-concepts receiver was conceived after the second-generation receiver and represents a further step toward commercialization, its test results are presented below following those of the second-generation receiver, despite the fact that it was tested first.

\subsection{Second-Generation Receiver Results}

The second-generation receiver was tested in 1993 on April 15, 19, 20, and 22, and on May 19, 20, and 24. The tests are summarized in Table 4. Before a detailed discussion of results is. presented, a few general comments are appropriate. The number of test days was more than we had originally planned. Some of this was weather-related: brisk winds and clouds required some tests to be repeated. However, most of the additional test days resulted from improvements to our test equipment and test plan. For example, after we found that our calorimetry with ethyleneglycol/water was not accurate enough, we ran additional tests with a once-through water-cooled calorimeter. Other improvements are discussed below.

Results from the first test day are shown in Figure 21. The test objectives were to characterize boiling behavior and hot-restart behavior at several temperatures. Since hot restarts were planned, the receiver was run without an aperture to maximize the area of the absorber viewed by the infrared camera. During the morning, before xenon was added, stable boiling was demonstrated at $700^{\circ} \mathrm{C}$ and $750^{\circ} \mathrm{C}$. Hot restarts (simulating cloud transients) were carried out by closing and 
Table 4. Second-generation pool-boiler-receiver test summary

\begin{tabular}{|c|c|c|c|c|c|c|c|}
\hline $\begin{array}{l}\text { TEST } \\
\text { NO. }\end{array}$ & DATE & PURPOSE & $\begin{array}{l}\text { TORR } \\
\text { XENON } \\
\end{array}$ & $\begin{array}{l}\text { APERTURE } \\
\text { OPEN? }\end{array}$ & $\begin{array}{l}\text { ABSORBER } \\
\text { PAINTED? }\end{array}$ & $\begin{array}{l}\text { COOL } \\
\text { WITH } \\
\text { H2O? }\end{array}$ & COMMENTS \& RESULTS \\
\hline 1 & $4 / 15 / 93$ & $\begin{array}{l}\text { Stability, } \\
\text { hot restarts }\end{array}$ & $0,1 / 3$ & yes & no & no & $\begin{array}{l}\text {-stable at } 700,750^{\circ} \mathrm{C} \\
\text {-loud restarts with hot spots } \\
\text { - Add xenon... } \\
\text {-stable at } 700,750^{\circ} \mathrm{C} \\
\text {-good restarts... } \\
3 \times\left(725,700,650^{\circ} \mathrm{C}\right)\end{array}$ \\
\hline 2 & $4 / 19 / 93$ & $\begin{array}{l}\text { Efficiency, } \\
\text { restarts }\end{array}$ & $1 / 3$ & no & no & no & $\begin{array}{l}\text { - } 3 \text { hrs stable at } 750^{\circ} \mathrm{C} \\
\text {-too windy for efficiency } \\
\text {-clouds preclude restarts }\end{array}$ \\
\hline$\overline{3}$ & $4 / 20 / 93$ & $\begin{array}{l}\text { Efficiency, } \\
\text { restarts }\end{array}$ & $1 / 3$ & $\begin{array}{l}\text { no, } \\
\text { yes }\end{array}$ & no & no & $\begin{array}{l}\text {-washed mirrors } \\
-3 \text { hrs stable at } 750^{\circ} \mathrm{C} \\
\text {-good restarts... } \\
3 \times\left(725,700,650^{\circ} \mathrm{C}\right) \\
1 \times\left(500,450,350^{\circ} \mathrm{C}\right)\end{array}$ \\
\hline 4 & $4 / 22 / 93$ & Efficiency & $1 / 3$ & no & no & yes & $\begin{array}{l}\text {-add gasket to aperture } \\
\text { - } 1 \text { hr stable at } 750^{\circ} \mathrm{C} \\
\text {-clouds end test }\end{array}$ \\
\hline 5 & $5 / 19 / 93$ & $\begin{array}{l}\text { Warm } \\
\text { restarts }\end{array}$ & $1 / 3$ & yes & yes & yes & $\begin{array}{l}\text {-1st run w/Pyromark } 1200 \\
\text {-good low-power restarts... } \\
2 \times\left(350^{\circ} \mathrm{C}\right) \\
\text {-clouds end test }\end{array}$ \\
\hline 6 & $5 / 20 / 93$ & Restarts & $1 / 3$ & yes & yes & yes & $\begin{array}{l}\text {-good restarts... } \\
3 \times\left(750,725,700,650^{\circ} \mathrm{C}\right) \\
5 \times\left(350^{\circ} \mathrm{C}\right) \\
\text {-clouds end test }\end{array}$ \\
\hline 7 & $5 / 24 / 93$ & Efficiency & $1 / 3$ & no & yes & yes & $\begin{array}{l}\text {-washed mirrors } \\
-3 \text { hrs stable at } 750 \mathrm{C}\end{array}$ \\
\hline
\end{tabular}

opening the shutter in front of the receiver aperture. Restart conditions that would have triggered an automatic shutdown in the first receiver (without xenon) were successfully executed. However, some hot restarts were accompanied by a harsh sound similar to the flushing noise of a commercial commode. At the same time, the infrared video system showed mild transient hot spots on the absorber. This prompted the addition, at noon, of $1 / 3$ torr of xenon as provided for in the test plan. The change in the behavior of a series of hot restarts, upon the addition of xenon, is illustrated in Figures $22 \mathrm{a}$ and $22 \mathrm{~b}$. A more detailed view of a single restart from each series, including temperature time histories as well as colorized images from the infrared video system, is presented in Figures 23a and 23b. Figure 22a shows that without xenon the pool and vapor temperatures regularly and persistently separated during cool-down, indicating that boiling had stopped. Figure 23a shows that when the shutter opened, the pool temperature became moderately superheated and 


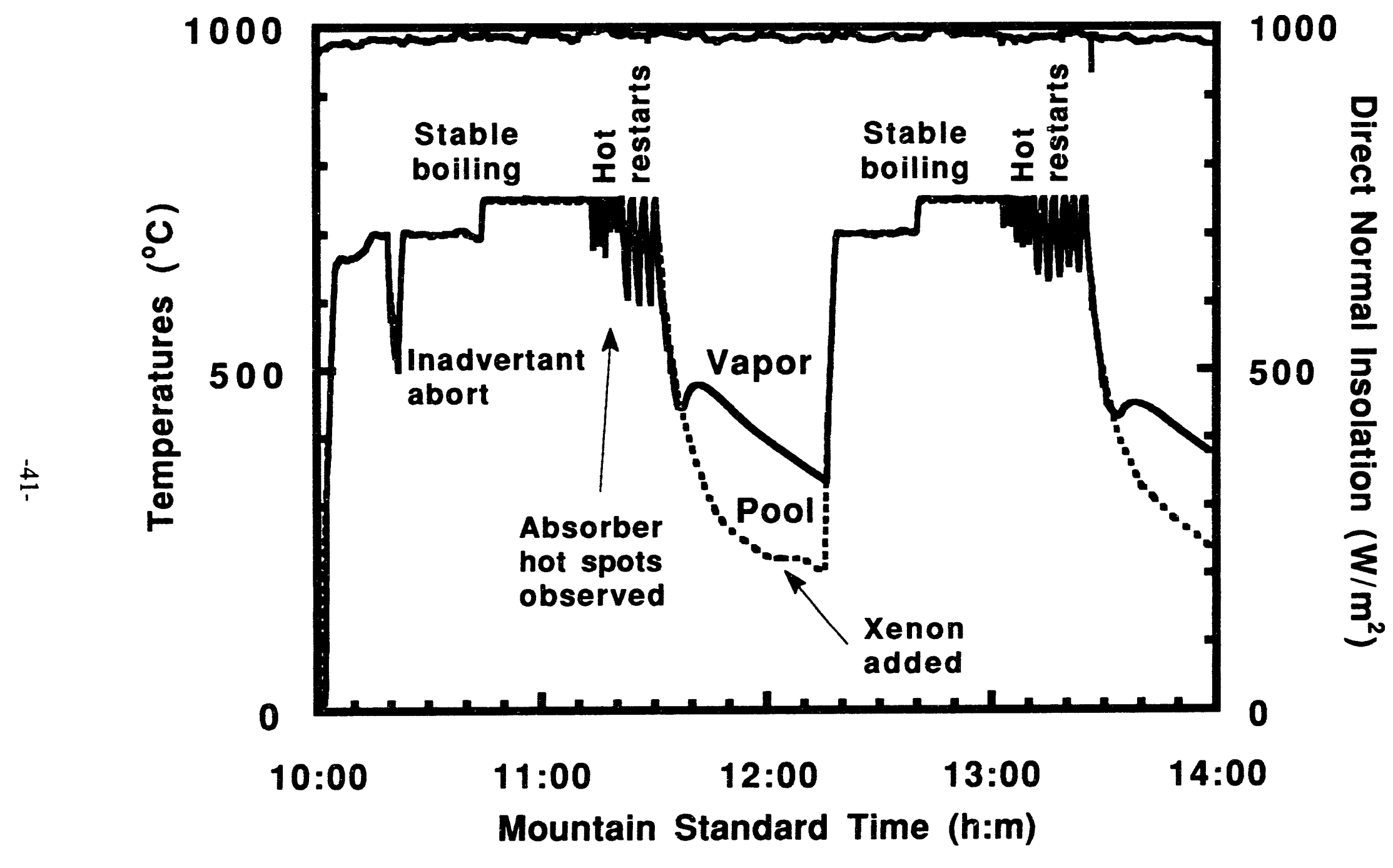

Figure 21. Second-generation receiver results, first test day. 


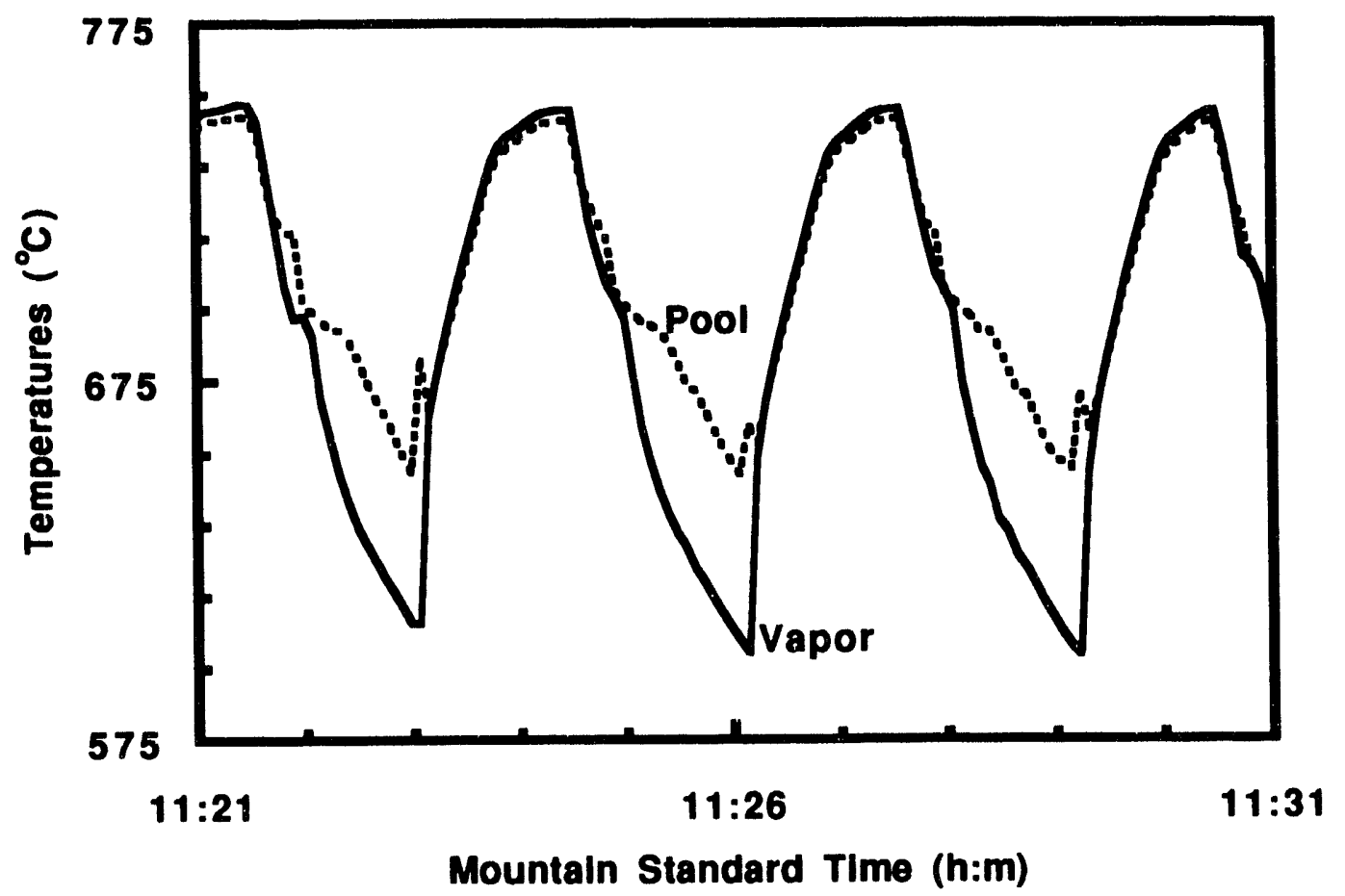

Figure 22a. Second-generation receiver, hot-restart superheating before xenon addition.

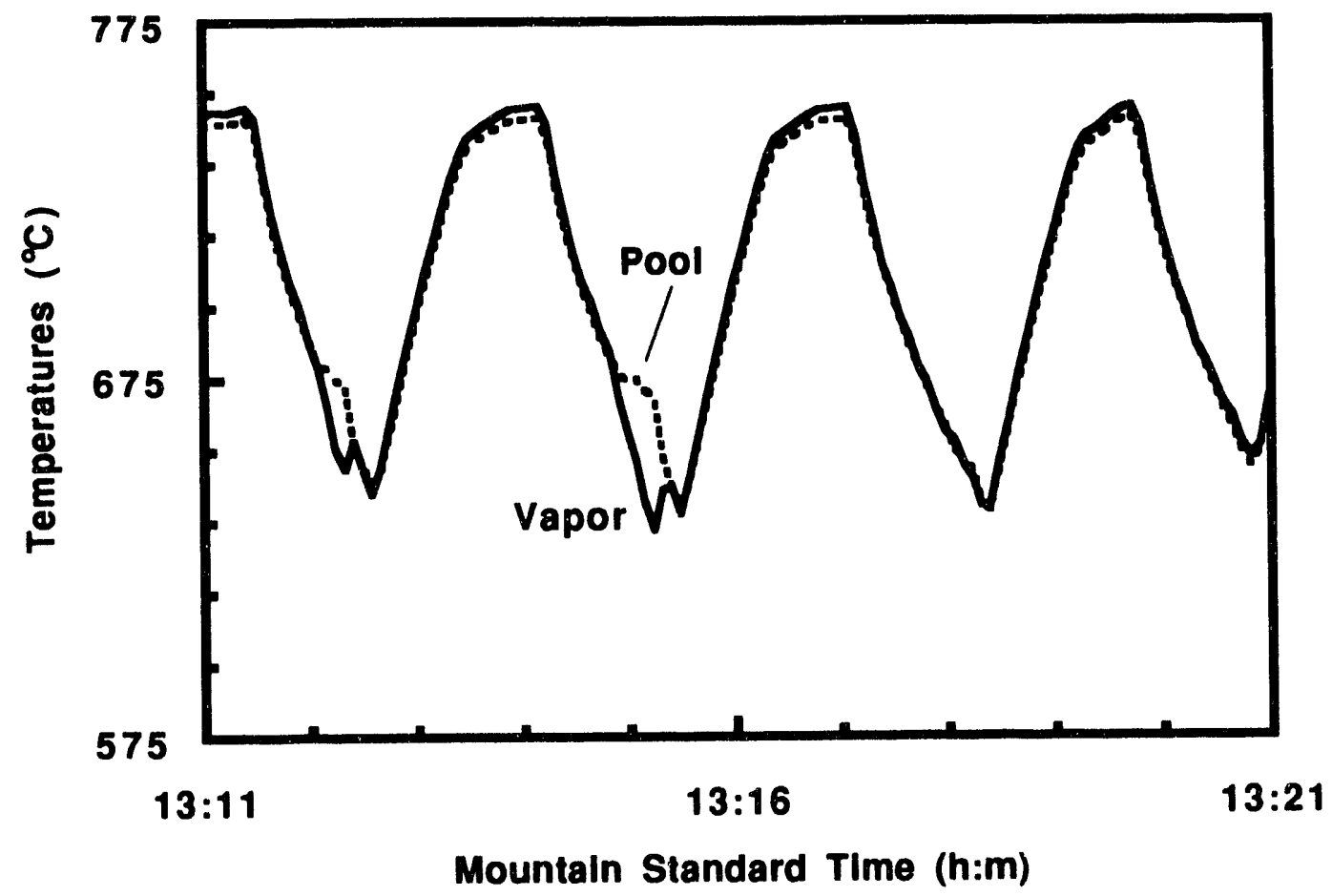

Figure 22.b. Second-generation receiver, well-behaved hot-restart series after xenon addition. 

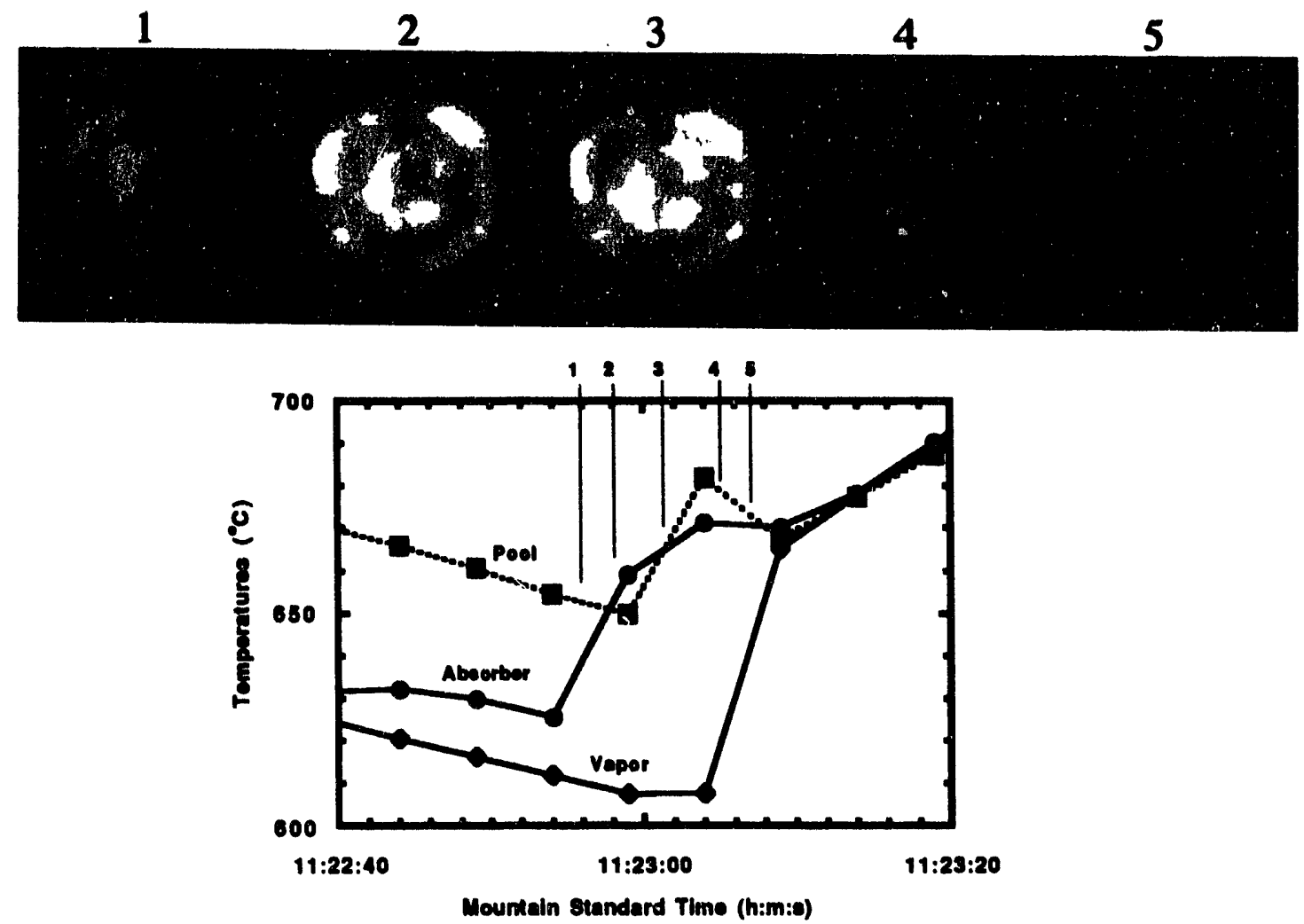

Figure 23a. 2nd-generation receiver, hot-restart overheating before xenon added, with IR images (white areas indicate mild hot spots).
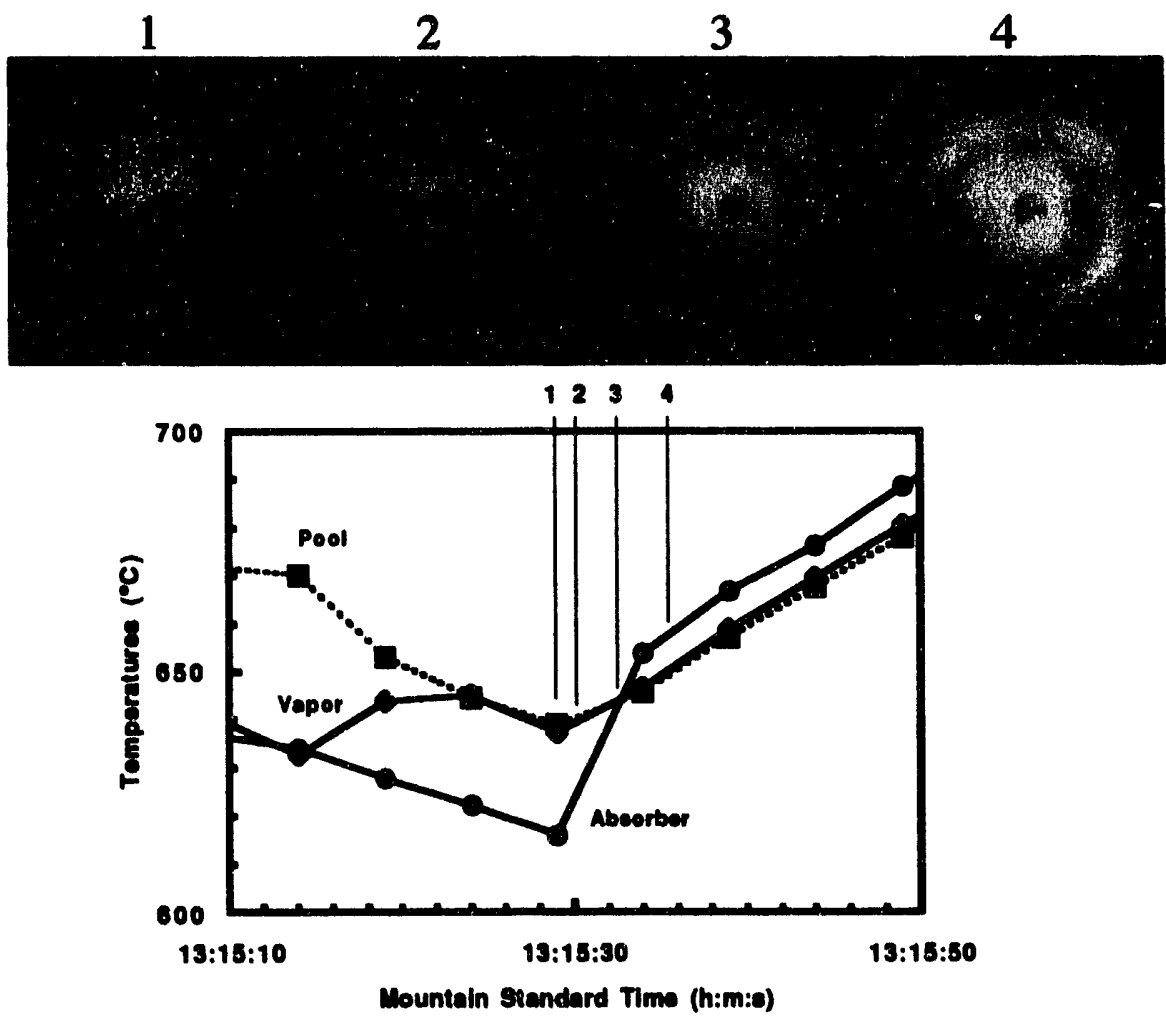

Figure 23b. 2nd-generation receiver, well-behaved hot restart after xenon added, with IR images. 
hot spots (seen as white in the colorized images) developed on the absorber and persisted until after boiling resumed. Overheating at the hot spots was judged to be mild - the color in the infrared images should not be interpreted as indicative of color temperature. After the addition of xenon, it was evident (as seen in Figure 22b) that the behavior was considerably improved. Figure $22 \mathrm{~b}$ happens to include the only two hot restarts that we observed after the addition of xenon in which boiling was not continuous during cooldown. In both cases however, boiling had resumed (as evidenced by the close agreement of pool and vapor temperatures) by the time the shutter opened. Figure 23b shows that when the shutter opened, boiling increased in intensity without incident. The harsh restart noise heard previously did not recur. During the remainder of the test days, we accumulated a total of 34 restarts at $450^{\circ} \mathrm{C}$ or higher, with no further evidence of pool superheating or absorber hot spots. Nine of these restarts were at a sun elevation of about $75^{\circ}$, twenty degrees higher than the elevation at which severe superheating occurred in the first-generation receiver.

Test results from the second test day are presented in Figure 24. The test objective was to determine the receiver thermal efficiency at $750^{\circ} \mathrm{C}$ under clear-sky steady-state conditions, therefore the 8.66-inch aperture was installed. Unfortunately, wind gusts up to 40 miles per hour as well as some clouds made this day unsuitable for determining efficiency and reduced the test to another demonstration of boiling stability.

Figure 25 illustrates the results from the third day of testing. The test objective was to determine the receiver thermal efficiency and if time permitted, to remove the aperture and perform additional hot restarts followed by warm restarts. Just prior to the test the concentrator mirrors were washed. Conditions for determining the efficiency were very good -- low winds, clear sky, and high direct normal insolation. However, the indicated efficiency, at about $85 \%$, was less than anticipated. It was noted during the test that the calorimeter seemed to have a higher thermal resistance than when it was used with the first-generation receiver. That is, it required a much greater percentage of helium than with the first receiver at the same vapor temperature and thermal power. This could adversely affect the measured efficiency, since the calorimeter gas ultimately permeates the receiver's insulation. Two relevant differences between the first and second receivers are the materials in the condenser wall (304L vs Haynes allny 230) and the coolants in the calorimeter (water, vs ethylene-glycol/water on the first three test days). The increased calorimeter thermal resistance might partly be a result of the emissivity difference between the condensers of the firstand second-generation receivers. However, it must also be a result of the poorer thermal-transport properties of ethylene glycol relative to water. With this realization, we decided to revert to a oncethrough water-cooling system for the calorimeter. It turned out that an even more important reason to switch to water was the later discovery of significant uncertainty in the composition of our 


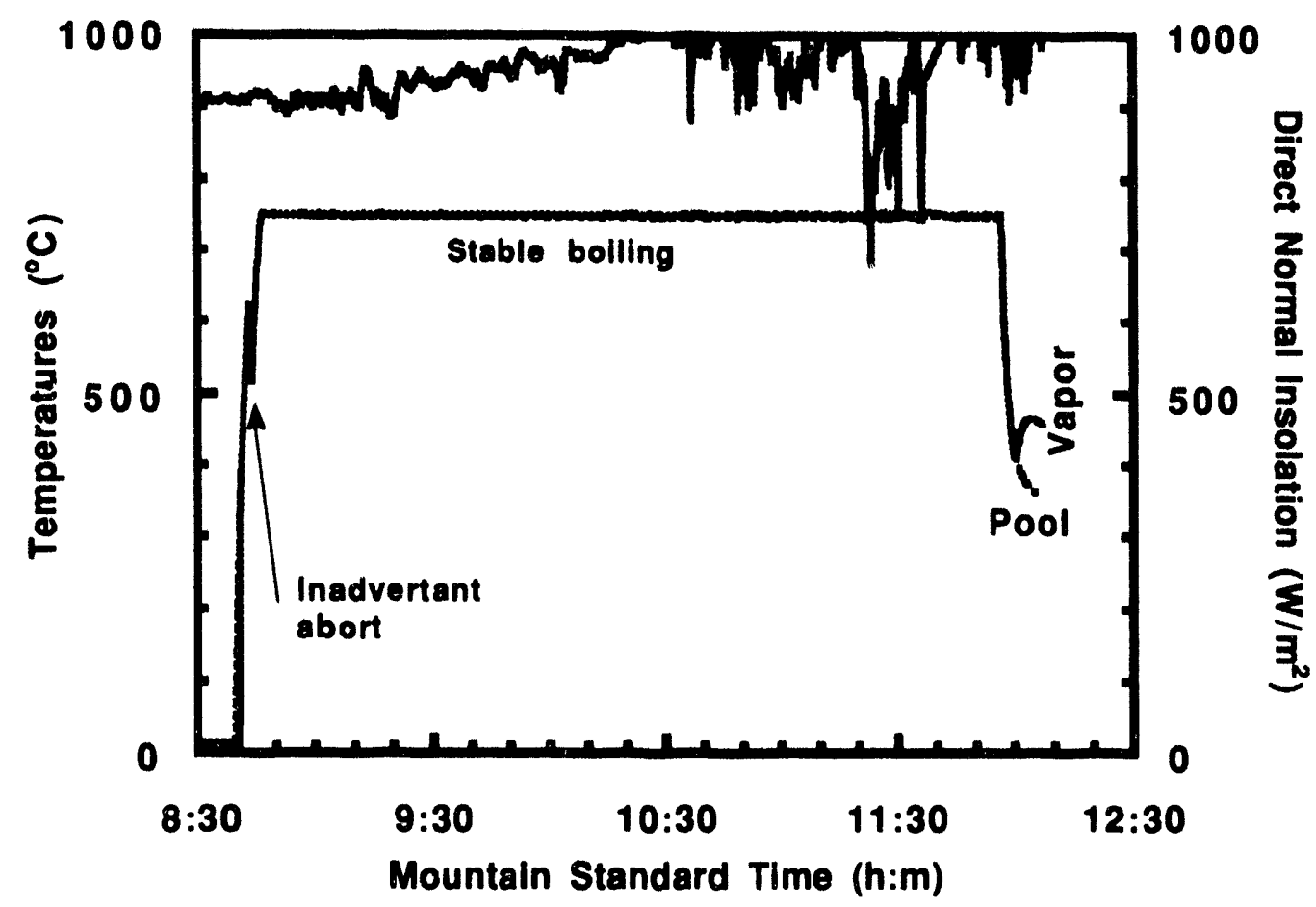

Figure 24. Second-generation-receiver stable boiling, second test day.

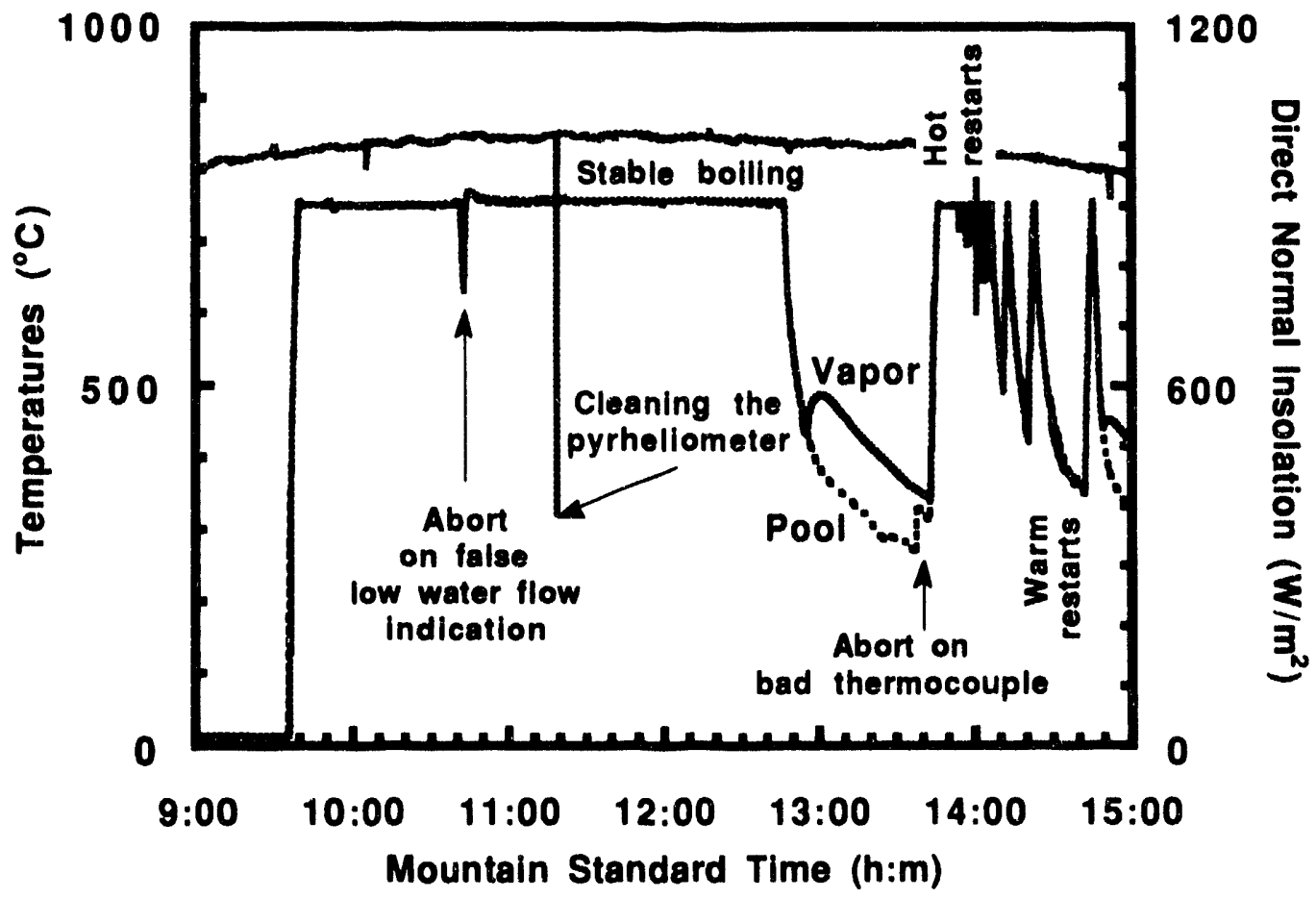

Figure 25. Second-generation-receiver stable boiling and well-behaved restarts, third test day. 
ethylene-glycol/water mixture, and therefore in its specific heat. This is a matter of continuing investigation.

After the efficiency test, still on the third day, the aperture was removed and nine hot restarts were executed, replicating the results from the first day. Three additional restarts were run, with the shutter opening at $500^{\circ} \mathrm{C}, 450^{\circ} \mathrm{C}$, and $350^{\circ} \mathrm{C}$, respectively. The latter two restarts were the first of a total of eleven warm restarts performed during the final five days of the test series, all without any indication of the difficulty encountered with the first-generation receiver. Presentation of warm-restart details is deferred to discussion of the sixth day's tests.

Results from the fourth test day are presented in Figure 26. The objective of this test was again to determine the receiver's thermal efficiency. Beginning with this test, we used water to cool the gasgap calorimeter. The most accurate determination of receiver efficiency is obtained when the same coolant and instruments are used in both the receiver and concentrator calorimetry. Thus, it was planned to perform water-cooled cavity calorimetry on the concentrator as soon as possible after the end of the test series. Before the test began, thermally-induced warpage was found in the stainless-steel sheet that forms the central part of the front of the receiver weather housing. A Kaowool gasket was fashioned and placed between the aperture and the receiver weather housing, to prevent hot air from leaving the optical cavity except by way of the aperture. As Figure 26 shows, the fourth day's test was terminated because of clouds after only about one hour. Later in the test series, after cold-water calorimetry for the concentrator was completed, it was determined that the peak efficiency reached on this day was $86.1 \%$ [42]. There are at least three reasons that the measured efficiency was this low: failure to reach therrnal equilibrium, the use of a cylindrical rather than conical cavity, and inadequate time-at-temperature for the solar absorptivity of Haynes alloy 230 to reach its maximum value. The last point was confirmed by direct measurement: a value of 0.83 was determined, while a value of at least 0.91 should eventually be reached [37].

After the fourth test day, the receiver was removed from TBC-2 and its absorber painted black as described in Section 2.3.2. The TBC facet alignment was checked - no adjustments were needed. Then, and again at the end of the test series, cold-water calorimetry was performed with freshlywashed mirrors. The average of the two determinations was $72.3 \mathrm{~kW}$ normalized to $1 \mathrm{~kW} / \mathrm{m}^{2}$ insolation.

The receiver was mounted on the concentrator again and the fifth day of tests (shown in Figure 27) was performed. The objective of this test was to conduct additional hot and warm restarts, so the aperture was removed. Because of the frequency of cloud transients, only two warm restarts were 


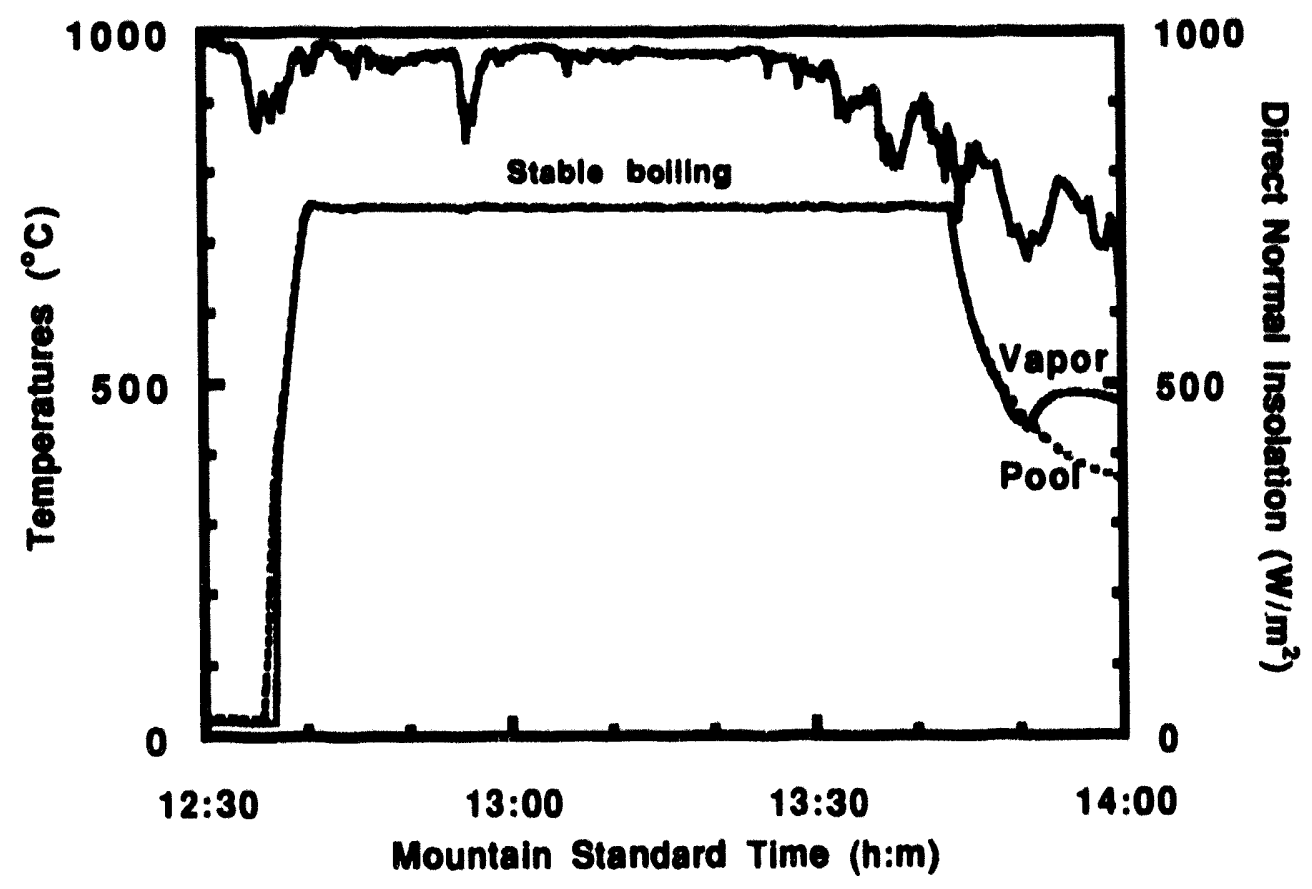

Figure 26. Second-generation-receiver stable boiling results, fourth test day.

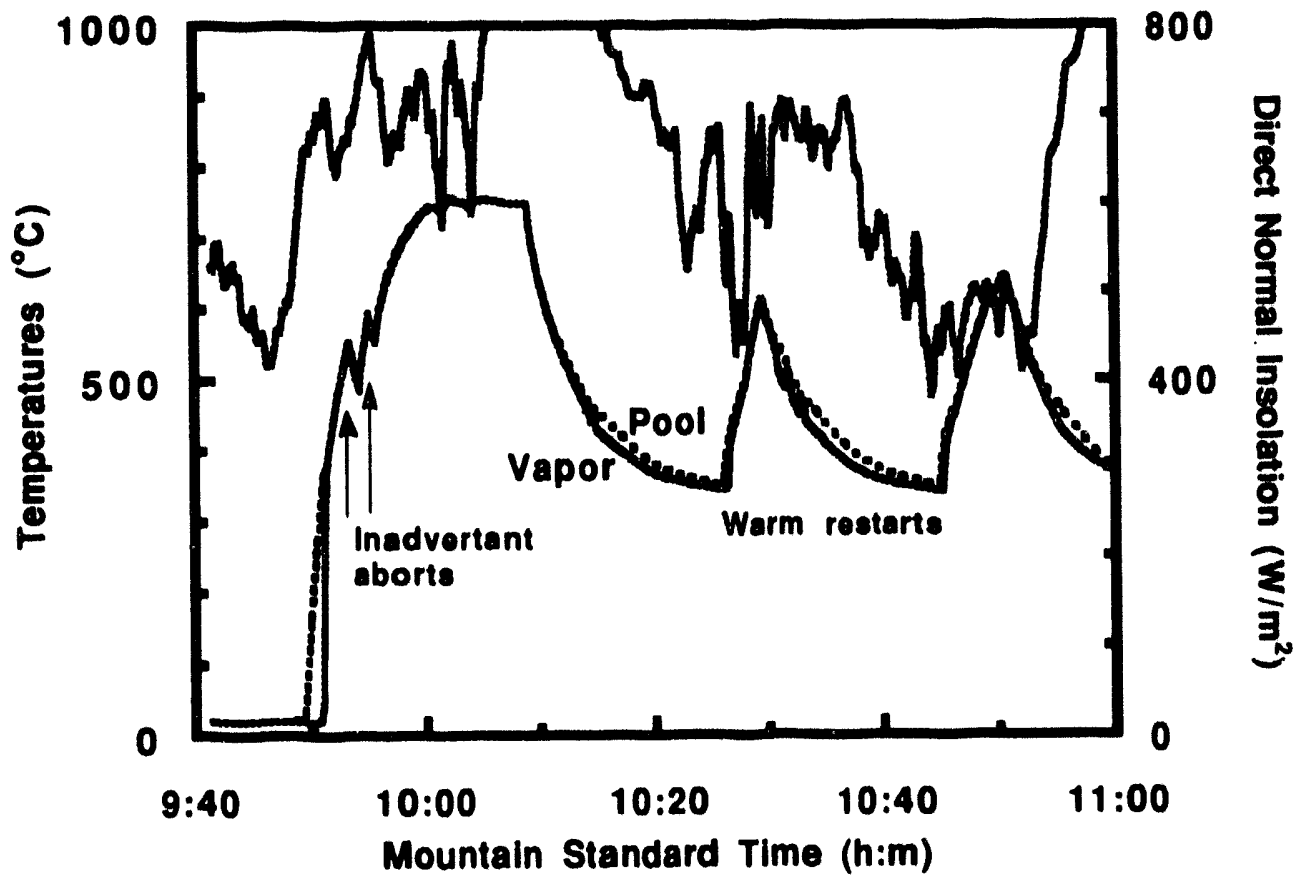

Figure 27. Second-generation-receiver well-behaved warm restarts, fifth test day. 
conducted. Both began at $350^{\circ} \mathrm{C}$ and were well-behaved; additionally, these restarts demonstrate stable boiling under reduced power conditions.

Throughout the test series, boiling always started above $308^{\circ} \mathrm{C}$. When the pool temperature was initially low, boiling often started below $412^{\circ} \mathrm{C}$. Recall from Sections 2.2 .2 and 2.2 .3 that this means that the safety factors for film boiling and flooding were respectively higher and lower than those of our first receiver. Thus, if flooding caused the burnout of our first receiver, it would be even more likely here. The fact that burnout did not occur in the second-generation receiver suggests that film boiling was the cause in the first -generation receiver.

On the sixth day, the objective was to conduct more hot and warm restarts. The results are presented in Figure 28. Twelve hot restarts and five warm restarts were completed before cloud cover ended the tests. All of the restarts were without incident -- we saw no evidence of behavior evolving with time. A closer view of some of the warm restarts is presented in Figure 29. Figure 30 shows more detail of a single warm restart, including IR-camera images. No evidence of pool superheat or absorber hot spots can be seen.

On the seventh (last) day of tests, the objective was once again to determine the receiver's thermal efficiency. Test conditions for this determination were good: low winds, clear sky, and direct normal insulation reaching about $0.96 \mathrm{~kW} / \mathrm{m}^{2}$. The test is illustrated in Figure 31 . For this test, the optical cavity was modified, using insulation-board inserts, to obtain a conical sidewall equivalent to that of the first-generation receiver. The mirrors were washed just prior to the test. During the test, it was noticed that the indicated water flow was higher than normal. It was later discovered that the cause was a foreign object lodged in the turbine meter inlet. The actual flow rate was determined without stopping the test, using a 55-gallon drum, a scale, and a stop watch. When the test was completed, additional flow-rate measurements were made to generate a calibration curve. Figure 31 shows that after three hours of operation at $750^{\circ} \mathrm{C}$, the receiver thermal efficiency approached steady state conditions, averaging $92.3 \%$ at $69.6 \mathrm{~kW}_{\mathrm{t}}$ input power over the final 40 minutes (these values supersede those in Reference 42). The winds averaged 3.0 miles per hour (mph) with a standard deviation of $1.0 \mathrm{mph}$ and a maximum of $5.5 \mathrm{mph}$. Our thermal model, which does not include the effects of wind, predicts a receiver efficiency of $94.1 \%$. A more stringent comparison is between measured and predicted heat losses which are, respectively, $7.7 \%$ and $5.9 \%$ of the power input. 


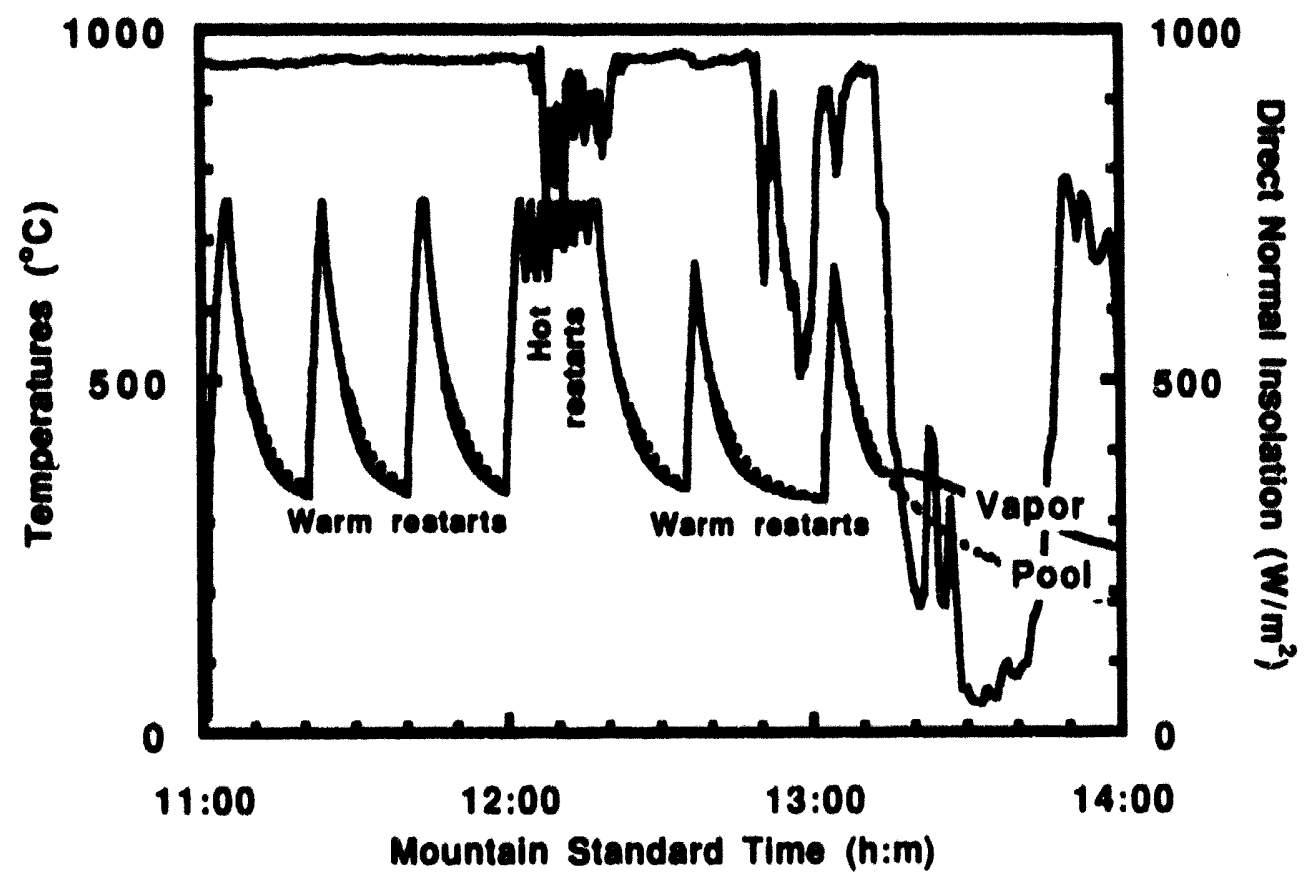

Figure 28. Second-generation-receiver well-behaved warm and hot restarts, sixth test day.

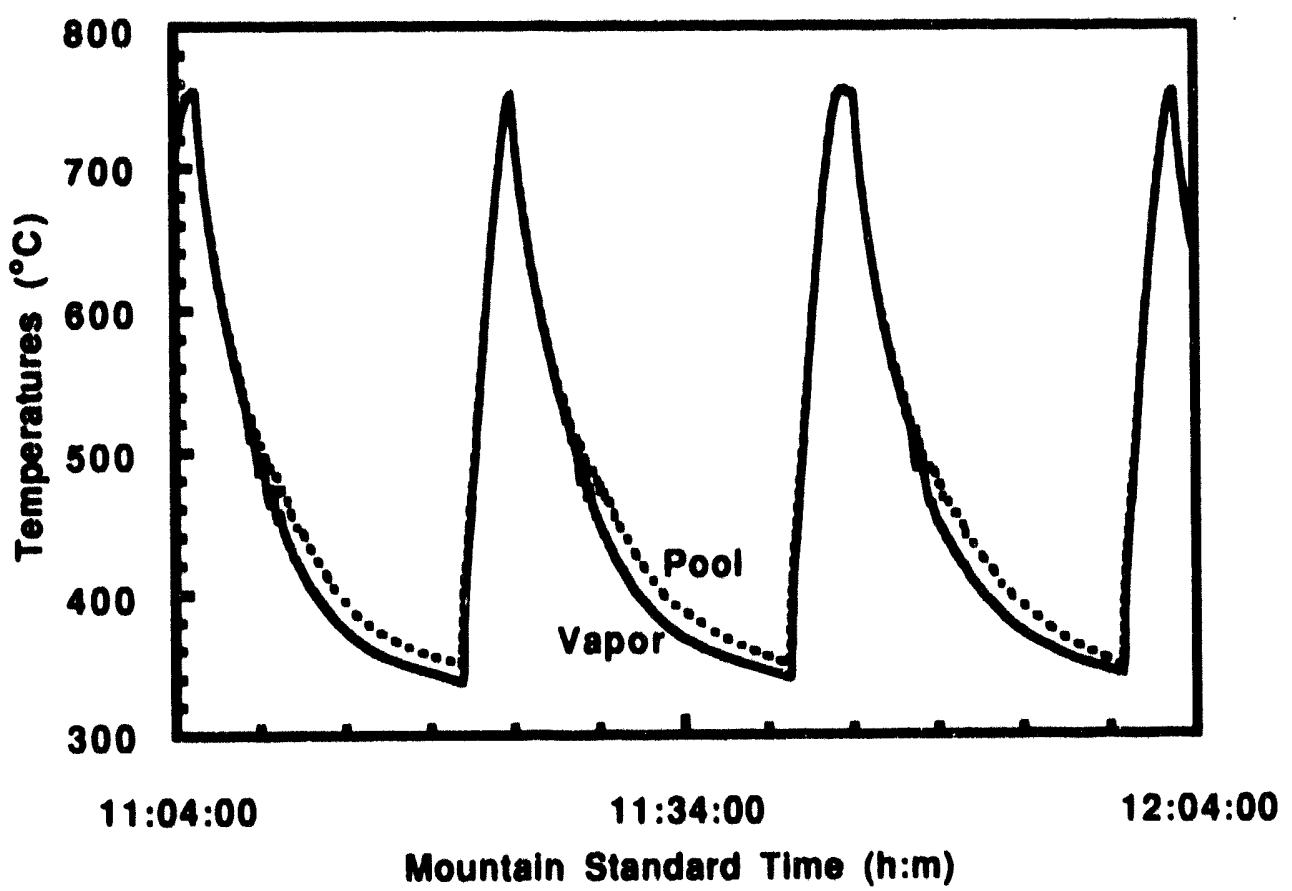

Figure 29. Second-generation receiver: a sequence of three well-behaved warm restarts. 

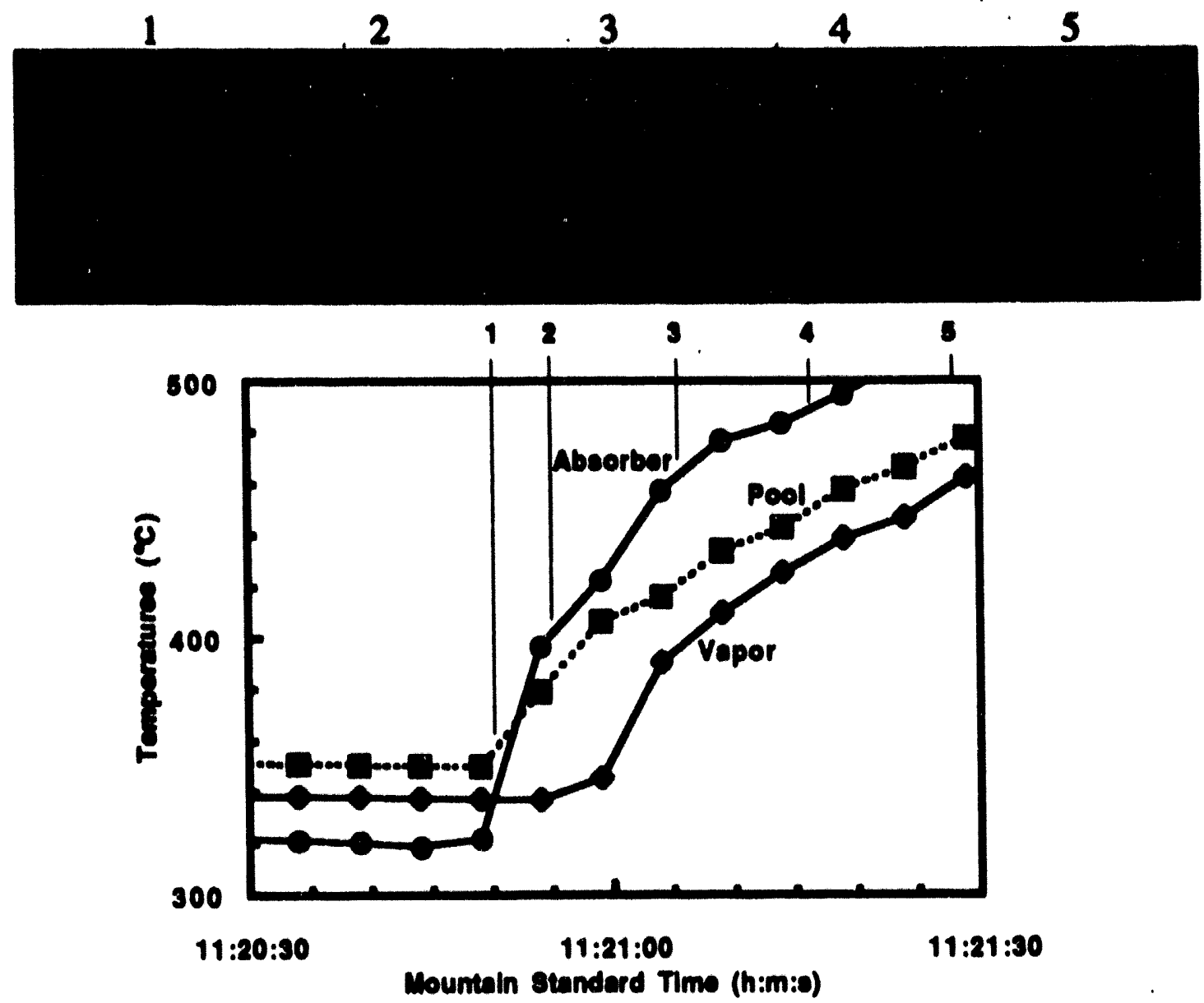

Figure 30. Second-generation receiver: a single well-behaved warm restart with IR-camera images.

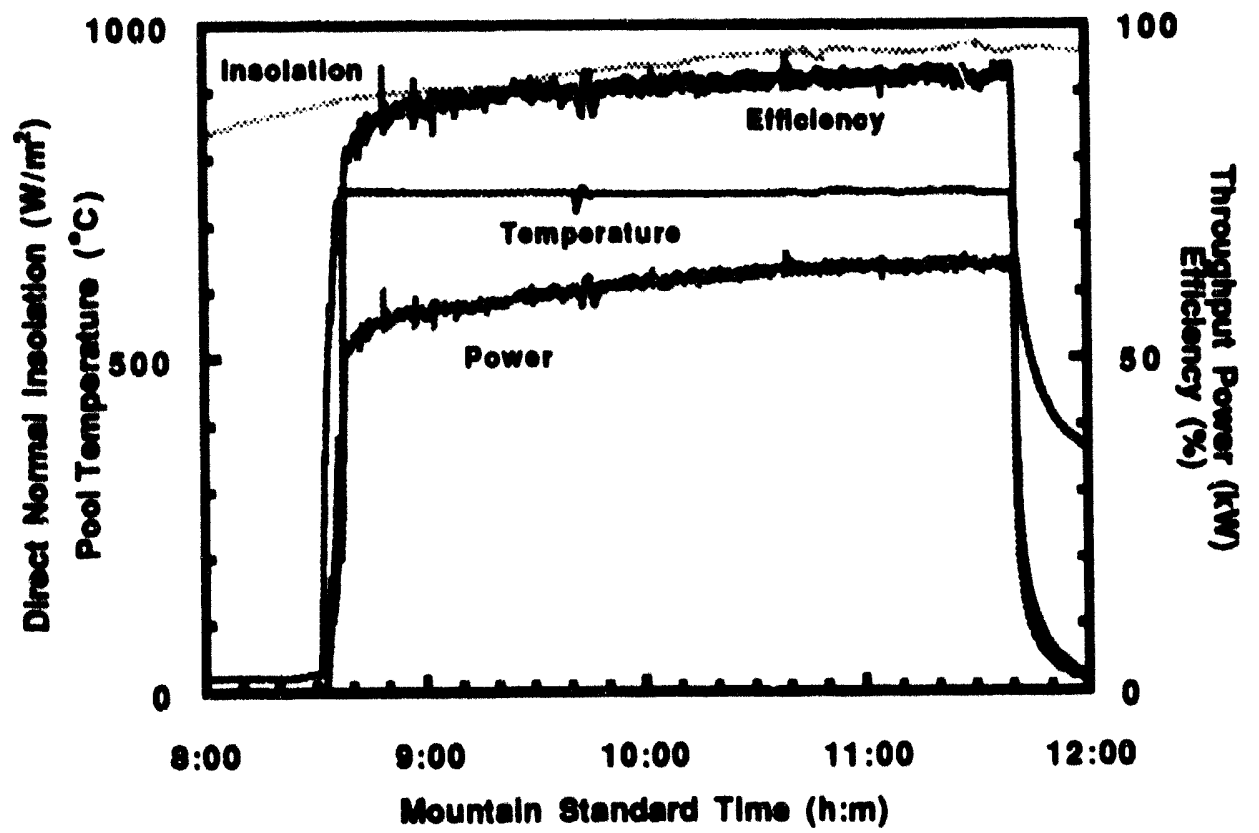

Figure 31. Second-generation-receiver efficiency results, seventh test day. 


\subsection{Advanced-Concepts Receiver Results}

The advanced-concepts receiver was tested in 1993 on March 8, 9, and 31, and on April 1. The tests are summarized in Table 5. The objective of these tests was to determine if stable boiling and good hot-restart behavior was possible in a $75-\mathrm{kW}, \mathrm{t}$ receiver without heated-surface modifications. As described in Section 3.2, the advanced-concepts receiver was a replica of the first-generation receiver, except that it did not have artificial cavities drilled in its heated surface. In contrast to the second-generation receiver, it was not re-sized to avoid warm-restart heat-transfer crises. Therefore, warm restarts were not included in the test plan. The test plan also did not provide for any determination of thermal efficiency, since that had already been accomplished for this configuration [10,11]. All of the tests were performed without an aperture and with the ethyleneglycol/water closed-loop cooling system.

The initial day's results are shown in Figure 32. For this test, the receiver was charged with about $1 / 3$ torr of xenon. The first two attempts to start were aborted by the infrared-camera safety system. Higher-than-expected pixel values were occurring because of very-high incident fluxes (a result of the small size of the absorber) and because of high reflectivity (where the absorber was

Table 5. Advanced-concepts pool-boiler-receiver test summary

\begin{tabular}{|c|c|c|c|c|c|c|c|}
\hline $\begin{array}{l}\text { TEST } \\
\text { NO. }\end{array}$ & DATE & PURPOSE & $\begin{array}{l}\text { TORR } \\
\text { XENON }\end{array}$ & $\begin{array}{l}\text { APERTURE } \\
\text { OPEN? }\end{array}$ & $\begin{array}{l}\text { ABSORBER } \\
\text { PAINTED? }\end{array}$ & $\begin{array}{l}\mathrm{COOL} \\
\text { W/H2O? }\end{array}$ & COMMENTS \& RESULTS \\
\hline$T$ & $3 / 8 / 93$ & $\begin{array}{l}\text { Stability, } \\
\text { hot restarts }\end{array}$ & $1 / 3$ & yes & no/yes & no & $\begin{array}{l}\text {-abort on reflections } \\
\text {-apply Pyromark paint } \\
\text {-abort on paint scale } \\
\text {-stable boiling at } 700^{\circ} \mathrm{C}\end{array}$ \\
\hline 2 & $3 / 9 / 93$ & $\begin{array}{l}\text { Stability, } \\
\text { hot restarts }\end{array}$ & $1 / 3$ & yes & yes & no & $\begin{array}{l}\text {-remove } 4 \text { thermocouples } \\
\text {-stable at } 725,775,800^{\circ} \mathrm{C} \\
\text {-good restarts...4x }\left(700^{\circ} \mathrm{C}\right) \\
\text {-helium flowrate data lost }\end{array}$ \\
\hline 3 & $3 / 31 / 93$ & $\begin{array}{l}\text { Stability, } \\
\text { hot restarts }\end{array}$ & $\pi$ & yes & yes & no & $\begin{array}{l}\text {-xenon removed } \\
\text {-abort: calor mis-plumbed } \\
\text {-startup aborted on hot spot } \\
\text {-hot restarts not attempted } \\
\text {-realign receiver }\end{array}$ \\
\hline 4 & $4 / 22 / 93$ & $\begin{array}{l}\text { Stability, } \\
\text { hot restarts }\end{array}$ & $0,1 / 3$ & yes & yes & no & $\begin{array}{l}\text {-startup aborted on hot spot } \\
\text {-add xenon } \\
\text {-couldn't maintain } 700^{\circ} \mathrm{C} \\
\text {-stable at } 750,800^{\circ} \mathrm{C} \\
\text {-good hot restarts... } \\
3 \times\left(750^{\circ} \mathrm{C}\right) \\
\left.3 \times\left(700^{\circ} \mathrm{C}\right)\right)\end{array}$ \\
\hline
\end{tabular}




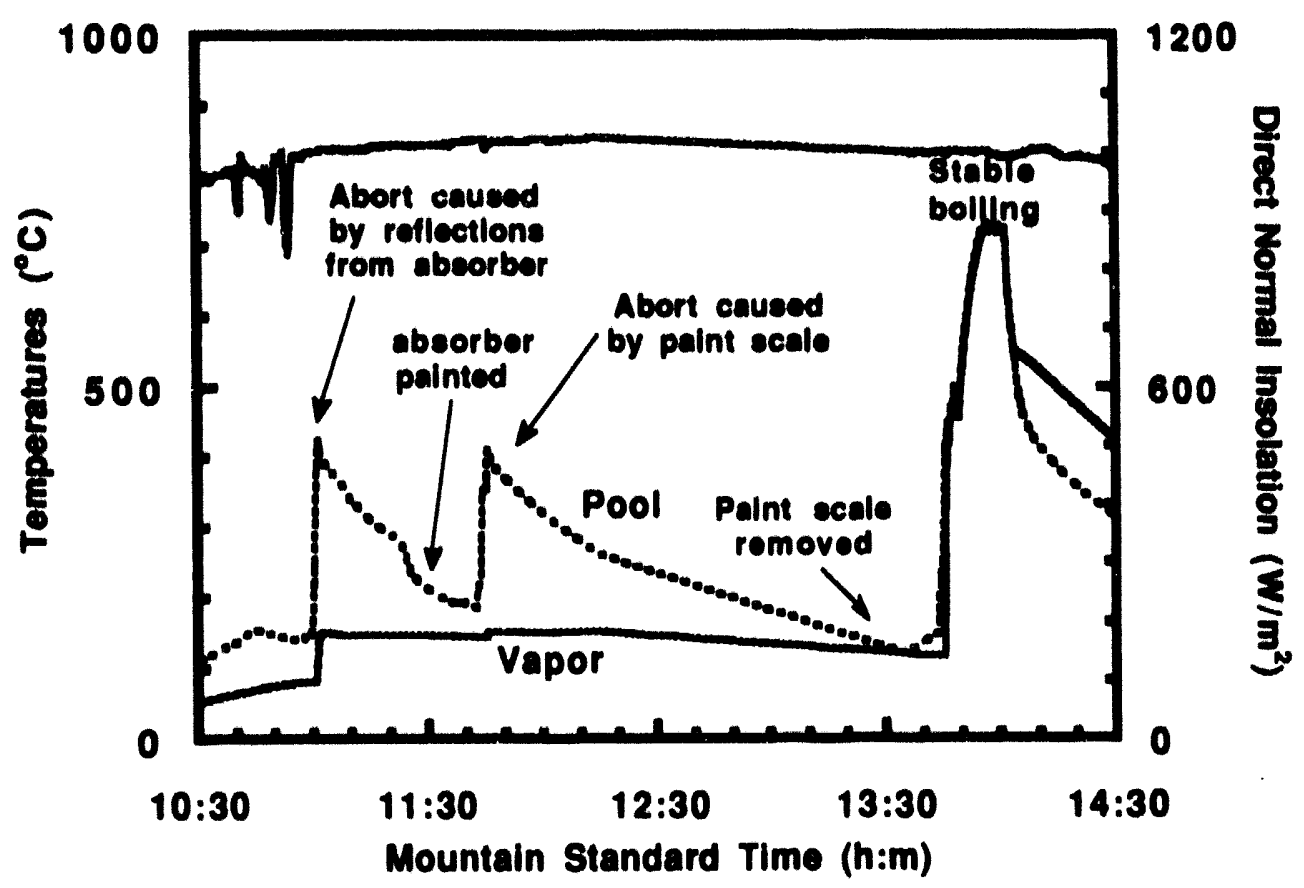

Figure 32. Advanced-concepts receiver with xenon: startup delays and stable-boiling results, first test day.

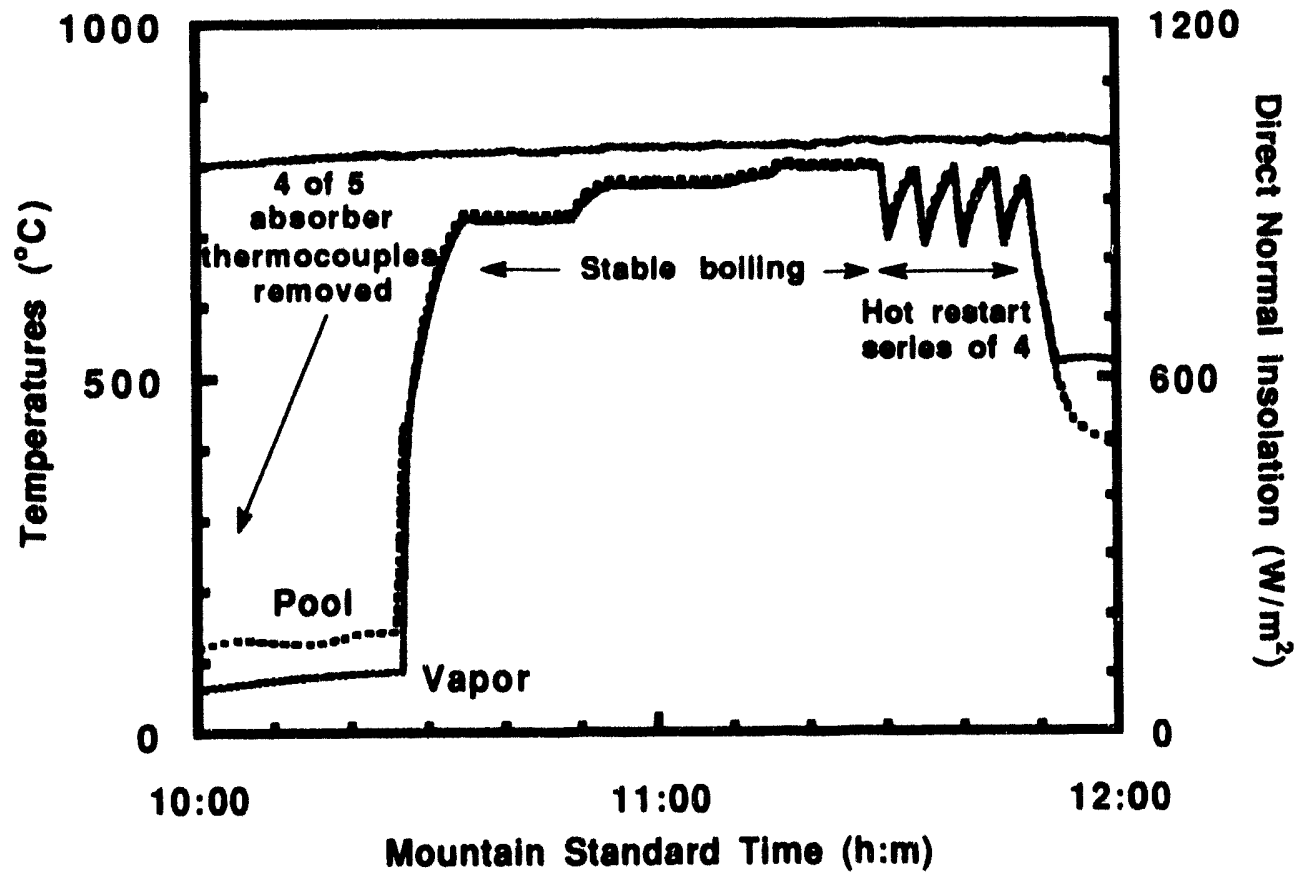

Figure 33. Advanced-concepts-receiver stable boiling and well-behaved hot restarts, 2nd test day. 
cleaned for intrinsic-thermocouple welds). To reduce these reflections, the absorber was coated with Pyromark 2500 black paint. Proper elevated-temperature curing of the paint was not possible. On the next startup, the safety system again aborted. This time, indications of hot spots occurred where the paint had formed loosely-adherent scales. The scales were brushed off, and finally the receiver was brought up to $700^{\circ} \mathrm{C}$ and stable boiling was demonstrated.

A remaining problem with the infrared-camera system was the high pixel values associated with the intrinsic-thermocouple ceramic beads. Again, this was a result of the very-high incident flux, and was not a problem with larger receivers tested previously. Since the high pixel values would cause safety shutdowns during hot restarts, all of the offending thermocouples on the absorber were removed. The one thermocouple that was not a problem (lower left) was left in place. The results from the second test day are shown in Figure 33. Stable boiling was demonstrated at vapor temperatures of $725^{\circ} \mathrm{C}, 775^{\circ} \mathrm{C}$, and $800^{\circ} \mathrm{C}$. The test ended with a series of four hot restarts from a pool temperature of $700^{\circ} \mathrm{C}$. Boiling continued during each cool-down, and consequently all of the hot restarts were well-behaved. These restarts were all run with the temperature controller calling for $100 \%$ argon in the calorimeter gas gap. This allowed us to distinguish between the known beneficial effect of high helium mole fractions in the gas gap $[10,11]$ and the inherent behavior of the receiver. Afterwards, it was discovered that the calorimeter helium flow controller was not functioning correctly, so that the helium flow rates for this day's tests are not known. Later in the test series, with the helium flow-control problem corrected, we obtained good restart behavior with only argon flowing in the calorimeter gas gap.

With the completion of the second day's test, it appeared that our initial test objective was fulfilled. However, the success prompted a question: is the added xenon necessary for boiling stability? Answering this question could contribute to a better understanding of how nucleation sites are reactivated. To address this question, we took the receiver off the concentrator and evacuated it as described in Section 4.1. The third test, with the xenon removed, is illustrated in Figure 34. The first startup was uneventful, with well-behaved boiling up to about $700^{\circ} \mathrm{C}$. A detailed view of the startup is presented in Figure 35a. Then it was discovered that the calorimeter was not extracting power and the test was stopped. After correcting a plumbing problem, the second startup was begun. After about 80 seconds of stable boiling, the test was terminated when an area of rapidlyincreasing temperature developed on the absorber at abcut the same location where the first receiver failed. A detailed view of this second start, presented in Figure 35b, shows no sign of boiling instability. An inspection of the absorber revealed no evidence of overheating. We did find that the receiver had shifted position slightly, and we re-tensioned its spokes to restore its alignment. 


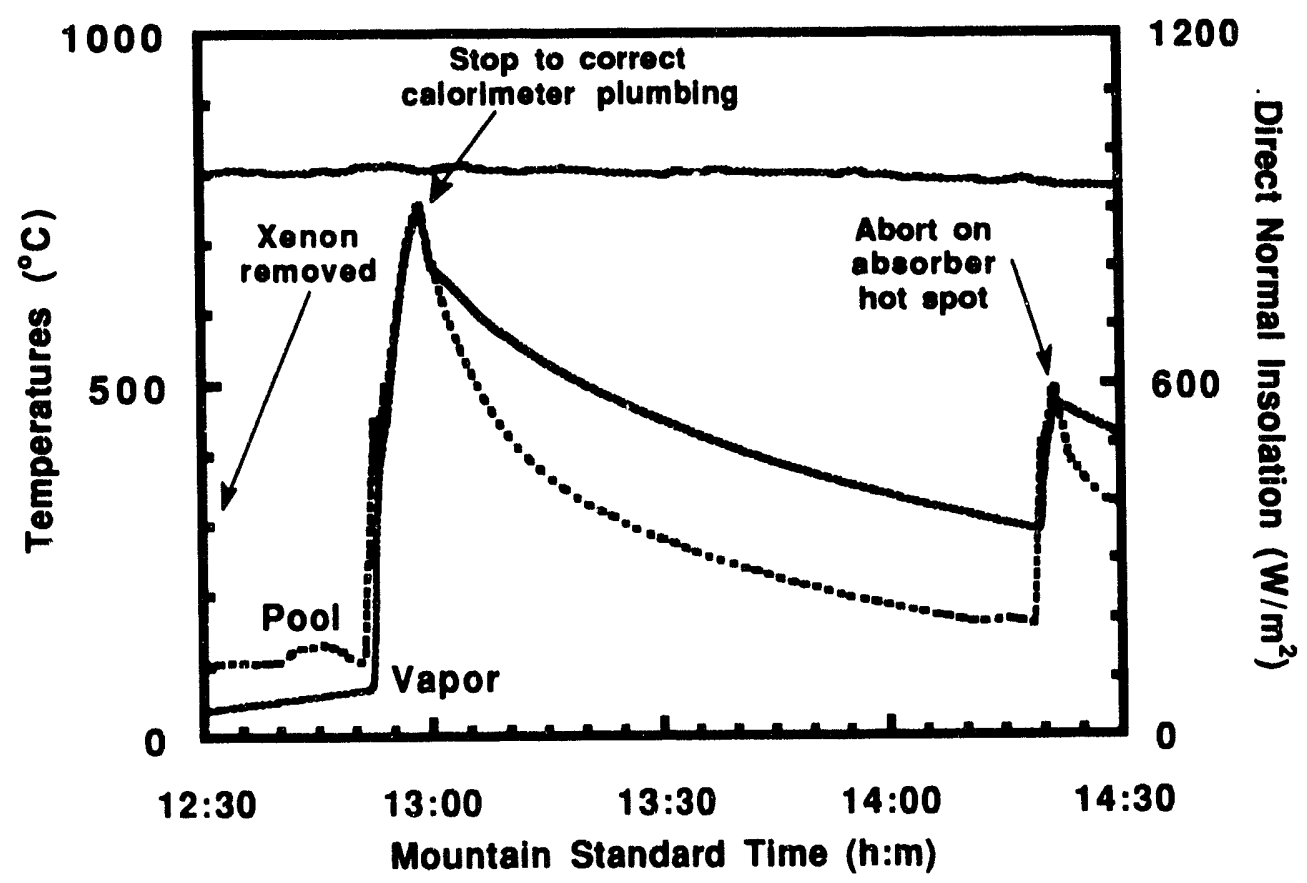

Figure 34. Advanced-concepts-receiver startup behavior after xenon was removed, third test day.

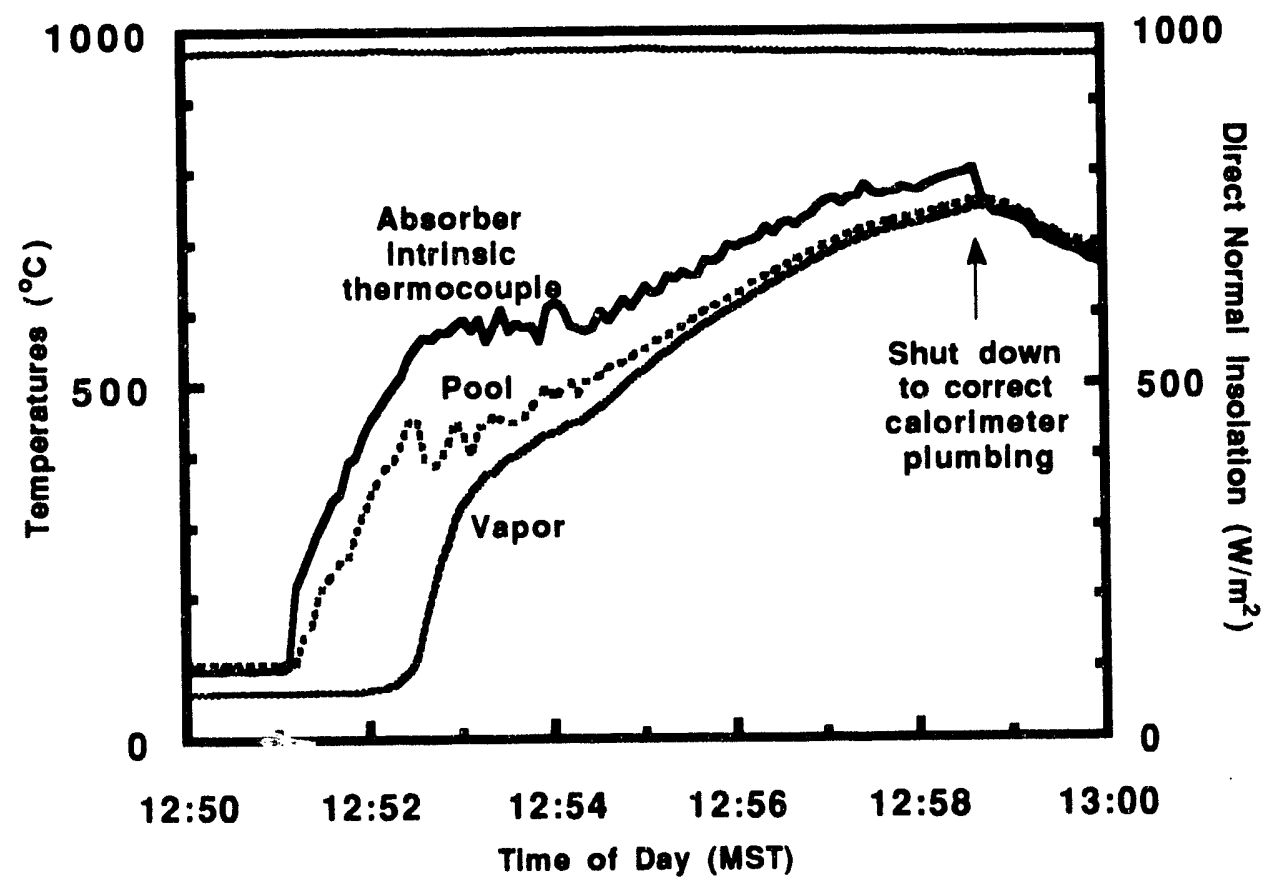

Figure 35a. Detailed view of well-behaved first start-up without xenon, advanced-concepts receiver, 3rd test day. 


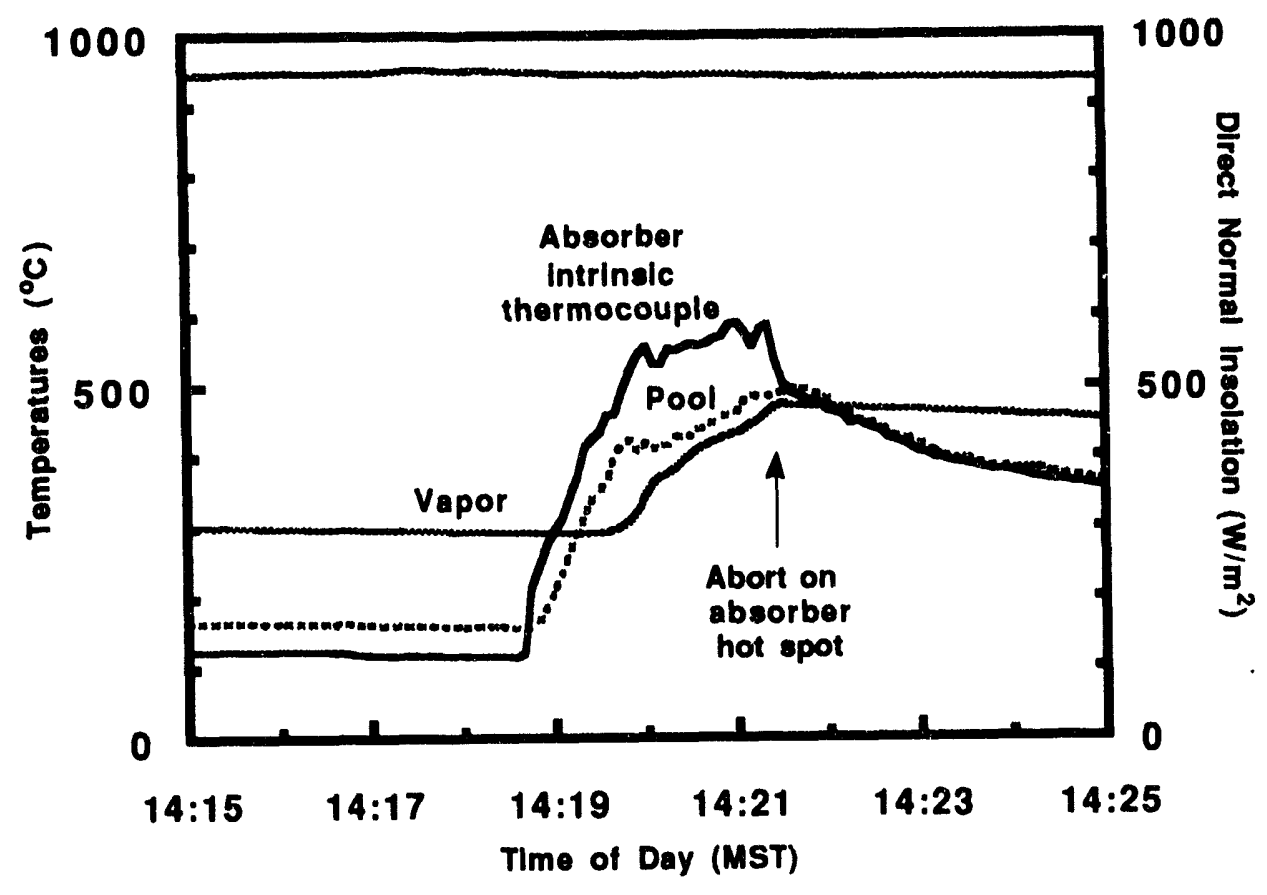

Figure 35b. Detailed view of advanced-concepts-receiver second start-up without xenon, ending in abort, third test day.

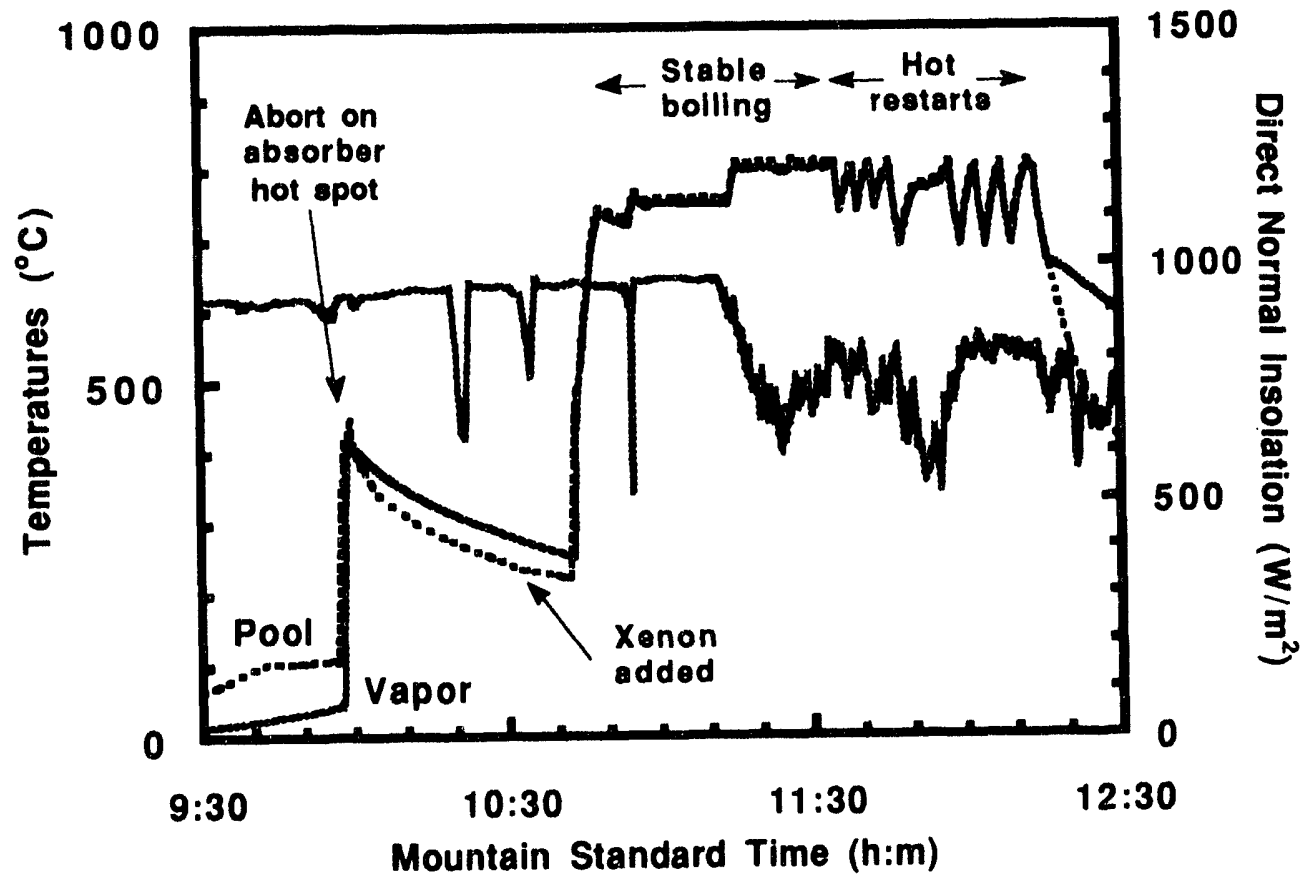

Figure 36. Advanced-concepts-receiver stable boiling and well-behaved hot restarts after xenon reintroduced, fourth test day. 
On the final day, we attempted another startup and experienced another hot spot, nearly identical in circumstances to its predecessor. Again, the thermocouple indications are not characteristic of boiling instability; rather, it appears that film boiling may have occurred at flux hot spots. It is not known whether similar hot spots developed on the first receiver before xenon was added, since the infrared camera was installed later. In the present case after we reintroduced 1/3 torr of xenon, the hot spot did not recur. Figure 36 is an overview of the day's testing. Stable boiling was again demonstrated at $750^{\circ} \mathrm{C}$ and $800^{\circ} \mathrm{C}$, and good hot-restart behavior was demonstrated in three starts each from pool temperatures of $700{ }^{\circ} \mathrm{C}$ and $750^{\circ} \mathrm{C}$.

\section{Summary and Conclusions}

Two 75-kW alkali-metal pool-boiler solar receivers were successfully tested. One was Sandia's second-generation receiver, designed to move the pool-boiler concept closer to commercialization. The other was Sandia's advanced-concepts receiver, designed to test our hypothesis that stable boiling is achievable in a $75-\mathrm{kW}_{\mathrm{t}}$ alkali-metal pool boiler without the use of surface modifications.

The second-generation receiver contained $\mathrm{NaK}-78$ (which freezes at $-12.6^{\circ} \mathrm{C}$ ) and therefore did not require costly electrical preheaters. A powdered-metal coating was substituted for expensive electric-discharge-machined (EDM) cavities to stabilize boiling. The receiver was constructed from Haynes alloy 230 for good high-temperature strength and oxidation resistance, and was designed to ASME Boiler Code intent. Fabrication and inspections were carried out in commercial shops. A quartz-lamp heated bench-scale version has been tested for about 7500 hours to assess long-term boiling behavior and materials compatibility. During the on-sun tests of the second-generation receiver:

1. Stable boiling was demonstrated without added gas at $750^{\circ} \mathrm{C}$ at near full power (peak input fluxes on the order of $58 \mathrm{~W} / \mathrm{cm}^{2}$ ).

2. Hot restarts without added gas were accompanied by moderate pool superheats and harsh sounds, along with mild transient hot spots on the absorber.

3. All 34 hot restarts conducted after the addition of about $1 / 3$ torr of xenon were wellbehaved, although in two sequential cases on the first day boiling during cooldown was intermittent. Eleven of the 34 hot restarts were carried out after 9 hours of boiling at above $700^{\circ} \mathrm{C}$. Nine were conducted at a sun elevation of 75 degrees -- 20 degrees higher than the elevation at which restart behavior became a problem in our first receiver. 
4. Boiling remained stable after the addition of xenon, for a total of 12 hours of operation above $700^{\circ} \mathrm{C}$. Boiling was also stable during brief operation at about $1 / 2$ of the design input power, at temperatures as low as $500^{\circ} \mathrm{C}$.

5. A total of 11 warm restarts were successfully performed, approximating conditions at which our first receiver burned out. Seven of these were carried out after 9 hours of boiling at above $700^{\circ} \mathrm{C}$.

6. The safety factors for film boiling and flooding relative to the first receiver suggest that the burnout of our first receiver was caused by film boiling.

7. A thermal efficiency of $92.3 \%$ was established at $750^{\circ} \mathrm{C}$ with an input power of 69.6 $\mathrm{kW}_{\mathrm{t}}$ (these values supersede those in Reference 42 ). Our thermal model predicts $94.1 \%$. The efficiency is expected to improve as the absorber solar absorptivity increases with time from 0.87 to 0.91 .

The advanced-concepts receiver was a duplicate of our first receiver, except that the absorber surface was not modified by the addition of EDM cavities. During its on-sun tests:

1. Stable boiling and well-behaved hot restarts were obtained when the receiver contained $1 / 3$ torr of xenon.

2. Stable boiling at temperatures up to $700^{\circ} \mathrm{C}$ was observed during the first brief test after the xenon was removed from the receiver. Rapidly-developing hot spots on the absorber caused two subsequent startups to be aborted. The thermocouples gave no indication of unstable boiling, leading us to suspect film boiling.

3. Stable boiling and well-behaved hot restarts were restored when xenon was again added to the receiver.

4. We confirmed our hypothesis that stable boiling is achievable in a $75-\mathrm{kW}_{\mathrm{t}}$ alkali-metal pool boiler without the use of surface modifications. 


\section{References}

[1] Andraka, C.E., Diver, R.B., Adkins, D.R., Rawlinson, K.S., Cordeiro, P.G., Dudley, V.E., and Moss, T.A., "Testing of Stirling Engine Solar Reflux Heat-Pipe Receivers," Paper No. 93IEC-295, Proceedings of the 28h IECEC, Atlanta, GA, 1993.

[2] Bean, J. R., and Diver, R. B., "Performance of the CPG 7.5-KW Eish-Stirling System," Paper No. 93054, Proceedings of the 28th IECEC, Atlanta, GA, 1993.

[3] Goebel, O., and Laing, D., "Second-Generation Sodium-Heat Pipe Solar Receiver for a USAB V-160 Stirling Engine: Development and On-Sun Test Results," Paper No. 93176, Proceedings of the 28th IECEC, Atlanta, GA, 1993.

[4] Isshiki, N., Watanabe, H., Shishido, K., Ohtomo, M., and Watanabe, K., "Studies on SolarDish Heated Stirling Engines TNT-3, NAS-2," Paper No. 93326, Proceedings of the 28th IECEC, Atlanta, GA, 1993.

[5] Loktionov, Y. U., Baum, I. V., Gonnov, I. V., and Trofimov, A. I., "Designs of Terrestrial Solar Electric Generating Sets," Paper No. 93023, Proceedings of the 28th IECEC, Atlanta, GA, 1993.

[6] Washom, B. J., "Parabolic Dish Stirling Module Development and Test Results," Paper No. 849516, Proceedings of the 19th IECEC, San Francisco, CA, 1984.

[7] Diver, R.B., Andraka, C.E., Moreno, J.B., Adkins, D.R., and Moss, T.A., "Trends in Dish Stirling Solar Receiver Design," Paper No. 905303, Proceedings of the 25th IECEC, Reno, NV, 1990.

[8] Osborn, D. B. and Pons, R. L., "Solar Power Converter with Pool Boiling Receiver and Integral Heat Exchanger,", United States Patent 4,335,578, 1982.

[9] Foust, O.J., Ed., Sodium Nak Engineering Handbook, Gordon and Breach, Science Publishers, Inc., 1979, Vol. 1, p. 59.

[10] Moreno, J. B.; Andraka, C. E.; Diver, R. B.; Ginn, W. C.; Dudley, V.; and Rawlinson, K.S., "Test Results from Full-Scale Sodium Reflux Pool-Boiler Solar Receiver," Proceedings of the 12th ASME International Solar Energy Conference, Miami, FL, 1990.

[11] Andraka, C. E.; Moreno, J. B.; Diver R. B.; and Moss, T. A., Sodium Reflux Pool-Boiler Receiver On-Sun Test Results, SAND89-2773, Sandia National Laboratories, Albuquerque, NM, July, 1992.

[12] Dwyer, O.E., Boiling Liquid-Metal Heat Transfer, American Nuclear Society, Hinsdale, Illinois, 1976, p. 207.

[13] Moreno, J.B. and Andraka, C.E., Test Results from Bench-Scale Sodium-Pool-Boiler Solar Receiver, SAND89-0899, Sandia National Laboratories, Albuquerque, June 1989.

[14] Andraka, C. E. and Moreno, J. B., "Pool Boiler Reflux Solar Receiver for Stirling DishElectric Systems," Paper No. 899462, Proceedings of the 24th IECEC, Washington, DC, 1989.

[15] Shai, I., and Rohsenow, W.M., "The Mechanism and Stability Criterion for Nucleate Boiling of Sodium," Trans. ASME. Series C, J. Heat Transfer, 91:315 (1969). 
[16] Saaski, E., Advanced Solar Conversion System (ASCS) Heat Transport System Working Group Meeting, Sandia National Laboratories, June 1989.

[17] Moreno, J.B., Andraka, C.E., Diver R.B., Moss, T.A., Hoffman, E.L., and Stone, C.M., "Reflux Pool-Boiler as a Heat-Transport Device for Stirling Engines: Postmortem Analysis and Next-Generation Design ," Paper No. 915355, Proceedings of the 26th IECEC, Boston, MA, August 1991.

[18] Moreno, J.B., Andraka, C. E. and Moss, T.A., "Boiling Behavior of Sodium-Potassium Alloy in a Bench-Scale Solar Receiver," Paper No. 929178, Proceedings of the 27th IECEC, San Diego, CA, August 1992.

[19] Moreno, J. B.; Moss, T. A., Bench-Scale Screening Tests for a Boiling Sodium-Potassium Alloy Solar Receiver, SAND92-2253, Sandia National Laboratories, Albuquerque, NM, June 1993.

[20] Andraka, C. E.; Jones, S. A.; Moreno, J. B.; and Moss, T. A., "NaK Pool-Boiler BenchScale Receiver Durability Test: Test Design and Initial Results," Paper No. 93IEC-294, Proceedings of the 28th IECEC, Atlanta, GA, 1993.

[21] Anderson, W.G., Rosenfeld, J.H., and Noble, J., "Alkali Metal Pool Boiler Life Tests for a 25 kWe Advanced Stirling Conversion System," Paper No. 915343, Proceedings of the 26th IECEC, Boston, MA, 1991.

[22] Diver, R. B., "Test Bed Concentrator Aim Points," Sandia National Laboratories Memorandum to Patricia Cordeiro, February 18, 1993.

[23] Diver, R. B., private communication.

[24] Romero, V. J., "CIRCE2/DEKGEN2: A Software Package for Facilitated Optical Analysis of 3-D Distributed Solar Energy Concentrators," Proceedings ASME-JSES-KSES International Solar Energy Conference, April, 1992, p. 961.

[25] Hogan, R. E. Jr., AEETES - Solar Reflux Receiver Thermal Performance Numerical Model," Proceedings ASME-JSES-KSES International Solar Energy Conference, April, 1992, p. 1015.

[26] Dwyer, O.E., p. 373.

[27] Anderson, W.G., Rosenfeld, J.H., Noble, J., and Kesseli, J., "Design of a Pool Boiler Heat Transport System for a 25 kWe Advanced Stirling Conversion System," Paper No. 915376, Proceedings of the 26th IECEC, Boston, MA, 1991.

[28] Hofiman, E. L.; and Stone, C. M., "Structural Analysis of a Dish Reflux Pool-Boiler Receiver," SAND91-0862, Sandia National Laboratories, Albuquerque, NM, June 1991.

[29] Hoffman, E. L.; and Stone, C. M., "Structural Analysis of a Dish Reflux Pool-Boiler Receiver," Proceedings of the 1992 ASME-JSES-KSES International Solar Energy Conference, Maui, HI, April, 1992.

[30] Hoffman, E. L., "Coupled Thermal-Structural Analysis of Next-Generation Reflux PoolBoiler Receiver," Sandia Laboratories Memo to J. B. Moreno, 1992. 
[31] Hoffman, E. L., "785 $\mathrm{C}$ and $830^{\circ} \mathrm{C}$ Operating Temperatures for the Next Generation Reflux Pool Boiler Receiver," Sandia Laboratories Memo to J. B. Moreno, 1993.

[32] Hoffman, E. L., private communication, 1992.

[33] American Society of Mechanical Engineers, ASME Boiler and Pressure Vessel Code, 1989..ASME, 1989.

[34] Haynes International, Inc., "Haynes 230 Alloy for High-Temperature ASME Boiler Code Case Applications," High-Temperature Alloys Tech Brief H-3119B, Haynes International, Inc., Kokomo, IN, November, 1991.

[35] Roark, R. J., Formulas for Stress and Strain, McGraw-Hill Book Company, New York, New York, 1965, p. 354.

[36] Mahoney, A. R., private communication, 1993.

[37] Mahoney, A. R., private communication, 1990.

[38] Hinze, R.B., Control of Oxygen Concentration in a Large Sodium System, USAEC Report NAA-SR-3638, Atomics International, Dec. 1, 1959.

[39] Fauske, H.K., "Nucleation of Liquid Sodium in Fast Reactors," Reactor Technology, Vol. 16, No. 4, Winter 1972-1973, p. 294.

[40] Sweatt, W. C.; and Phipps, G. S., "Solar-Blind Imaging Radiometer," Proceedings of the 1992 ASME-JSES-KSES International Solar Energy Conference, Maui, HI, 1992.

[41] Rawlinson, K. S.; Dudley, V. E., Test Bed Concentrator \#1 Calorimetry Results, SAND892840, Sandia National Laboratories, Albuquerque, NM, February 1990.

[42] Moreno, J. B.; Andraka, C. E.; Moss, T. A.; Cordeiro, P. G.; Dudley, V. E., and Rawlinson, K. S., "First On-Sun Test of a NaK-78 Pool-Boiler Solar Receiver," Paper No. 93IEC-270, Proceedings of the 28th IECEC, Atlanta, GA, 1993. 


\section{Distribution:}

U.S. Department of Energy (5)

Attn: G. Burch

S. Gronich

Forrestal Building

Code EE-132

1000 Independence Avenue, SW

Washington, DC 20585

U.S. Department of Energy (2)

Attn: R. Annan

Forrestal Building

Code EE-13

1000 Independence Avenue, SW

Washington, DC 20585

U.S. Department of Energy (2)

Attn: G. Tennyson

N. Lackey

Albuquerque Operations Office

P.O. Box 5400

Albuquerque, NM 87115

U.S. Department of Energy

Attn: R. Hughey

San Francisco Operations Office

1333 Broadway

Oakland, CA 94612

Arizona Public Sevive Company

Attn: S. McLellan

P.O. Box 53999, MS 1424

Phoenix, AZ 85072-3999

Arizona Solar Energy Office

Attn: F. Mancini

Dept. of Commerce

3800 N. Central

Phoenix, AZ 85012

Australian Nationai University

Attn: S. Kaneff

Department of Engineering Physics

P. O. Box 4

Canberra ACT 2600 AUSTRALIA

Battelle Pacific Northwest Lab (2)

Attn: D. Brown

P.O. Box 999

Richland, WA 99352
California Polytechnic University

Attn: W. Stine

Dept. of Mechanical Engineering

3801 West Temple Avenue

Pomona, CA 91768-406

Clever Fellows

Attn: J. A. Corey, P.E.

Innovation Consortium, Inc.

R.D. 1, Box 410, River Road

Melrose, NY 12121

Cummins Power Generation

Attn: J. Davis

MC 60125

P. O. Box 3005

Columbus, IN 47202-3005

Cummins Power Generation (2)

Attn: I. Kubo

MC 50179

P. O. Box 3005

Columbus, IN 47202-3005

Cummins Power Generation South

Attn: M. McGlaun

150 Tannehill Drive

Abilene, TX 79602

DLR

Attn: R. Buck

Pfaffenwaldring 38-40

7000 Stuttgart 80 GERMANY

Dynatherm Corporation

Attn: David Wolf

1 Beaver Court

P.O. Box 398

Cockeysville, MD 21030

Electric Power Research Institute

Attn: J. Schaeffer

P.O. Box 10412

Palo Alto, CA 94303

Energy Research Centre (2)

Attn: K. Inall

R. S. Phy. Sc.

Australian National University

Canberra ACT 2601 AUSTRIALIA 
Energy Technology Engr. Center (2)

Attn: W. Bigelow

R. LeChevalier

Rockwell International Corp.

P. O. Box 1449

Canoga Park, CA 91304

Florida Solar Energy Center

Attn: Library

300 State Road, Suite 401

Cape Canaveral, FL 32920

Georgia Power

Atm: W. King

7 Solar Circle

Shenandoah, GA 30265

Institute of Gas Technology

Attn: Library

34245 State Street

Chicago, IL 60616

Jet Propulsion Laboratory

Attn: M. Alper

4800 Oak Grove Drive

Pasadena, CA 91109

Lawrence Berkeley Laboratory

Attn: A. Hunt

MS 90-2024

One Cyclotron Road

Berkeley, CA 94720

Los Alamos National Laboratory

Attn: M. Merrigan

MS-E13

Los Alamos, NM 87545

McDonnell-Douglas Astronautics Co. (3)

Attn: R. L. Gervais,

J. Rogan,

D. Steinmeyer

5301 Bolsa Avenue

Huntington Beach, CA 92647

Mechanical Technology, Inc. (2)

Attn: G. Dochat

J. Wagner

968 Albany Shaker Road

Latham, NY 12110
NASA Lewis Research Center (4)

Attn: R. Shaltens

J. Schrieber

21000 Brook Park Road

Cleveland, $\mathrm{OH} \mathbf{4 4 1 3 5}$

National Renewable Energy Lab(6)

Attn: M. Bohn

G. Jorgensen

A. Lewandowski

L. M. Murphy

T. Wendelin

T. Williams

1617 Cole Boulevard

Golden, CO 80401

Northern Research and Eng. Corp.

Attn: J. Kesseli

39 Olympia Avenue

Woburn, MA 01801-2073

Pacific Gas and Electric Company

Attn: G. Braun

3400 Crow Canyon Road

San Ramon, CA 94583

Pacific Power

Attn: P. Lynch

Park and Elizabeth Streets

GPO Box 5257, Sydney

New South Wales 2001

AUSTRALIA

Power Kinetics, Inc. (2)

Attn: W. E. Rogers

415 River Street

Troy, NY 12180-2822

Research International

Attn: E. Saaski

18706 142nd Avenue NE

Woodinville, WA 98072

Schlaich, Bergermann \& Partner

Attn: W. Schiel

Hohenzollernstr. 1

D - 7000 Stuttgart 1 GERMANY

Science Applications International Corp.

Attn: K. Beninga

15000 W 6th Avenue Suite 202

Golden, CO 80401 
Science Applications International Corp.

Attn: B. Butler

Mail Stop 32

10260 Campus Point Court

San Diego, CA 92121

Solar Energy Industries Assoc. (2)

Attn: K. Sheinkopf

S. Sklar

777 North Capitol St. NE Suite 805

Washington, D.C. $20002-4226$

Solar Kinetics, Inc. (2)

Attn: J. A. Hutchison

$$
\text { P. Schertz }
$$

P.O. Box 540636

Dallas, TX 75354-0636

Stirling Technology Company (2)

Attn: M. A. White

2952 George Washington Way

Richland, WA 99352

Stirling Thermal Motors (2)

Attn: Lennart Johansson

275 Metty Drive

Ann Arbor, MI 48103

Stirling Machine World

Attn: B. Ross

1823 Hummingbird Court

West Richland, WA $99352-9542$

Sunpower, Inc.

Attn: W. Beale

6 Byard Street

Athens, $\mathrm{OH} 45701$

Thermacore, Inc. (2)

Attn: D. Ernst

780 Eden Road

Lancaster, PA 17601

University of Houston (2)

Attn: J. Richardson

Solar Energy Laboratory

4800 Calhoun

Houston, TX 77704

University of Minnesota (2)

Attn: E. A. Fletcher

Dept. of Mechanical Engineering

111 Church St., SE

Minneapolis, MN 55455

\section{Sandia Internal Distribution:}

0835

0835

0835

0835

0724

0735

0704

1127

1127

1127

1127

1127

0703

0703

0703

0703

0703

0703

0703

0703

0899

0619

0100 Document Processing for

D. R. Adkins, 1513

R. E. Hogan, 1513

V. J. Romero, 1513

R. D. Skocypec, 1513

D. L. Hartley, 6000

D. E. Arvizu, 6200

P. C. Klimas, 6201

C. P. Cameron, 6215

P. G. Curdeiro, 6215

V. E. Dudley, 6215

A. R. Mahoney, 6215

K. S. Rawlinson, 6215

C. E. Tyner, 6216

C. E. Andraka (5), 6216

R. B. Diver, 6216

D. R. Gallup, 6216

T. R. Mancini, 6216

D. F. Menicucci, 6216

J. B. Moreno (10), 6216

T. A. $\operatorname{Moss}(5), 6216$

Technical Library (5), 7141 DOE/OSTI (10), 7613-2

9018 Central Technical Files, 8523-2 

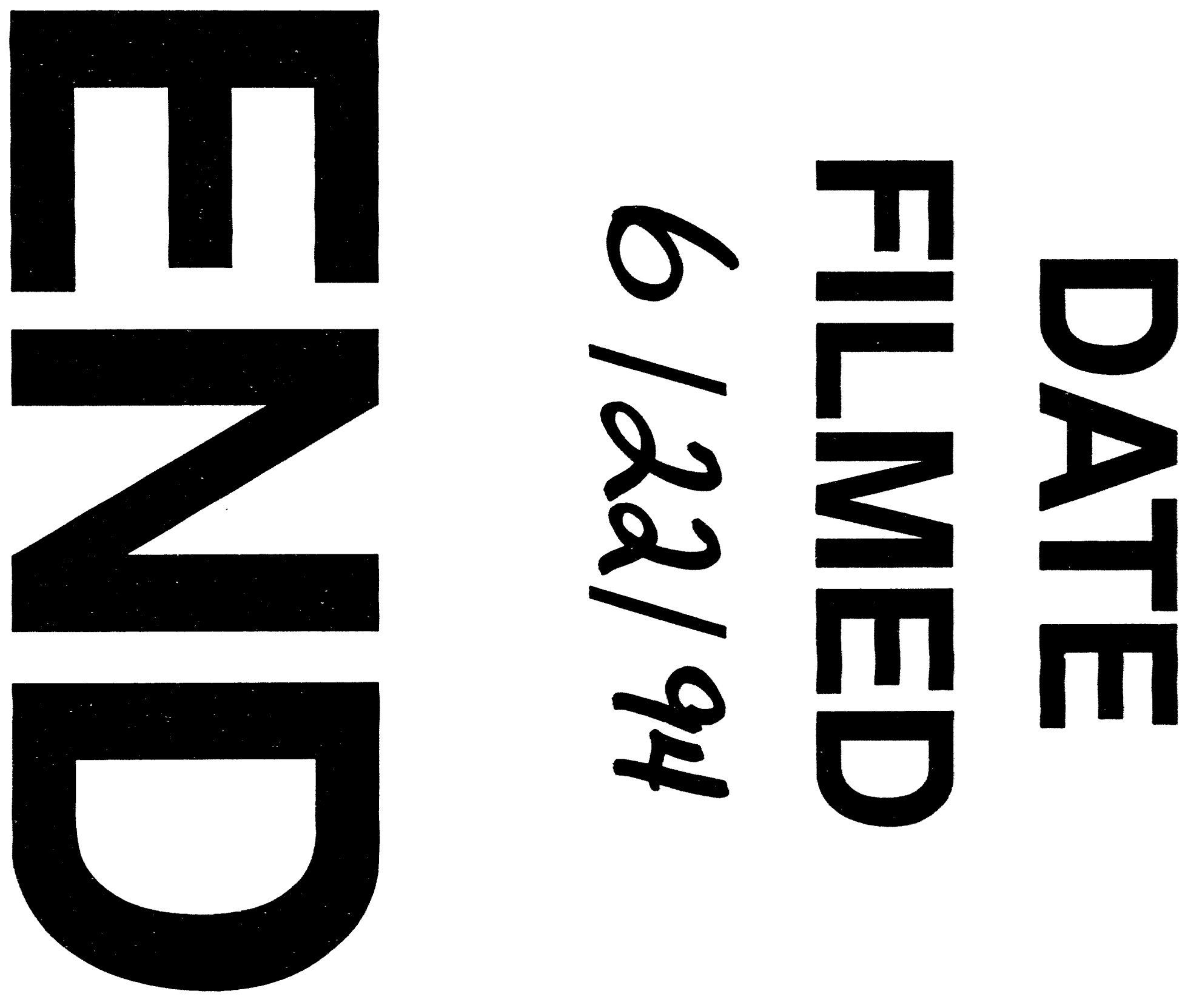


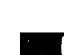
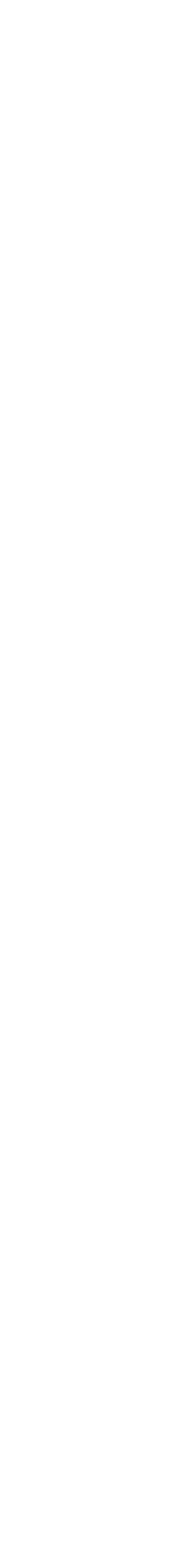